University of Louisville

ThinkIR: The University of Louisville's Institutional Repository

$5-2011$

\title{
Achievement motivation and self-evaluative emotions in preschool children from low-income families.
}

Crystal A. Day

University of Louisville

Follow this and additional works at: https://ir.library.louisville.edu/etd

\section{Recommended Citation}

Day, Crystal A., "Achievement motivation and self-evaluative emotions in preschool children from lowincome families." (2011). Electronic Theses and Dissertations. Paper 323.

https://doi.org/10.18297/etd/323

This Doctoral Dissertation is brought to you for free and open access by ThinkIR: The University of Louisville's Institutional Repository. It has been accepted for inclusion in Electronic Theses and Dissertations by an authorized administrator of ThinkIR: The University of Louisville's Institutional Repository. This title appears here courtesy of the author, who has retained all other copyrights. For more information, please contact thinkir@louisville.edu. 


\title{
ACHIEVEMENT MOTIVATION AND SELF-EVALUATIVE EMOTIONS IN PRESCHOOL CHILDREN FROM LOW-INCOME FAMILIES
}

\author{
By \\ Crystal A. Day \\ B.S., Northern Kentucky University, 2006 \\ M.S., University of Louisville, 2008

\begin{abstract}
A Dissertation
Submitted to the Faculty of the

College of Arts and Sciences of the University of Louisville

in Partial Fulfillment of the Requirements

for the Degree of
\end{abstract} \\ Doctor of Philosophy \\ Department of Psychological and Brain Sciences \\ University of Louisville \\ Louisville, Kentucky
}

May 2011 
Copyright 2011 by Crystal A. Day

All Rights Reserved 



\title{
ACHIEVEMENT MOTIVATION AND SELF-EVALUATIVE EMOTIONS IN PRESCHOOL CHILDREN FROM LOW-INCOME FAMILIES
}

\section{By}

\author{
Crystal A. Day \\ B.S., Northern Kentucky University, 2006 \\ M.S., University of Louisville, 2008 \\ A Dissertation Approved on
}

March 28, 2011

by the Following Dissertation Committee:

Dissertation Director (Barbara Burns)

\begin{tabular}{c}
\hline Kathleen Rudasill \\
\hline Cara H. Cashon \\
\hline Janet Woodruff-Borden
\end{tabular}

Paul Salmon 


\section{DEDICATION}

This dissertation is dedicated to my parents

\section{Charles and Julia Day}

for always supporting me. 


\section{ACKNOWLEDGMENTS}

I would like to thank my mentor, Dr. Barbara Burns, for her positive guidance, patience, and support over the past five years. I am truly thankful to have had the opportunity to attend the University of Louisville and to work with her. I would also like to thank Dr. Lora Haynes and the members of my dissertation committee, Drs. Cara Cashon, Janet Woodruff-Borden, Paul Salmon, and Kathleen Rudasill, for their support and feedback throughout this process.

I am grateful for my fellow lab members over the years, especially Dr. Danielle Brown, Paulette Flores, and Melissa Gordon, who were always willing to lend a sympathetic ear or share some laughs. This study would not have been possible without the participation of the local Head Start program administrators, teachers, parents, and children, and the data collection and coding of multiple undergraduate research assistants. I especially want to thank my fiancé, Jeremy Hess, for his unconditional support, love, and patience every step of the way. Finally, I want to thank my parents, Charles and Julia Day, and family members, Phil and Cheryl Hess, for their support and encouragement. I love you all. 


\title{
ABSTRACT \\ ACHIEVEMENT MOTIVATION AND SELF-EVALUATIVE EMOTIONS \\ IN PRESCHOOL CHILDREN FROM LOW-INCOME FAMILIES
}

\author{
Crystal A. Day
}

March 28, 2011

The current study was designed to better understand the early behavioral and emotional factors influencing young children's responses to challenge, which have important implications for learning. Understanding why children respond to challenge as they do is particularly important for young children from poverty, who face many contextual factors that place them at-risk for experiencing negative academic outcomes (Brooks-Gunn, Linver, \& Fauth, 2005). Previous research suggests that children adopt distinct behavioral and emotional reactions to challenge. Such reactions have been studied in terms of either achievement motivation or self-evaluative emotion research (Dweck \& Leggett, 1988; Lewis \& Sullivan, 2005), with achievement motivation researchers explaining behavioral responses and self-evaluative emotion researchers explaining emotional responses.

The present study integrated the research on achievement motivation and selfevaluative emotions and tested a new model that described the early developmental relationship between these variables in preschool-aged children from poverty. The goals of this research were to: (1) replicate and extend upon research examining children's 
cognitive and behavioral/motivational responses to challenge, (2) provide empirical research examining children's self-evaluative emotional responses to challenge, and (3) describe and examine the relationship between achievement motivation and selfevaluative emotions within this sample.

Results showed that children with mastery and attenuated-mastery oriented patterns made different patterns of verbalizations across individual challenging puzzles. Mastery oriented children were more focused throughout the entire task and engaged in more strategy-related cognitions; attenuated-mastery children initially demonstrated less focus and more negative cognitions, but became more focused and engaged in more strategy-related cognitions as they were continually presented with challenge. With regard to self-evaluative emotions, all children demonstrated increasing amounts of shame behaviors across subsequent puzzles and demonstrated more pride on the final, solvable puzzle as compared to previous, unsolvable puzzles during the task. Consistent with the proposed model, mastery oriented children demonstrated significantly fewer shame behaviors throughout the challenging puzzle task than did attenuated-mastery oriented children, suggesting that these children were interpreting challenge differently. These findings provide new information about the early development of children's responses to challenge, which have important theoretical, empirical, and applied implications for supporting mastery motivation in young children from poverty. 


\section{TABLE OF CONTENTS}

PAGE

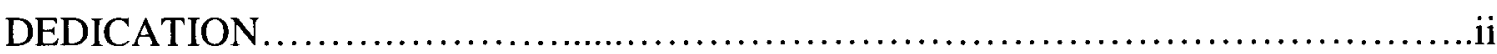

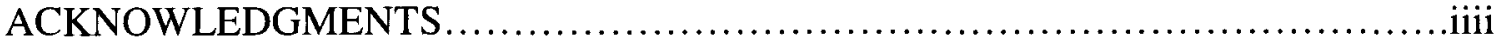

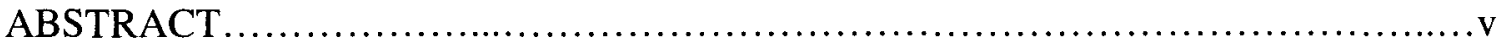

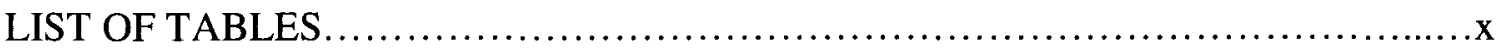

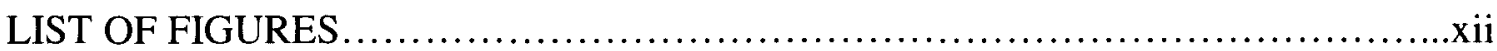

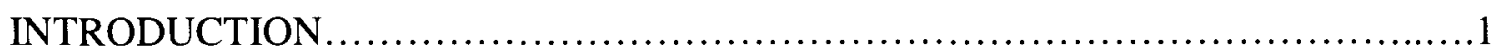

Achievement Motivation......................................................

Achievement Motivation and Verbalizations............................

Current Views of the Development of Achievement Motivation...........6

Importance of Achievement Motivation for School Success.................7

Achievement Motivation in Children of Poverty .........................

Cognitive Goal Model of Achievement Motivation........................12

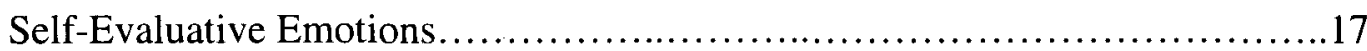

Current Views of the Development of Self-Evaluative Emotions..........18

Specific Self-Evaluative Emotions: Descriptions and Measurement......21

Shame.......................................................

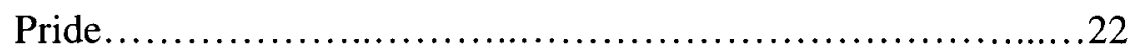

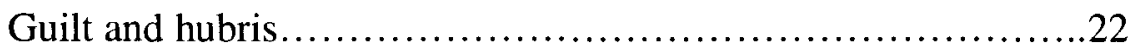

Universality of Self-Evaluative Emotions............................23

Importance of Self-Evaluative Emotions in School Success..............25 
Emotion Regulation and Self-Evaluative Emotions in Children

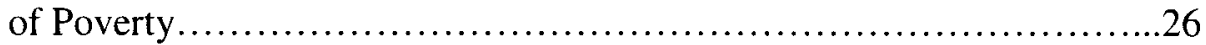

Cognitive-Attribution Model of Self-Evaluative Emotions...............28

Integrating Achievement Motivation and Self-Evaluative Emotions ..............30

Research Relating Achievement Motivation and Self-Evaluative

Emotions....................................................... 31

Achievement motivation and general affect....................31

Achievement motivation variables and self-evaluative emotions..................................................33

Achievement motivation and self-evaluative emotions............35

Models and Theories Integrating Achievement Motivation and Self-Evaluative Emotions........................................36

Intrapersonal attributional theory........................... 37

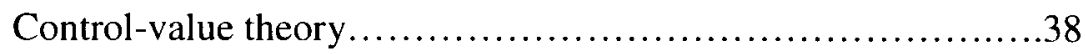

Proposed Integrative Model of Achievement Motivation and

Self-Evaluative Emotions......................................42

Proposed Model........................................42

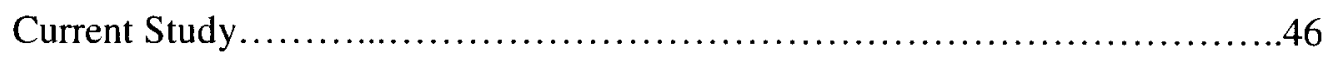

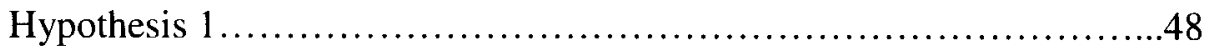

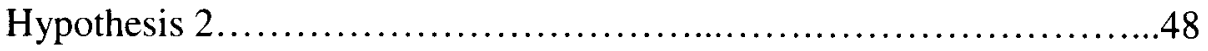

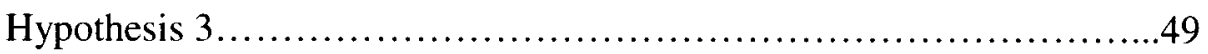

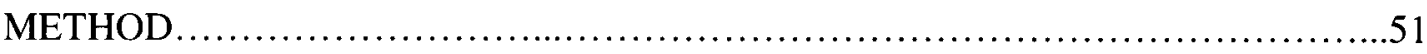

Participants....................................................... 51

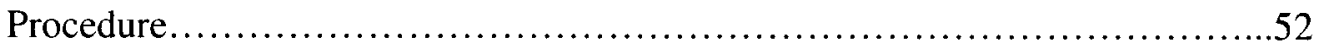

Measures.........................................................52

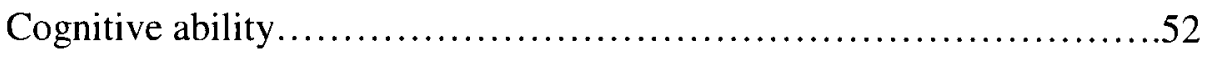


Puzzle-solving ability .......................................53

Achievement motivation..........................................55

Self-evaluative emotions.........................................57

Verbalizations .................................................... 57

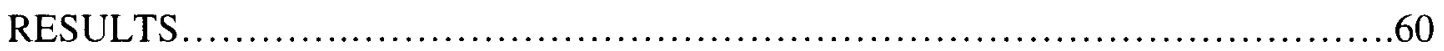

Preliminary Analyses............................................60

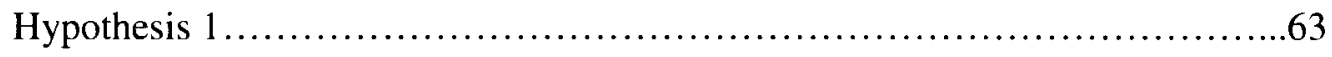

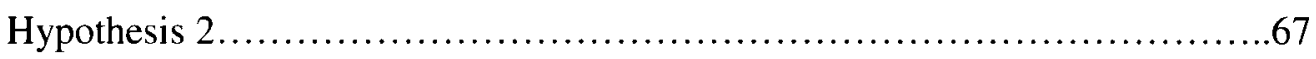

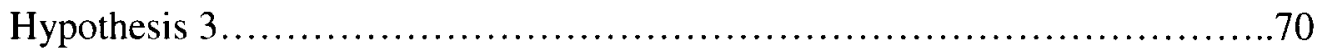

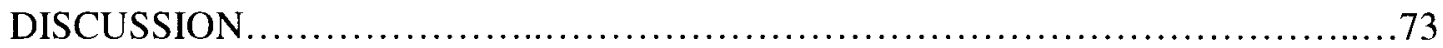

Achievement Motivation and Verbalizations................................ 75

Achievement Motivation and Self-Evaluative Emotions......................78

Shame..........................................................

Pride............................................................ 81

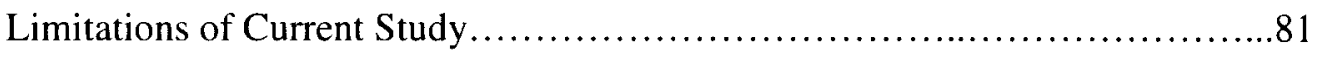

Theoretical and Research Implications.................................84

Applied Implications............................................... 86

Future Directions....................................................90

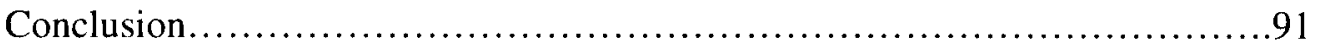

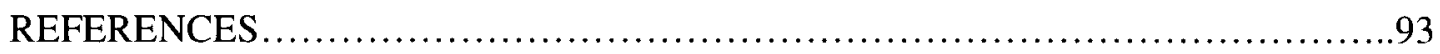

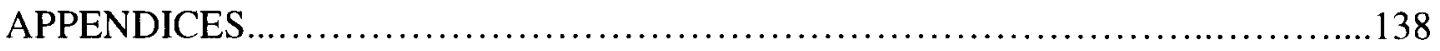

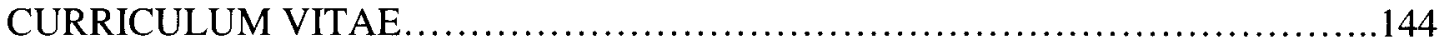




\section{LIST OF TABLES}

TABLE

PAGE

1. Proposed Integrative Model............................................... 116

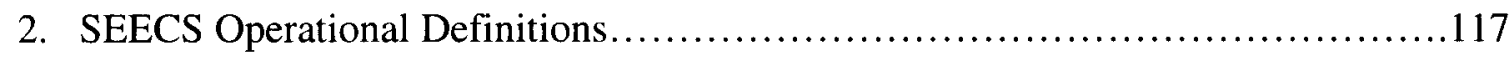

3. SEECS Feature Combinations for Coding Shame and Pride......................118

4. Verbalization Categorization Definitions and Examples..........................119

5. Summary of Goal-Confidence and Motivation Orientation Patterns................121

6. Motivation Orientation Group Differences in Age, Cognitive Ability, and Puzzle Task Variables.................................................... 122

7. Summary of Intercorrelations, Means, and Standard Deviations for Age, Cognitive Ability, Puzzle Variables, Self-Evaluative Emotions, and Verbalization Proportions............................................. 123

8. Verbalization Means and Standard Deviations by Gender.........................124

9. Self-Evaluative Emotion Means and Standard Deviations by Gender...............125

10. Total Self-Evaluative Emotion Means and Standard Deviations by Puzzle and Motivation Orientation.......................................... 126 


\section{LIST OF FIGURES}

FIGURE

PAGE

1. Puzzles used in challenging puzzle task to assess achievement

motivation orientation

2. Motivation orientation categorizations based on challenging puzzle task..........128

3. Mean proportion of verbalizations for each verbalization category across all children

4. Mean proportion of overall verbalizations across all children by puzzle..............130

5. Mean proportion of verbalizations produced by all children by puzzle

6. Mean proportion of overall verbalizations produced by attenuated-mastery and mastery oriented children by puzzle

7. Mean proportion of verbalizations for each verbalization category produced by attenuated-mastery and mastery oriented children.

8. Mean proportion of verbalization for each verbalization category produced by attenuated-mastery and mastery oriented children by puzzle

9. Mean number of shame and pride behaviors produced by puzzle.

10. Mean number of self-evaluative shame and pride behaviors produced by attenuated-mastery and mastery oriented children

11. Mean number of shame and pride behaviors produced by attenuated-mastery and mastery oriented children by puzzle 


\section{INTRODUCTION}

Learning is a complex process that begins in infancy and occurs continually throughout development. Nearly everything infants and young children do involves learning, including walking, talking, managing social interactions, and, eventually, mastering early academic skills. Successful and optimal learning requires children to set goals, plan, and revise their behaviors as necessary (Bransford, Brown, \& Cocking, 1999). Once children have reached their goal, they must attempt increasingly challenging tasks in order to continue learning (Bransford et al., 1999). When children try something that is new and challenging, however, they almost always make errors and must modify their behavior in order to reach their goal and learn the task at hand (Tangney \& Dearing, 2002). Thus, errors made in the context of a challenging task are integral to learning. The focus of the current work is on how to best characterize the significance of children's reaction to challenge and errors.

It is well accepted that many factors influence children's learning, with their behavioral and emotional responses to challenge and error playing particularly important roles (Dweck \& Leggett, 1988; Lewis \& Sullivan, 2005; Op't Eynde, De Corte, \& Verschaffel, 2007; Schutz \& Pekrun, 2007; Stipek, Recchia, \& McClintic, 1992). Despite the fact that children's behavioral and emotional responses are both important factors to consider, researchers have separately examined these variables from two different approaches: achievement motivation research and self-evaluative emotion research. 
Achievement motivation provides a framework for describing children's behavioral response to challenge, which then influences a variety of variables, such as preference for challenging tasks, persistence in the face of difficulty, school engagement, and, ultimately, achievement (see Elliot \& Dweck, 2005b for review). Self-evaluative emotion researchers provide a framework for describing children's emotional responses to challenge. Similar to achievement motivation, children's self-evaluative emotions, particularly shame, have also been shown to be related to variables important for learning (Stipek et al., 1992), including children's preference for challenging tasks, persistence, perceived competence, and academic achievement (see Tracy, Robins, \& Tangney, 2007 for review).

Although researchers have examined achievement motivation and self-evaluative emotions independent of one another, behavioral and neuropsychological research has shown that these variables are not only related to learning, but are also related to one another and begin developing at approximately the same age (e.g., Pekrun, Elliot, \& Maier, 2006; Pessoa, 2009; Schutter, de Weijer, Meuwese, Morgan, \& van Honk, 2008). Specifically, studies have shown that learning can be jointly influenced by these variables because "both emotion and motivation interact with executive control to determine behavioral outcome" (Pessoa, 2009, p. 160; Schutter et al., 2008). These findings demonstrate the link between aspects of achievement motivation and self-evaluative emotions and further demonstrate the importance of a model that integrates these variables. The few existing integrative models that have been proposed (i.e., intrapersonal attributional theory and control-value theory), however, describe how these variables influence one another in older children and adults, and do not address the early 
developmental relationship of these variables and their impact on young children's response to challenge (see Schutz \& Pekrun, 2007). There is great potential for better understanding the significance of children's reactions to errors in the context of learning if achievement motivation and self-evaluative emotions are integrated. Such integration would provide a significant contribution to the literature because it would provide researchers with a framework for better understanding how and why children respond to challenges as they do, which could then inform interventions to support these variables.

Integrating these variables in a model developed for children from poverty is of particular importance. It has been well established that, due to the multiple risk factors associated with living in poverty, children from low-income families are at risk for developing negative behavioral and emotional response patterns to challenge, which can then limit their academic achievement (Garner \& Spears, 2000; Howse, Lange, Farran, \& Boyles, 2003; Malakoff, Underhill, \& Zigler, 1998). This is of particular importance, as research examining academic outcomes has shown that children from low-income families enter school with basic academic skills significantly below their middle-income counterparts (Barbarin et al., 2006; Bryant, Burchinal, Lau, \& Sparling, 1994; Smith, Brooks-Gunn, \& Klebanov, 1997; Stipek \& Ryan, 1997; Zill \& West, 2001) and tend not to catch up in terms of their academic skills and achievement (Axinn, Duncan, \& Thornton, 1997; Bettler, Miles, \& Burns, 2006; Pagani, Boulerice, \& Tremblay, 1997). The resulting achievement gap between children from low- and middle-income families is significant and represents one of education's most serious and important educational problems to address (Arnold \& Doctoroff, 2003). As such, it is important for researchers to identify and better understand variables, including children's developing achievement 
motivation and self-evaluative emotions, which influence their response to challenge and contribute to this achievement gap.

The current study proposes a new model integrating achievement motivation and self-evaluative emotions in preschool-aged children from poverty. The study is designed to provide a novel and significant contribution to the current literature on achievement motivation and self-evaluative emotions by establishing a new framework for examining and understanding the unique ways young children respond to errors, which is necessary to support learning and later academic achievement.

\section{Achievement Motivation}

Achievement motivation refers to the "direction [task choice], intensity, persistence, and quality" of behavior children demonstrate in a learning context (Maehr \& Meyer, 1997, p. 373; also see Brophy, 2004; Sternberg, 2005). When faced with a challenging task, variation in children's achievement motivation becomes especially important. There are many different theories and models of achievement motivation, each with their own unique terminology and way of describing it, but all are similar in that they attempt to address the fact that there is a range of more and less adaptive responses to challenge, often termed "achievement motivation patterns," that describe children's responses to challenge (Dweck \& Leggett, 1988; Eccles et al., 1983; Elliot \& Thrash, 2001; see Stipek, 2002 for review). Children with more adaptive achievement motivation patterns, frequently referred to as mastery oriented motivation, seek out and approach challenging tasks, show high levels of effort and persistence, demonstrate effective problem solving, and generally view errors as useful and necessary for optimal learning (Dweck \& Leggett, 1988; Elliot \& Dweck, 2005a). However, children with less adaptive 
achievement motivation patterns, often referred to as attenuated-mastery or performance oriented motivation, typically seek out easier tasks and actively avoid challenging tasks, show comparably decreased effort and persistence, demonstrate less effective problem solving, and often view errors as failure and indicative of low ability (Dweck \& Leggett, 1988; Elliot \& Dweck, 2005a).

\section{Achievement Motivation and Verbalizations}

Based on the work of Vygotsky (1934/1986) and others (Alexander, White, \& Daugherty, 1997; Chiu \& Alexander, 2000; Smiley \& Dweck, 1994), research has also shown that children with different motivation patterns demonstrate distinct verbalization patterns while working on challenging tasks, which are indicative of their cognitive processes related to the task. For example, it has been shown that children with less adaptive motivation tend to demonstrate more negative, nonfacilitative private speech (e.g., "This is too hard" and "I can't do this"), whereas children with adaptive motivation patterns tend to demonstrate more positive and facilitative speech patterns (e.g., "I can do this" and "I need to try another way") (Alexander et al., 1997; Chiu \& Alexander, 2000; Harris, Brown, Day, \& Burns, 2007; Smiley \& Dweck, 1994).

Smiley and Dweck (1994), for example, examined verbalization differences between mastery, attenuated-mastery, and performance oriented preschool children from middle- and upper-SES backgrounds. They found that mastery and attenuated-mastery oriented children did not differ in the types of verbalizations made during the task, but that mastery and performance oriented children did. In other words, mastery and attenuated-mastery oriented children were similar to one another and tended to remain more focused and planful during the puzzle task, while performance oriented children 
were more negative and less focused and planful during the task. Similarly, our previous work (Harris, Brown, et al., 2007) with preschool children from middle-SES backgrounds showed that performance oriented children were less focused, as indicated by their increased disengaged verbalizations, during the puzzle task than mastery oriented children; the study did not examine potential differences of attenuated-mastery oriented children.

Other researchers examining associations between preschoolers' motivation and verbalizations have found different results, likely due to their different definitions and measurement of motivation. Chiu and Alexander (2000), for example, examined middleand upper-SES children's verbalizations during challenging tasks, with motivation being defined on a continuum by how long they persisted on the tasks and their desire to work independently. They found that higher motivation scores were moderately correlated with metacognitive verbalizations, which were reflective of children's "awareness and regulation of their own thinking" (Manning et al., 1994, as cited in Chiu \& Alexander, 2000 , p. 134), but were not correlated with off-task, negative task-relevant, or cognitive verbalizations.

\section{Current Views of the Development of Achievement Motivation}

Early research established the presence of distinct motivation patterns in children around 10 years of age and older (e.g., Diener \& Dweck, 1978, 1980; Dweck \& Leggett, 1988); however, more recent research has shown that toddlers and preschool-aged children also demonstrate distinct motivation orientation patterns similar to those

observed in older children (e.g., Gilmore, Cuskelly, \& Purdie, 2003; Heyman, Dweck, \& Cain, 1992; Stipek et al., 1992; Turner \& Johnson, 2003; Ziegert, Kistner, Castro, \& 
Robertson, 2001). Although there is general consensus about when distinct achievement motivation patterns develop, different models and theories present different explanations as to how motivation develops and what variables influence its development. In the following, the most influential model of achievement motivation in young children will be described and critically reviewed. Discussions of the importance of motivation in learning, achievement, and overall school success, as well as the impact of poverty on achievement motivation in young children will also be presented.

\section{Importance of Achievement Motivation for School Success}

Research has shown that some types of adaptive motivation patterns may serve as a protective factor, supporting academic success in at-risk children, and are associated with better, more educationally adaptive achievement outcomes for children of all ages (Dweck, 1986; Rouse \& Fantuzzo, 2008; Skinner \& Belmont, 1993). Research with preschool- and elementary school-aged children has found that adaptive, or mastery, motivation patterns are correlated with positive immediate and long-term learning and achievement outcomes (Gottfried, Gottfried, Morris, \& Cook, 2008). Specifically, preschool-aged children with more adaptive mastery motivation patterns show the greatest increases in general cognitive skills associated with early literacy, math concepts, and fine- and gross-motor skills across the course of a preschool year, as compared to children who do not exhibit such motivation patterns (Angelo, 2006, as cited in Rouse \& Fantuzzo, 2008). Preschoolers with adaptive mastery motivation patterns also demonstrate better performance on general achievement tests and other tasks important for academic achievement (Howse et al., 2003; Lange, MacKinnon, \& Nida, 1989; Stipek \& Ryan, 1997; Turner \& Johnson, 2003), with similar positive effects demonstrated 
through first grade (see Rouse \& Fantuzzo, 2008). These children have been shown to prefer challenging tasks, be persistent when challenged, demonstrate effective problem solving strategies, and show more adaptive attention skills (Chang \& Burns, 2005; Diener \& Dweck, 1978, 1980; Elliott \& Dweck, 1988; Harris, Robinson, Chang, \& Burns, 2007; Smiley \& Dweck, 1994).

Other motivation patterns have consistently been identified that relate to adverse learning and education outcomes. Children with these less adaptive non-mastery patterns tend to avoid challenging tasks, show decreased performance and persistence when faced with difficulty, plan and strategize ineffectively, and demonstrate less adaptive attention skills (Chang \& Burns, 2005; Diener \& Dweck, 1978, 1980; Elliott \& Dweck, 1988; Harris, Robinson, et al., 2007; Smiley \& Dweck, 1994). These children also tend to score lower on tests of academic achievement (Gottfried et al., 2008; Stipek, 2002), demonstrate decreased engagement in school (Fredricks, Blumenfeld, \& Paris, 2004), and are more likely to experience school retention and dropout (Alexander, Entwisle, \& Dauber, 2003).

\section{Achievement Motivation in Children of Poverty}

Research has shown that the achievement motivation of children of all ages is greatly impacted by family and neighborhood income (see Brooks-Gunn, Linver, \& Fauth, 2005 for review; Castenell, 1983; Lloyd \& Barenblatt, 1984; Malakoff et al., 1998; Terrell, Durkin, \& Wiesley, 1959; Zigler \& De Labry, 1962). This is particularly important, as adaptive mastery motivation patterns have been shown to act as protective factors and are related to more positive academic outcomes in children and young adults (Dweck, 1986; Grant \& Dweck, 2003; Howse et al., 2003; Turner \& Johnson, 2003). As 
the risk factors associated with living in poverty accumulate and persist, children from low-income families and neighborhoods are more likely to develop a lower sense of competence (Brooks-Gunn et al., 2005), demonstrate lower academic achievement (McLoyd, 1998; Zill \& West, 2001), and potentially develop less adaptive, non-mastery patterns of achievement motivation (Brooks-Gunn et al., 2005; Malakoff et al., 1998), although research with young children and teens from low-income backgrounds has produced mixed findings. Some studies have not found motivation differences between individuals from different income backgrounds (e.g., Anderson \& Keith, 1997; Howse et al., 2003; Schultz, 1993; Stipek \& Ryan, 1997), while others have generally shown that children from low-income backgrounds demonstrate less adaptive motivation patterns than their middle-income counterparts (e.g., Castenell, 1983; Day \& Burns, 2011; Lloyd \& Barenblatt, 1984; Malakoff et al., 1998; Terrell et al., 1959; Zigler \& De Labry, 1962).

Malakoff and colleagues (1998), for example, found that children from lowincome families who were not attending preschool scored lower on measures of effectance motivation than those who attended Head Start, who then demonstrated lower effectance motivation than children from middle-income families. Recent research by Day and Burns (2011) has also shown that children from low-income families may demonstrate more maladaptive motivation patterns, as supported by the finding that they made significantly more negative performance-related verbalizations while working on a series of challenging puzzle tasks. This suggests that preschoolers from low-income families had more negative cognitions while working on the challenging puzzle tasks. This may be of critical importance, as negative cognitions in preschoolers have been shown to be negatively related to academic achievement and, over time, become 
predictive of later established performance oriented motivation patterns (Alexander et al., 1997; Sideridis, 2007; Smiley \& Dweck, 1994). Work with older children and teens has produced similar findings, with individuals from economically disadvantaged backgrounds demonstrating decreased motivation, persistence, and preference for challenge as compared to children and teens from more economically advantaged backgrounds (Castenell, 1983; Lloyd \& Barenblatt, 1984; Terrell et al., 1959; Zigler \& De Labry, 1962).

In addition to studying achievement motivation patterns in children from poverty, research has also examined the mediating and moderating variables underlying the relation between poverty and achievement motivation. It is important to consider that children growing up in low-income families face many challenges to their physical, cognitive, emotional, social, and academic development (Brooks-Gunn \& Duncan, 1997; Brooks-Gunn et al., 2005; Gershoff, Aber, Raver, \& Lennon, 2007; McLoyd, 1990 , 1998). These challenges are often present in the community and home environments and it is through their impact on these environments that such challenges influence children's development of achievement motivation (Brooks-Gunn et al., 2005). For example, children growing up in low-income neighborhoods have access to fewer and lower quality community resources than children from middle-income families, generally including things such as lower quality schools, less access to quality health clinics, and access to fewer libraries (see Arrighi \& Maume, 2007a, 2007b; McLoyd, 1998). Community violence is also more prevalent in low-income neighborhoods (Aber, 1994; Garbarino, Hammond, Mercy, \& Yung, 2004). These community-based factors have been shown to be related to children's and parents' subjective well-being, which have 
both been shown to be related to children's development of achievement motivation, among other important developmental variables (Lever, Piñol, \& Uralde, 2005).

Another way in which poverty impacts children's achievement motivation is via its effects on various family mechanisms, including the parent-child relationship (BrooksGunn et al., 2005; Turner \& Johnson, 2003). Research has shown that factors associated with poverty, including chronic unemployment, inadequate housing, low parental education levels, and various other life stressors, place emotional and financial strains on the family, which ultimately influence the relationship of the parent-child dyad (Bakermans-Kranenburg, Van IJzendoorn, \& Kroonenberg, 2004; Diener, Nievar, \& Wright, 2003; Schiffman, Omar, \& McKelvey, 2003). Due to these stressors, low-income parents are at a greater risk for experiencing psychological distress, including issues such as depression, which makes it difficult for them to demonstrate warmth, responsiveness, and sensitivity with their children (e.g., Hwa-Froelich, Cook, \& Flick, 2008; Riley et al., 2009). This is especially problematic for children from low-income families because these variables have been shown to be important for the development of adaptive achievement motivation (Pomerantz, Grolnick, \& Price, 2005). Work examining the role of parents on children's development of achievement motivation has shown that parents influence motivation development primarily by meeting children's psychological needs, which then enables them to "adopt a positive approach to achievement" (Pomerantz et al., 2005, p. 260; Eccles, Wigfield, \& Schiefele, 1998). When parents are warm and responsive to the child's needs, engage in scaffolding, and support the children's sense of autonomy, children are more likely to develop regulatory resources, a sense of competence and efficacy, and effective learning strategies that support the development 
of adaptive mastery oriented motivation patterns in response to challenge (Deci \& Ryan, 2000; González, Moll, \& Amanti, 2005; Linnenbrink-Garcia \& Fredricks, 2008;

Pomerantz et al., 2005; Turner \& Johnson, 2003).

\section{Cognitive Goal Model of Achievement Motivation}

Many different models and theories have been proposed that describe achievement motivation (see Elliot \& Dweck, 2005b for review). These theories define motivation differently and include a wide range of variables, but they all share the common purpose of attempting to explain why different people respond to the same task or situation in very different ways (Murphy \& Alexander, 2000). It is important to note that many of these models were developed with the aim of describing achievement motivation in older children and adults and that the cognitive goal model is the only model that has been developed and applied to describe the early development of achievement motivation in preschool-aged children.

The cognitive goal model characterizes achievement motivation by describing how an individual's implicit theories, achievement goals, and confidence in their ability interact to predict their behavior patterns in response to challenging tasks (Dweck \& Leggett, 1988; Elliott \& Dweck, 1988; Smiley \& Dweck, 1994). In their early work, Diener and Dweck $(1978,1980)$ identified two broad patterns of behavior that individuals exhibit in response to challenging, error-eliciting situations: (1) the more adaptive mastery oriented response and (2) the less adaptive "helpless", or performance oriented, response. In an effort to better understand what led people to derive such different behavioral and motivational patterns in response to the same situation, the focus of their research turned to individuals' goals as a way to explain their reaction to tasks (Elliott \& 
Dweck, 1988). This work was later expanded to include individuals' theories of intelligence to account for differences in the types of goals they pursue (Dweck \& Leggett, 1988) and the effect of confidence on behavioral responses to challenge (Smiley \& Dweck, 1994).

The cognitive goal model states that an individual's implicit theory of intelligence, or their general belief about the nature of ability, forms the foundation for the type of goals and motivation patterns they develop (see Dweck \& Leggett, 1988 for review). Individuals with an entity theory hold the view that intelligence is an uncontrollable, fixed trait and that increased effort or persistence will not improve intelligence. Conversely, an incremental theory is associated with the belief that intelligence is malleable and is something that can be controlled and increased through effort and persistence. Research with older children and adults has consistently shown that entity and incremental theories of intelligence are related to the adoption of different achievement goals (Cain \& Dweck, 1995; Dweck \& Bempechat, 1983). Specifically, individuals with an entity theory typically adopt performance goals, while people with an incremental theory most frequently adopt learning goals. Children and adults who pursue performance goals are most concerned with proving their competence. Individuals who have learning goals, however, are focused on improving their intelligence or mastering new and challenging tasks (Dweck \& Leggett, 1988; Elliot, 2005; Elliott \& Dweck, 1988).

According to Dweck and colleagues, the types of tasks children choose (when given a choice) depends on the type of achievement goal they pursue, as well as their task-related confidence in their ability to achieve that goal (Elliott \& Dweck, 1988; 
Smiley \& Dweck, 1994). Children who hold performance goals and have low confidence in their ability tend to choose easy tasks that will guarantee success and allow them to prove their competence, avoiding any potential displays of incompetence. When presented with a difficult task that elicits errors, children with performance goals and low confidence in their ability experience the least adaptive response patterns (Dweck \& Leggett, 1988; Elliot, 2005). Because their goal is to prove their competence, errors are equated to failure. In the context of a perceived failure, these children become increasingly concerned about their performance, as indicated by their verbalizations during and after the task (Diener \& Dweck, 1978, 1980; Smiley \& Dweck, 1994). Children also demonstrate a decrease in effective and appropriate problem solving strategies and decreased persistence and performance on the task at hand. Children with this goal-confidence-behavior pattern are described as having a performance oriented motivation pattern (Dweck \& Leggett, 1988; Smiley \& Dweck, 1994).

Children with performance goals paired with high confidence tend to choose tasks that are slightly more difficult, but still ensure success without errors. Children with this goal-confidence pattern demonstrate a slightly different pattern of behavior in response to difficulty and errors, although they still view errors as failure (Dweck \& Leggett, 1988; Elliot, 2005). These children demonstrate a moderate level of performance concern (Diener \& Dweck, 1978, 1980; Smiley \& Dweck, 1994), but are usually able to remain engaged in the task. They also maintain effective problem solving strategies and taskrelated performance. Despite their adequate performance on challenging tasks, however, these children still will not choose to engage in such tasks when given a choice (Dweck \& Leggett, 1988). Children with performance goals and high confidence who 
demonstrate this type of behavioral pattern in response to challenge are referred to as having an attenuated-mastery orientated motivation pattern (Dweck \& Leggett, 1988; Smiley \& Dweck, 1994).

Lastly, children who hold learning goals typically choose difficult tasks, regardless of whether they have high or low confidence in their ability in a given domain. Given that children with learning goals are focused on improving and increasing their competence and ability, their confidence becomes irrelevant to their task choice. In fact, having low confidence in one's ability may be viewed by children with learning goals as another reason why a difficult task should be attempted (Elliott \& Dweck, 1988). When presented with a difficult task, these children demonstrate the most adaptive behaviors in response to challenge and errors (Dweck \& Leggett, 1988; Elliot, 2005). Children with a learning goal view errors as being an important part of learning, as opposed to being indicative of failure. Due to this way of thinking, these children do not demonstrate maladaptive performance concerns in the context of difficulty and errors (Diener \& Dweck, 1978, 1980; Smiley \& Dweck, 1994). Children with a learning goal use errors to their advantage and view them as a form of feedback about how they might modify their problem solving strategies to increase understanding and task mastery, demonstrating a level of engagement and persistence not seen in children with performance goals. Due to the manner in which they behave in response to challenge and errors, children with a learning goal are described as having a mastery oriented motivation pattern (Dweck \& Leggett, 1988; Smiley \& Dweck, 1994).

Children's behaviors and motivation in the context of challenging tasks and errors have important implications for learning (Brophy, 2004; Dweck, 1986; Dweck \& 
Leggett, 1988; Stipek, 2002; Urdan \& Turner, 2005). Children who adopt performance goals and demonstrate either performance or attenuated-mastery oriented patterns of motivation are ultimately "limiting their attainments" because they do not actively seek challenges and are unable to function effectively when they are confronted with a challenge (Dweck \& Leggett, 1988, p. 257). Conversely, children with learning goals and mastery oriented motivation patterns are able to remain persistent and adapt their behaviors when faced with challenge and even seek out challenging tasks, which serves to "maximize their attainments" (Dweck \& Leggett, 1988, p. 257). Interestingly, research has also shown that children with learning goals are better able to transfer information they learn in one context to that of another more accurately and effectively (Farrell \& Dweck, 1985, as cited in Dweck \& Leggett, 1988).

The cognitive goal model takes into account many concepts that have been shown to be important to understanding children's motivation to learn. For example, the inclusion of children's goals is considered a strength of the cognitive goal model because goals serve to guide behavior in the context of learning (Dweck \& Leggett, 1988; Elliot, 2005; Elliott \& Dweck, 1988; Smiley \& Dweck, 1994). Particularly important and unique to this model is the fact that children's confidence in their ability (perceived competence) interacts with their goals, which directly influences their motivation (see Sternberg, 2005 for review). Another advantage of this model is that it attempts to describe the early development of achievement motivation and, as such, can be applied to and assessed in young children, with the exception of the theory of intelligence component. In fact, multiple studies have been conducted using this general model of achievement motivation with early elementary and preschool-aged children from middle-income (Cain 
\& Dweck, 1995; Day \& Burns, 2011; Harris, Brown, et al., 2007; Smiley \& Dweck, 1994; Ziegert et al., 2001) and low-income families (Chang \& Burns, 2005; Day \& Burns, 2011; Day, Harris, Carter, \& Burns, 2008; Day, Harris, Ford, \& Burns, 2008; Harris, Robinson, et al., 2007).

Although there are many advantages associated with the cognitive goal model, it includes some complex concepts that have prevented it from being fully applied to and tested in young children. For example, the idea of a theory of intelligence, although important for explaining goals and motivation in older children and adults (Dweck \& Leggett, 1988), is a very complex concept that has been shown to be beyond the cognitive capacity of preschool-aged children. Studies with $1^{\text {st }}, 3^{\text {rd }}$, and $5^{\text {th }}$ grade children have found that their motivation patterns are not associated with theory of intelligence until $5^{\text {th }}$ grade (Cain \& Dweck, 1995). Once children's theories of intelligence and motivation become associated with one another, however, intervention studies show that it is possible to change adolescents' theories of intelligence and, thus, influence motivation by providing them with incremental theory training (Blackwell, Trzesniewski, \& Dweck, 2007).

\section{Self-Evaluative Emotions}

Researchers who study self-evaluative emotions have also examined responses to challenge of children and adults. It is well accepted that individuals' emotional experiences play an important role in learning and influence how they react to challenging tasks (Schutz \& Pekrun, 2007; Stipek et al., 1992). Children's developing self-evaluative emotions have been described as providing the "emotional backdrop for learning and achievement" (Lewis \& Sullivan, 2005, p. 188), with shame and pride 
playing important roles in achievement-related contexts (Heckhausen, 1987; Schutz \& Pekrun, 2007; Stipek, 1995; Stipek, 1983; Stipek, Feiler, Daniels, \& Milburn, 1995; Stipek et al., 1992). As their name suggests, self-evaluative emotions occur only after children are able to evaluate their task-related actions and behaviors against a set of standards and then make judgments about their responsibility for the outcome (Lewis \& Sullivan, 2005). Before describing the literature relating self-evaluative emotions and reaction to error in challenge, the larger developmental context for understanding these emotions in general and in the context of poverty will be discussed.

\section{Current Views of the Development of Self-Evaluative Emotions}

Self-evaluative emotions develop after the basic emotions (i.e., joy, sadness, surprise, anger, and fear) and are thought to require more complex cognitive abilities, which typically emerge between 24 and 30 months of age (Lagattuta \& Thompson, 2007; Lewis \& Sullivan, 2005). Researchers have consistently identified three cognitive prerequisites for the development of self-evaluative emotions in young children (Lagattuta \& Thompson, 2007; Lewis, 2001; Lewis, Sullivan, Stanger, \& Weiss, 1989). To experience self-evaluative emotions, children must: (1) have a sense of self-awareness, (2) have representations of standards, rules, and goals, and (3) internalize and be able to evaluate their behaviors and actions against these standards, rules, and goals.

Self-evaluative emotions are self-directed and first require that children have developed a sense of objective self-awareness, or self-concept (Lewis et al., 1989). Selfreferential behavior, including self-recognition and the use of personal pronouns, can often be observed in children between the ages of 15 and 24 months (Lewis \& BrooksGunn, 1979; Lewis \& Ramsay, 2004; Lewis et al., 1989), indicating that they have 
developed a sense of self-awareness. In the context of learning, having a sense of self means that children are aware that their performance on a challenging task is, at least in part, a result of their own actions (Lewis \& Sullivan, 2005).

The second cognitive prerequisite for experiencing self-evaluative emotions is that children must also be able to recognize standards, rules and goals (Lewis et al., 1989). Standards, rules, and goals are defined as "the information children acquire about expected behavior through their socialization in a particular society" (Lewis \& Sullivan, 2005, p. 188). Children can learn standards, rules, and goals from watching other people or from direct experience and accompanying feedback from parents or others (Lewis \& Sullivan, 2005; Lewis et al., 1989). Research has shown that children typically begin to understand normative behavior, standards, rules, and goals between 18 and 24 months of age (Heckhausen, 1987; Kagan, 1981; Stipek et al., 1992). The standards and goals children acquire from their environment will ultimately impact learning by influencing how they react to challenging tasks and errors (Elliott \& Dweck, 1988; Lewis, 2007).

Finally, children must internalize, and adopt as their own, standards, rules, and goals against which they evaluate their behaviors and actions (Lewis, 2007; Lewis \& Sullivan, 2005). Children evaluate whether they have exceeded, met, or failed to meet a standard, rule, or goal, with one of two outcomes occurring: success or failure. Success is interpreted if the child exceeds or meets the standards, rules, and goals; failure is interpreted if they are not met. Children begin to internalize and use standards, rules, and goals in their self-evaluations around the same time that they begin to understand these concepts, which occurs between 18 and 24 months of age (Kagan, 1981; Stipek et al., 1992). By the time children enter preschool, they have fully begun to evaluate their 
performance based on these factors and self-evaluative emotions can be seen (Stipek et al., 1992). Children's standards, rules, and goals and their perceptions of success versus failure play important roles in learning and achievement by influencing whether children experience shame as a reaction to challenging tasks that initially elicit errors and whether they experience pride after they have successfully met their standards, rules, and goals.

In line with Vygotsky's sociocultural development theory, researchers have shown that children first learn specific standards, rules, and goals from "more knowledgeable others" in their environment (see van der Veer \& Valsiner, 1994). Having adopted standards, rules, and goals from those in their social environment, children's self-directed mental processes then influence their experience of self-evaluative emotions. As children get older, they begin to take into account others' evaluations of their performance and they have more complex experiences of self-evaluative emotions. Children can then experience self-evaluative emotions as a result of either private or public evaluation (Lagattuta \& Thompson, 2007; Lewis \& Sullivan, 2005), with the latter resulting only after children have developed theory of mind, or the awareness that others have their own thoughts, beliefs, and desires. Self-evaluative emotions resulting from private evaluation occur when children reflect on their own mental states and their internalized standards, rules and goals, not taking into consideration whether others may be evaluating them. Once children have developed theory of mind, however, they are able to take into account not only their own thoughts about their performance, but also the thoughts and potential evaluations that others may hold about their performance (Lagattuta \& Thompson, 2007). Theory of mind is not necessary for the early experience of self-evaluative emotions because children are able to evaluate their behavior based on 
their own thoughts. However, the eventual ability to also take into consideration others' thoughts enhances, and makes more complex, children's experience of these emotions (Cutting \& Dunn, 2002; Heerey, Keltner, \& Capps, 2003).

\section{Specific Self-Evaluative Emotions: Description and Measurement}

According to Lewis and Sullivan (2005), once children have met the aforementioned cognitive prerequisites and accept responsibility for a given outcome, they are able to experience self-evaluative emotions. Depending on whether one perceives an outcome as a success or failure and whether they focus on their global sense of self or the actions leading to the outcome, children will experience self-evaluative emotions. While there are four self-evaluative emotions, including shame, pride, guilt, and hubris, only shame and pride can readily be observed and measured in preschoolaged children and are important in achievement-related contexts.

Shame. Shame has been described and measured in a variety of ways. It is experienced when a person perceives or interprets failure, takes responsibility for the failure, and considers this outcome as reflecting negatively on their global sense of self (Lewis \& Sullivan, 2005; Tangney \& Dearing, 2002; Tracy \& Robins, 2007b). There are many ways to assess the experience of shame in older children and adults, which often require the individual to listen to a scenario or a list of statements and elaborate on the extent to which they would feel a given emotion (Robins, Noftle, \& Tracy, 2007; Tangney \& Dearing, 2002). In order to measure shame in preschool-aged children, however, researchers observe their physical and verbal behaviors during a challenging task. Physically, shame is characterized by unique combinations of a closed in or collapsed posture, gaze aversion, and/or frowning (Geppert, Schmidt, \& Galinowski, 
1997). Additionally, negative self-evaluative statements are also considered to be important indicators of shame (Geppert et al., 1997). The feeling of shame is described as being such a "painful and temporarily immobilizing experience" (Ferguson, Stegge, Eyre, Vollmer, \& Ashbaker, 2000, p. 320), that attempts to rid oneself of this feeling often results in maladaptive behavior, such as the tendency to withdraw from the situation that led to the shame experience (Ferguson et al., 2000; Lewis \& Sullivan, 2005; Tangney \& Dearing, 2002). The feeling of shame has also been shown to diminish confidence in one's ability (Covert, Tangney, Maddux, \& Heleno, 2003; Tangney \& Dearing, 2002).

Pride. Pride is experienced when a person perceives and accepts responsibility for success and focuses on the specific behaviors leading to the success (Lewis, Alessandri, \& Sullivan, 1992; Lewis \& Sullivan, 2005; Tracy \& Robins, 2007a). Similar to shame, pride is often assessed in older children and adults by presenting them with scenarios and asking them a series of questions about their emotional reactions (Robins et al., 2007). Also similar to shame, expressions of pride in preschool-aged children are assessed by observing their physical and verbal behaviors during a given task. Pride is characterized by different combinations of behaviors, including an erect and inflated posture, raised head, smiling, and victorious gestures, such as pointing to oneself or the successful outcome (Geppert et al., 1997). Positive self-evaluative statements are also considered to be important indicators of pride (Geppert et al., 1997). Research suggests that the pride an individual experiences during or after a successful experience feels good, leading the individual to continue doing the same behaviors that led to the initial pride experience (Lewis \& Sullivan, 2005; Stipek et al., 1992; Tracy \& Robins, 2004, 2007a).

Guilt and hubris. Guilt is experienced as a result of perceived failure for which 
the individual accepts responsibility, with a focus on the specific actions that led to the failure (Lewis \& Sullivan, 2005; Tangney \& Dearing, 2002). Research also shows that, unlike shame, guilt does not lead to maladaptive behavior, but instead leads to reparative actions that allow individuals to rid themselves of this emotion (Lewis \& Sullivan, 2005). Guilt can be identified in older children and adults via questionnaires (Robins et al., 2007; Tangney \& Dearing, 2002). Important for the current study, due to the complex nature of guilt, "it seems unlikely that [young children] could experience a wellarticulated feeling of guilt" (Tangney \& Dearing, 2002, p. 144). Due to these same reasons, guilt cannot be physically observed in preschool-aged children (Geppert et al., 1997). Much research has found that guilt is often only observed in older children and adults in the context of social or moral situations, not in academic contexts (e.g., Ferguson, Brugman, White, \& Eyre, 2007; Tangney \& Dearing, 2002).

Hubris is experienced when success is perceived and the individual accepts responsibility for this outcome, with the success reflecting positively on their overall sense of self (Lewis \& Sullivan, 2005; Tracy \& Robins, 2007a). Unlike pride, hubris reflects a grandiose or self-aggrandized sense of self and can lead to maladaptive behaviors (Baumeister, Campbell, Krueger, \& Vohs, 2003; Lewis, 2007; Tracy \& Robins, 2007a). Similar to other self-evaluative emotions, hubris can be assessed in older children and adults via questionnaires (Robins et al., 2007), but physical manifestations of hubris cannot be observed in preschool-aged children (Geppert et al., 1997), making this emotion irrelevant to the current study.

\section{Universality of Self-Evaluative Emotions}

Although there are no previous studies examining self-evaluative shame and pride 
in children from poverty, a large body of research suggests that the physical manifestations of self-evaluative emotions are universal and can be observed across all cultures (Geppert et al., 1997; also see Goetz \& Keltner, 2007 for an extensive review). Although the physical displays of self-evaluative emotions are universal, research suggests that differences exist between collectivistic and individualistic cultures in the "valuation, elicitors, and behavioral consequences of these emotions" (Wong \& Tsai, 2007, p. 212; also see Goetz \& Keltner, 2007). There are many studies which show that people from collectivistic cultures tend to view shame as being positively valenced and those from individualistic cultures view it as a negative emotion (e.g., Li, Wang, \& Fischer, 2004; Rozin, 2003), while opposite patterns are found with regard to pride (e.g., Eid \& Diener, 2001).

Due to their different views of the self as independent versus interdependent, individuals from individualistic and collectivistic cultures generally experience selfevaluative shame and pride in different contexts (Goetz \& Keltner, 2007; Wong \& Tsai, 2007). People from individualistic cultures tend to only feel shame when they themselves have failed in some way, while individuals from collectivistic cultures often also experience shame when someone they associate themselves with fails to meet some standard, rule, or goal (Stipek, 1998; Wong \& Tsai, 2007). Pride is usually experienced in individualistic cultures by the individual who has successfully met his or her goals, while collectivistic cultures view and experience pride as a positive emotion only when it is exhibited in response to some group achievement (Pickett, Gonsalkorale, Tracy \& Robins, 2006, as cited in Tracy \& Robins, 2007a; Stipek, 1998).

Finally, the behavioral consequences of self-evaluative shame and pride also vary 
between cultures (for reviews, see Goetz \& Keltner, 2007; Tracy \& Robins, 2007a; Wong \& Tsai, 2007). Individuals from collectivistic cultures tend to be positively motivated by shame experiences, and negatively impacted by personal feelings of pride as a result of the cultural value placed on these emotions (Eid \& Diener, 2001; Heine, Lehman, Markus, \& Kitayama, 1999; Heine, 2004; Li et al., 2004; Wallbott \& Scherer, 1995). This same research has shown that people from individualistic cultures demonstrate an opposite pattern, such that shame negatively impacts motivation and leads to withdrawn task-related behaviors, while pride can serve as a positive motivating factor.

\section{Importance of Self-Evaluative Emotions in School Success}

While all of the self-evaluative emotions (shame, pride, guilt, hubris) are important for influencing general human behavior, only shame and pride have consistently been found to play an important role in learning and the academic achievement of individuals of all ages (Heckhausen, 1987; Schutz \& Pekrun, 2007; Stipek, 1993, 1995; Stipek et al., 1992, 1995). As children learn new skills, they must attempt novel and challenging tasks on which they will undoubtedly make errors; it is how children respond to these errors that is important for the learning process (Tangney \& Dearing, 2002). It is in this context of challenge and errors that shame becomes the self-evaluative emotion of most importance, while pride becomes important to examine in the context of success experiences.

Research with young children has found that shame is only experienced and observed in error-eliciting contexts, while pride is only experienced and observed in success contexts (Alessandri \& Lewis, 1996; Lewis et al., 1992; Stipek et al., 1992, Study 2). As children go through the learning process and inevitably make errors along the way, 
there is great potential for experiencing shame (Tangney \& Dearing, 2002). This is particularly important because the feeling of shame can lead to maladaptive behaviors that can prevent optimal learning, such as inhibiting a child from approaching challenging tasks in the future, as well as decreased effort and persistence (Stipek, 2002). Research examining pride in success has shown that the feelings associated with this selfevaluative emotion lead children to continue demonstrating the same behaviors that led to their success (Lewis \& Sullivan, 2005; Stipek et al., 1992; Tracy \& Robins, 2004, 2007a; Turner \& Waugh, 2007).

\section{Emotion Regulation and Self-Evaluative Emotions in Children of Poverty}

A wide body of research has shown that the multiple stressors associated with living in poverty can negatively impact children's emotion regulation abilities (BrooksGunn \& Duncan, 1997; Garner \& Spears, 2000; Gershoff et al., 2007), and that these children are at a significantly greater risk of displaying such issues than children from more advantaged families (Aber, Jones, \& Cohen, 2000). Emotion regulation refers to "the process by which individuals influence which emotions they have, when they have them, and how they experience and express these emotions" (Gross, 1998, p. 275; as cited in Schutz, Hong, Cross, \& Osbon, 2006). The ability to regulate one's emotions in a challenging academic situation is especially important when considering the previously discussed research showing that self-evaluative emotions influence children's behavioral response to challenge, particularly their persistence and preference for challenging tasks (Stipek, 2002), which are important aspects related to children's achievement motivation and later academic achievement.

While research in areas other than response to challenge and achievement 
motivation has shown that effective emotion regulation can mediate the negative effects of shame on behavioral responses (e.g., Gupta, Rosenthal, Mancini, Cheavens, \& Lynch, 2008), studies targeting children from low-income backgrounds have found that when emotion regulation issues are present, it is typically negative emotions that these children have the most difficulty regulating (Garner \& Spears, 2000; Turner \& Waugh, 2007). As such, it can be inferred that when children with emotion regulation issues experience failure or errors, they may have greater difficulty regulating their experience of shame, which can then lead to more behavioral responses associated with attenuated-mastery and performance oriented motivation, including decreased effort, persistence, and problemsolving and preference for non-challenging tasks. Although studies have not examined the prevalence of self-evaluative shame or pride in the context of poverty, research on emotion regulation in this population provides another example of how poverty can negatively influence children's responses to challenge and error.

Taking into consideration the fact that children from poverty are at a significantly greater risk of developing emotion regulation issues, and thus may also have issues regulating shame in challenging contexts, researchers have sought to better understand how and why poverty exerts a negative influence on emotion regulation in this population. Research has shown that poverty influences children's emotion regulation via its impact on community and family mechanisms (Brooks-Gunn et al., 2005). Community-based risk factors, such as access to lower quality health care and schools, have been shown to be related to the subjective well-being of both children and their parents, which then influences children's development of self-evaluative emotions and emotion regulation (Garner \& Spears, 2000; Lever et al., 2005). Poverty also influences 
various family mechanisms, including the parent-child relationship (Brooks-Gunn et al., 2005; Turner \& Johnson, 2003), that then influence the development of self-evaluative emotions and emotion regulation. Factors associated with living in poverty place multiple strains on the family that can negatively impact the relationship of the parent-child dyad (Bakermans-Kranenburg et al., 2004; Diener et al., 2003; Schiffman et al., 2003) by decreasing parental warmth, responsiveness, and sensitivity with their children (e.g., Hwa-Froelich et al., 2008; Riley et al., 2009), which are important for the development of emotions and emotion regulation (Thompson \& Meyer, 2007).

\section{Cognitive-Attribution Model of Self-Evaluative Emotions}

Although researchers have long acknowledged the existence of self-evaluative emotions, most theories assume that they follow the same developmental pathway as the basic emotions (Lewis \& Sullivan, 2005; Tracy et al., 2007). Lewis and colleagues, however, have proposed a theory and supporting model that differentiates between the development of basic and self-evaluative emotions (Lewis, 1992; Lewis \& Sullivan, 2005). This cognitive-attribution model improves upon models of basic emotions by identifying and describing the more complex cognitive processes necessary to experience self-evaluative emotions. Given this advantage over previous models, the cognitiveattribution model has provided the basis for much of the research involving selfevaluative emotions. By discussing this theory of self-evaluative emotions, one can better understand children's self-evaluative emotional response to challenge and how this likely relates to children's behavioral responses to challenge as described by the achievement motivation literature.

The cognitive-attribution model distinguishes among the four self-evaluative 
emotions previously discussed, while taking into account children's standards rules and goals, as well as various aspects of the self (Lewis, 1992, 2007; Lewis \& Sullivan, 2005). According to this model, once children have met the necessary cognitive prerequisites, self-evaluative emotions are differentially experienced as a result of children's standards, rules, and goals; judgments of internal versus external responsibility for an outcome; and focus of attention on global versus specific aspects of the self (Lewis, 2007).

According to the cognitive-attribution model, children will experience either positive or negative emotions, depending on whether or not they meet their standards, rules, and goals and interpret success or failure, and only if they attribute the outcome to some internal responsibility. Specifically, shame is experienced if an individual interprets failure, accepts an internal responsibility for the failure, and focuses on the global, stable/unchanging self. Thus, children who experience shame view the failure, and the errors leading to the failure, as resulting from some negative and stable aspect of the self, over which they have no control. This type of thinking has negative implications for learning. Children who believe that the failure has occurred due to some stable aspect of the self that they cannot control are likely to avoid challenging tasks in the future, limiting their future learning (Lewis \& Sullivan, 2005).

Children experience pride when they interpret success, take responsibility for the success, and focus their attention on specific aspects of the self that lead to the success experience. Children who experience pride view the success as resulting from some positive, specific action, resulting in a sense of personal satisfaction (Lewis $\&$ Sullivan, 2005). Particularly important, and because pride is connected with some specific behavior leading to success, children should be able to "identify the means by which they 
can recreate this rewarding state at a future date" (Lewis \& Sullivan, 2005, p. 199).

Finally, as a complete model of self-evaluative emotions, the cognitive-attribution model also takes into account and describes the experience of guilt and hubris (Lewis, 2007;

Lewis \& Sullivan, 2005), although these emotions are not relevant to the current research for reasons previously discussed.

Multiple aspects of the cognitive-attribution model are particularly useful and important for understanding why children emotionally respond to challenge and error in certain ways. Most importantly, the model takes into account children's standards and goals (Lewis \& Sullivan, 2005). The standards and goals children adopt have a significant impact on their reaction to challenge; their standards determine their definition of what it means to fail or succeed, while their goals define their purpose in working on certain tasks. These standards and goals are also important components of the achievement motivation literature (Dweck \& Leggett, 1988; Elliot \& Church, 1997; Elliot \& McGregor, 2001; Smiley \& Dweck, 1994) and, as such, have important implications for the model and design of the current study.

\section{Integrating Achievement Motivation and Self-Evaluative Emotions}

Past research examining how individuals respond to challenge and errors in the context of learning has generally been described in terms of either achievement motivation or self-evaluative emotions. Using different constructs and methods to form and test their theories and models, both fields of research have provided important information aiding our understanding of how children and adults respond to challenge the way they do; however, each approach also presents unique limitations. Achievement

\footnotetext{
${ }^{1}$ Guilt is experienced when an individual perceives failure, takes responsibility for the failure, and focuses on the specific behaviors leading to the outcome. Hubris occurs when the individual perceives success, takes responsibility for the success, and attributes the success to global, stable aspects of the self.
} 
motivation researchers only attempt to explain individuals' behavioral responses to challenge, while self-evaluative emotion researchers only attempt to explain individuals' emotional responses. As such, integrative frameworks including these variables "seem to be largely lacking, thereby limiting theoretical and empirical progress" (Pekrun, Frenzel, Goetz, \& Perry, 2007, p. 14). The integration of these variables is important to better understanding response to challenge in all children, but is especially important to consider in preschool-aged children from poverty because they face many risk-factors that place them at risk for developing less adaptive motivational and emotional response patterns to challenge and, subsequently, lower academic achievement (Arnold \& Doctoroff, 2003; Day \& Burns, 2011; Garner \& Spears, 2000; Malakoff et al., 1998; Smith et al., 1997; Zill \& West, 2001).

\section{Research Relating Achievement Motivation and Self-Evaluative Emotions}

Research with older children from economically advantaged backgrounds has examined the relationships between general affect and achievement motivation and between motivation-related variables (e.g., persistence) and self-evaluative emotions, while recent research with adults provides the only examination of the relationship between motivation orientations and self-evaluative emotions. This work is important, as understanding that there is a relationship between these variables can provide researchers with an empirical basis for creating an integrative model that better describes how and why young children respond to challenge.

Achievement motivation and general affect. Although motivation models have not examined how specific emotions influence the early development of certain motivation patterns in preschool-aged children, these models have noted that children 
demonstrate general positive or negative affect or mood after a task, depending on their motivation orientation. Research has generally shown that children with less adaptive performance oriented motivation patterns are more likely to demonstrate negative affect than are children with more adaptive mastery oriented motivation orientations, particularly in error/failure contexts (Diener \& Dweck, 1978; Elliot \& Dweck, 1988; Smiley \& Dweck, 1994). Conversely, children with mastery oriented motivation patterns have generally been found to demonstrate more positive affect and mood (Diener \& Dweck, 1978; Linnenbrink, 2005; Smiley \& Dweck, 1994).

Smiley and Dweck (1994), for example, examined middle- and upper-SES preschool children's general affect after completing a series of challenging puzzles (the same puzzle task assessment used in the current study). Children rated their emotions on a five-point face scale, ranging from "very sad" to "very happy." They found that mastery and attenuated-mastery oriented children did not differ from one another in their selfreported general affect after the task, but that performance oriented children reported more negative affect, while mastery and attenuated- mastery oriented children reported more positive affect ratings. In their study in which they manipulated fifth-graders' motivation via task instructions and feedback, Elliott \& Dweck (1988) also found that relationships between general affect and motivation. Similar to Smiley and Dweck, they found that children with performance goals and low perceived ability (comparable to the performance orientation) demonstrated more negative affect during challenge than did children with performance goals and high perceived ability (comparable to the attenuated-mastery orientation) and learning goals with high or low perceived ability (comparable to the mastery orientation), but that performance goal-high ability and 
learning goal-high/low ability children did not differ from one another. Also assessing fifth-graders' general affect during challenge, Diener and Dweck (1978) found that children with a less adaptive, "helpless" motivation pattern (conceptually equivalent to a performance motivation orientation) were more likely to demonstrate negative affect, as indicated by their verbalizations. Mastery oriented children, however, continued to express positive affect after challenge.

Although assessments of children's general affect in response to challenge provide a good starting point for understanding how motivation and emotions may be related to one another, these assessments only provide a very broad measure of emotions and do not fully explain the relationship between motivation orientation and more specific self-evaluative emotions. For example, negative affect is a general term that encompasses multiple negative or unfavorable emotions, such as sadness, anger, frustration, or shame. Similarly, positive affect ratings may result from a variety of positive, more favorable emotions, including happiness, excitement, or pride. Thus, stating that individuals with adaptive motivation patterns demonstrate less negative and more positive affect, while those with less adaptive patterns demonstrate more negative and less positive affect does not adequately define the motivation/self-evaluative emotion relationship; the specific emotional relationship remains unclear.

Achievement motivation variables and self-evaluative emotions. Research has shown that important variables associated with achievement motivation, such as persistence, are negatively associated with self-evaluative shame. This is especially important because these "individual differences in [self-evaluative] emotions are related to individual differences in children's self-cognitions, including their beliefs about 
themselves, their performance, and ultimately, their competence" (Lewis \& Sullivan, 2005, p. 185; Tracy et al., 2007). These same cognitions and beliefs, in turn, play an important role in the development of children's achievement motivation patterns (see Elliot \& Dweck, 2005a).

Children as young as 3 years of age, and across a range of family incomes, who experience shame in failure demonstrate maladaptive behaviors, including decreased persistence and effort and avoidance of challenging tasks in subsequent situations (Kelley, Brownell, \& Campbell, 2000; Stipek et al, 1992; Turner \& Waugh, 2007). Similar studies have generally found that pride is not related to persistence (e.g., Kelley et al., 2000). Particularly relevant to the current study, Kelley and colleagues (2000) presented toddlers with easy and difficult versions of wooden puzzles and shape sorters and assessed their persistence by measuring the amount of time they remained on task. Using an earlier, broad-based and less stringent version of Geppert's Self-Evaluative Emotions Coding System, they examined whether children demonstrated shame and pride during the task, which were each defined as occurring when three of five behaviors occurred at any point for 30 seconds after ceasing work on the tasks. They found that toddlers' occurrences of shame behaviors after challenge was negatively correlated with their persistence on the task; children who were less persistent were more likely to demonstrate shame behaviors after the task. Pride, however, was not correlated with toddlers' persistence. Given that persistence is one of many important components of achievement motivation, Kelley and colleagues' study provides the only example of previous work demonstrating a relationship between challenge and young children's selfevaluative emotions. Taking such findings into consideration, it should come as no 
surprise that self-evaluative emotions, particularly shame, are considered to be "important motivators of behavior" in challenging learning situations (Stipek, 1983; Stipek et al., 1992).

Achievement motivation and self-evaluative emotions. The previously discussed research examined variables related to and/or similar to achievement motivation and self-evaluative emotions, but did not directly relate these variables to one another. Although there is no research relating these variables to one another in preschool-aged children or children from poverty, there is a body of research conducted with undergraduates that relates achievement motivation and self-evaluative emotions (Pekrun, 2006; Pekrun, Elliot, \& Maier, 2006, 2009). This work defines motivation in terms of models that aren't applicable to the early development of motivation in young children, but their findings are informative to the current study nonetheless. Generally, these studies have found that adults with more adaptive motivation report less shame and more pride, while individuals with less adaptive motivation patterns report more shame and less pride.

Pekrun and colleagues $(2006,2009)$ defined college students' achievement motivation based on their responses to a questionnaire assessing their achievement goals. Depending on their responses, individuals were classified as having mastery goals, performance-approach goals, or performance-avoidance goals. Although not identical, these goals are conceptually similar to mastery, attenuated-mastery, and performance motivation orientations defined by the cognitive-goal model of motivation, respectively. Students' self-evaluative emotions, or achievement emotions as they are referred to by Pekrun and colleagues, were assessed by their responses to a questionnaire measuring 
their emotions while studying for an exam. They found that mastery goals were a negative predictor of shame and that performance-avoidance goals were a positive predictor of shame; performance-approach goals were not predictive of shame.

Individuals with mastery goals were less likely to show shame, those with performanceavoidance goals were more likely to show shame, and those with the intermediate performance-approach goals were neither more nor less likely to demonstrate shame behaviors. In their most recent study (Pekrun et al., 2009), they found differences in pride, such that mastery goals and performance-approach goals were positive predictors of pride, while performance-avoidance goals were a negative predictor of pride. Adults with mastery goals and performance-approach goals reported more feelings of pride, while those with performance-avoidance goals reported fewer feelings of pride.

\section{Models and Theories Integrating Achievement Motivation and Self-Evaluative}

\section{Emotions}

Given the importance of motivation and self-evaluative emotions to learning, as well as their relationship to one another, it is important to have models and theories that integrate these variables. Although such work has not been conducted with preschoolaged children or children from poverty, work with older children and adults has recognized this relationship and has attempted to integrate these two approaches. Two distinct theories have been identified that incorporate both achievement motivation and self-evaluative emotions into a single model: the intrapersonal attributional theory and the control-value theory. Although these models do not explain the early, interactive development or relationship of achievement motivation and self-evaluative emotions in young children, they provide important insights that can inform the development of such 
a model, such as that of the current study.

Intrapersonal attributional theory. Attribution theory is based on the idea that people are primarily motivated to understand why events occur, particularly if the outcome is negative or unexpected (Weiner, 1985; Weiner \& Kukla, 1970). In line with this idea, the intrapersonal attributional theory incorporates self-directed thoughts and emotions into a single model that is used to explain and predict behaviors (Weiner, 1985, 2000 ). According to this theory, the motivation process begins with the completion of an event followed by a series of causal attributions, which lead the individual to experience specific emotions that influence their subsequent behavior.

Once an event has been completed, the outcome elicits either a basic positive or negative affective reaction. If the outcome is unexpected, negative, or important, the individual will evaluate a series of causal attributions in an attempt to figure out why the specific outcome occurred. An individual's perception as to why an outcome occurred will vary depending on a variety of antecedent factors, such as one's past performance, which then leads the individual to determine whether the outcome is due to ability, effort, strategy, task-related factors, luck, or some other cause. The individual then evaluates these causal ascriptions along three causal dimensions: locus, stability, and control (Weiner, 1985, 2000). Once causal antecedents have been reviewed and ascriptions of locus, stability, and control classifications have been made, psychological consequences will follow. According to Weiner (2001), and similar to the cognitive attribution model of self-evaluative emotions, shame and pride can only be experienced if the outcome is attributed to an internal cause. Pride will be experienced if the outcome is positive and is attributed to an internal cause. If the outcome is considered negative, internal to the 
person, and uncontrollable, the individual will experience shame. The causal attributions and the emotions an individual experiences then influence their future achievementrelated behaviors (Weiner, 1985, 2000, 2001; Weiner \& Kukla, 1970).

The intrapersonal attributional theory represents one of the earliest models that attempts to articulate the role of self-evaluative emotions in predicting behavioral response to situations in older children and adults (see Elliot \& Dweck, 2005a). The inclusion of self-evaluative emotions in the theory is very important and informative to forming an integrative model for preschool-aged children, as these emotions have been shown to be related to behavior and motivation (e.g., Pekrun et al., 2006) and also play an integral role in learning and education (Schutz \& Pekrun, 2007). Despite these positive aspects of the theory, it contains certain components that make it an inappropriate model for predicting and examining response to challenge in preschool-aged children (e.g., Asmus, 1986; Weiner, Russell, \& Lerman, 1979). For example, research suggests that children may not be able to adequately differentiate among the causal attributions of locus, stability, and control until middle childhood and beyond (e.g., Normandeau \& Gobeil, 1998; Stipek \& DeCotis, 1988). Another limitation of the intrapersonal attributional theory is that it only accounts for future behavior, while findings from the motivation literature suggest that an individual's behavior while working on the task is also important (Elliott \& Dweck, 1988; Smiley \& Dweck, 1994). Finally, the theory would benefit from including children's achievement goals and confidence, as the interaction of these variables is important for predicting children's motivation (Dweck \& Leggett, 1988; Smiley \& Dweck, 1994).

Control-value theory. The control-value theory of achievement emotions 
provides an integrative model that attempts to explain how a variety of antecedents and appraisals interact to determine the arousal of achievement, or self-evaluative, emotions and their influence on learning and academic performance (Pekrun, 2000, 2006). Drawing from previous theories of motivation and emotions, the control-value theory posits that the control attributions and value appraisals individuals make about tasks and task outcomes are of particular importance in determining behavior (Pekrun, 2000; Pekrun, Goetz, Titz, \& Perry, 2002).

The amount of control an individual thinks they have over achievement activities and outcomes, as well as the value they associate with these factors, are central to the control-value theory (Pekrun, 2000; Pekrun et al., 2002). Similar to Weiner's attributional theory, this sense of control is influenced by the expectancies and attributions an individual ascribes to a given situation (Pekrun, 2006). Personal achievement goals of motivation and factors associated with the learning environment influence individuals' control and value appraisals of past, present, and future achievement-related outcomes (Pekrun, 2000, 2006; Pekrun et al., 2002; Pekrun \& Schutz, 2007). More specifically, individual's with mastery goals tend to focus their attention on the activity and the controllability and positive value of the activity; those with performance-approach goals prospectively focus on the task outcome and the controllability and positive outcome value of the activity; performance-avoidance goals focus one's prospective attention on the task outcome and the lack of controllability of and negative outcome value associated with the task (Pekrun et al., 2006).

Control and value appraisals, as well as temperament and other genetic dispositions, then directly influence the achievement emotions experienced (Pekrun, 
2000; Pekrun et al., 2007; Pekrun et al., 2002). Relevant to the current work, and in line with the cognitive-attribution model of self-evaluative emotions, the control-value theory states that individuals will experience shame only in the context of a negatively valued failure for which the individual accepts responsibility, while pride is experienced in the context of a positively valued success for which the individual accepts responsibility. The achievement emotions an individual experiences, in addition to their general competencies and cognitive abilities, then influence learning and achievement via their effect on cognitive, regulatory, and motivational processes (Pekrun, 2000, 2006; Pekrun et al., 2007). In general, positive emotions, such as pride, help to focus one's cognitive resources on the task at hand, facilitate the use of flexible and creative learning strategies, facilitate their self-regulation of learning, and increase student's motivation to learn (Pekrun et al., 2007). Negative emotions, such as shame, however, may consume cognitive resources by focusing attention on negative aspects of a task, lead to ineffective and inappropriate problem solving strategies, discourage self-regulated learning, and decrease students' motivation to learn (Pekrun, 2006). As a final step in the theory, individuals' learning and achievement reflect back on their environment, appraisals, and emotions, thus linking these variables by "reciprocal causation over time" (Pekrun et al., 2007, p. 16).

There are several positive aspects of the control-value theory that make it a good model for understanding the role of emotions and motivation in an older children's and adults' responses to challenge. The inclusion of achievement goals and self-evaluative emotions are perhaps two of the most important aspects of this theory, as these variables are important for understanding and explaining behavioral and emotional response to 
challenge (Elliot \& Dweck, 2005a; Schutz \& Pekrun, 2007). The acknowledgment of the influence of environmental, genetically-based, and cognitive ability factors on motivation, self-evaluative emotions, and learning also represent positive aspects of this theory.

Although there are advantages to the control-value theory, research suggests that understanding and applying task outcome expectancies and value concepts, as described in this model, is beyond the cognitive capabilities of preschool-aged children (e.g., Parsons \& Ruble, 1977; Wigfield \& Eccles, 1992). Similar to the intrapersonal attributional theory, the controllability aspect of the control-value theory represents another developmental limitation of this model, as preschool-aged children are not able to adequately differentiate among the causal attributions of control (Normandeau \& Gobeil, 1998; Stipek \& DeCotis, 1988). Although it is important that the theory acknowledges the importance of achievement goals, the focus on approach-avoidance goals, as opposed to those included in the cognitive goal model, represents another disadvantage of the theory when considering preschool-aged children. This approach-avoidance distinction is problematic, as research has shown that preschool-aged children tend to be overly optimistic in estimating their ability to succeed on a task (Parsons \& Ruble, 1977), suggesting that they don't make the positive versus negative valence distinction that differentiates among approach and avoidance goals.

The intrapersonal attributional and control-value theories provide important information that describes and explains the relationship between self-evaluative emotions and achievement motivation in older children and adults, which can inform such models in young children. It is also important to consider the idea that a model examining the 
early development and relationship of these variables in preschoolers can also inform adult models. For example, understanding when and how these variables begin to influence one another in early development, as well as understanding the impact of poverty on their relationship and development, may provide researchers studying adults with a more complete understanding of the later interactions between these variables.

\section{Proposed Integrative Model of Achievement Motivation}

\section{and Self-Evaluative Emotions}

Individual differences in children's responses to challenge have been described in terms of either achievement motivation or self-evaluative emotion models and theories (e.g., Dweck \& Leggett, 1988; Smiley \& Dweck, 1994; Lewis \& Sullivan, 2005). Although both the achievement motivation and self-evaluative emotion approaches provide an important basis for describing and understanding how children respond to challenge, neither line of research is able to provide a complete picture of how and why children respond and react the way they do. Taking this into consideration, the current study proposed and tested a new model that integrated the achievement motivation and self-evaluative emotion research to better understand early individual differences in responses to challenge and errors of preschool-aged children from poverty.

\section{Proposed Model}

Based on the presented theoretical and empirical research, an integrative model was proposed that demonstrates how achievement motivation and self-evaluative emotion models can be combined to best describe and explain children's early responses to challenge and errors. Generally, the proposed model states that self-evaluative emotions, particularly shame, influence the relationship between children's standards, rules, and 
goals and their behavioral responses to challenge. According to this model, and based upon both approaches, children first adopt certain standards, rules, and goals (including performance and learning goals as described by the achievement motivation research). These standards, rules, and goals influence how children interpret task outcomes (interpreted success or failure as described by the self-evaluative emotion research), which then determine whether children will experience shame in a given situation. Finally, the amount or intensity of shame experienced then influences children's behavioral responses to challenge, which define their achievement motivation orientation. The following provides a more detailed description of the proposed model (see Table 1). Similar to the literature on self-evaluative emotions (Lagattuta \& Thompson, 2007; Lewis \& Sullivan, 2005), the first step in the proposed model focuses on children's achievement standards. The achievement standards children adopt determine their definitions of what constitutes success and failure. Some children have standards that focus on task outcome, while others tend to focus on the learning process associated with the task. Children who focus on outcome tend to view success as resulting from the correct completion of a task, while errors and non-completion of a task are interpreted as failure and have negative implications for their global sense of self-worth as a learner (Dweck \& Leggett, 1988; Lewis, 1992; Tangney \& Dearing, 2002). For children whose focus is on process, learning from a task, even if errors are made, is interpreted as success. These children consider errors to be a normal part of task involvement and learning and, as such, do not view errors or non-completion of a task as failure. As a result of having different standards for what it means to experience success and failure, children who focus on outcome versus process adopt different achievement goals. 
Children whose achievement standards and definitions of success and failure are defined in terms of task outcome will adopt performance goals. As defined by the cognitive goal model (Dweck \& Leggett, 1988), children with a performance goal are focused on proving their competence by correctly completing a task; thus, when they are faced with a challenging task that leads to errors, these children tend to feel that they have failed to prove their competence. As opposed to children who focus on outcome, children whose standards focus on the process of working on a challenging task will adopt learning goals. Children with learning goals focus on improving their competence (Dweck \& Leggett, 1988). As previously mentioned, these children do not perceive errors as failure, but as part of the learning process.

When faced with a challenging task that elicits errors, children with performance and learning goals will experience different emotional responses. According to research on self-evaluative emotions, shame is experienced in the context of failure, while pride is experienced in the context of success (Lewis, 1992; Lewis \& Sullivan, 2005). Thus, because children with a performance goal perceive the errors associated with a challenging task as failure, they will experience shame. Due to a variety of factors that are beyond the scope of this paper (e.g., temperament and socialization), some children will experience higher levels of shame in the context of failure, while others will experience less shame. Children with learning goals will not experience significant levels of shame if they have not perceived themselves as failing in a specific situation; this is supported by research showing that higher amounts of shame are only associated with clear indications of perceived failure (Alessandri \& Lewis, 1996; Lewis et al., 1992; Stipek et al., 1992). 
Depending on an individual's adopted goals and the level of shame they experience, a child will exhibit distinct response patterns to challenging tasks, which parallel those described in the cognitive goal model (Dweck \& Leggett, 1988; Smiley \& Dweck, 1994). First, children with a performance goal who experience high levels of shame will respond to challenging tasks by demonstrating performance declines, ineffective problem solving, and decreased persistence and effort. Children demonstrating this response pattern are referred to as having performance oriented motivation. Children with a performance goal who experience lower levels of shame demonstrate a somewhat more adaptive response pattern to challenge and failure. These children are described as having an attenuated-mastery oriented motivation pattern and demonstrate a slight decrease in performance, moderately effective problem solving skills, and moderate levels of persistence and effort. Finally, a child who approaches a specific error-eliciting, challenging task with a learning goal will experience very little or no shame in that particular situation because they tend not to interpret errors as failure. As such, these children demonstrate the most adaptive response to challenge and errors; they maintain performance levels, use effective problem solving strategies, and show high levels persistence and effort. These children are described as having a mastery oriented motivation pattern.

It is important to note that the proposed model focuses on how children respond to errors and perceived failure and, as such, only includes shame as the self-evaluative emotion of importance. In the context of a perceived success experience, however, there is no previous theoretical or empirical research to suggest that young children with different motivation orientations will experience different amounts of pride (e.g., see 
Kelley et al., 2000). Researchers agree that pride results in a positive emotional experience, which children try to recreate by performing the same behaviors that led to the initial pride experience (Lewis \& Sullivan, 2005; Stipek et al., 1992; Tracy \& Robins, 2004, 2007a). Wanting to re-experience the initial success, however, means that all children will continue to adopt their specific standards and achievement goals because they have experienced that these standards and goals will lead to success. Thus, although they will likely experience equal amounts of pride in success, children with performance goals will continue to adopt performance goals, while those with learning goals will maintain their learning goals.

\section{Current Study}

The current study tested a portion of a new model that integrates research on selfevaluative emotions and achievement motivation to better understand children's response to challenge. This model will provide researchers with a new framework for examining self-evaluative emotions and achievement motivation in preschool-aged children. The integration of these two lines of research will provide a basis that will allow researchers to better understand how and why children react to challenges the way they do. This may be especially important to examine in children from low-income families who, due to the effects of the multiple risk factors associated with living in poverty, have been shown to be at risk of developing maladaptive achievement motivation patterns and are more likely to have poorer emotion regulation skills, which could lead to issues regulating shame in challenging learning contexts (e.g., Aber et al., 2000; Brooks-Gunn et al., 2005; Garner \& Spears, 2000; Malakoff et al., 1998). Considering the influence of self-evaluative emotions on achievement motivation in the context of learning also has important and 
practical implications for the assessment and prediction of children's response to challenge, which can inform early interventions in educational settings (Pekrun, 2006; Pekrun \& Schutz, 2007).

The overall goal of the current study was to better understand the relationship between self-evaluative emotions, particularly shame and pride, and achievement motivation of children from low-income families in the context of specific failure and success experiences. More specifically, the study tested the portion of the proposed model examining the relationship of self-evaluative emotions and children's behavioral response to challenge, as defined by their achievement motivation orientation. By examining this relationship, we were be able to establish, in a poverty sample, how frequently self-evaluative emotion responses accompany behavioral responses in young children during specific tasks. To better understand children's response to challenge, the study also included measures of children's verbalizations during a challenging task, which have been shown to reflect their cognitions while working on a task (Alexander et al., 1997; Chiu \& Alexander, 2000; Vygotsky, 1934/1986), with the goal of establishing how different patterns of motivation relate to private speech.

The specific goals of the current study were to: (1) replicate and extend upon previous research examining the relationship between preschool-aged children's cognitions, as assessed by their verbalizations, and achievement motivation, (2) provide new research examining self-evaluative emotional responses to failure and success experiences in at-risk preschool-aged children, and (3) test a portion of a new model that examines the relationship between self-evaluative emotions and achievement motivation in preschool-aged children from poverty. 


\section{Hypothesis 1. Mastery, attenuated-mastery, and performance oriented preschool-}

aged children from poverty will differ in the proportion of Task-Relevant Facilitative, Task-Relevant Nonfacilitative, and Task-Irrelevant verbalizations produced during the challenging puzzle tasks.

More specifically, it was hypothesized that mastery oriented preschool children would demonstrate the lowest proportion of Task-Irrelevant verbalizations, followed by attenuated-mastery oriented and performance oriented children. Similarly, it was expected that mastery oriented children would also demonstrate the lowest proportion of Task-Relevant Nonfacilitative verbalizations, followed by attenuated-mastery oriented and performance oriented children. It was also hypothesized that mastery oriented children would demonstrate the greatest proportion of Task-Relevant Facilitative verbalizations, followed by attenuated-mastery oriented and performance oriented children.

These hypotheses were supported by research that has shown that children with performance oriented versus mastery oriented achievement motivation demonstrate different patterns of verbalizations while working on challenging tasks (e.g., Chiu \& Alexander, 2000; Harris, Brown, et al., 2007; Smiley \& Dweck, 1994). More specifically, this research has shown that children with less adaptive achievement motivation patterns tend to engage in more negative, nonfacilitative and off-task private speech, whereas children with more adaptive achievement motivation patterns demonstrate more positive, facilitative private speech.

Hypothesis 2. The self-evaluative shame and pride responses to challenge by preschool-aged children from poverty will differ across puzzles on the puzzle task, 
such that children will demonstrate increasing shame across subsequent puzzles, and more pride on the solvable puzzle than on the unsolvable puzzles.

The hypothesis that children would demonstrate increasing amounts of shame as they worked on subsequent puzzles was supported by research on self-evaluative emotions, which has shown that children experience shame when they make errors and interpret failure (Alessandri \& Lewis, 1996; Lewis \& Sullivan, 2005; Stipek et al., 1992, Study 2; Tangney \& Dearing, 2002; Tracy \& Robins, 2007b). Such shame was expected to be elicited by the unsolvable puzzles, which provided opportunities for making errors and, thus, possibly perceiving failure. It was expected that children would also demonstrate increased shame expressions as they made any errors during the fourth puzzle, as they were not aware that this puzzle was different from the first three puzzles attempted. The hypothesis that children would demonstrate more pride on the solvable puzzle than on the unsolvable puzzles was also supported by the self-evaluative emotion research, which has shown that children experience pride in the context of a success experience (Alessandri \& Lewis, 1996; Lewis et al., 1992; Lewis \& Sullivan, 2005; Tracy \& Robins, 2007a), as was elicited by the solvable puzzle.

Hypothesis 3. The self-evaluative shame responses by preschool-aged children from poverty during the challenging puzzle task will differ between motivation orientation groups, while self-evaluative pride responses will not differ between children of different motivation orientations.

This major hypothesis of the proposed study was designed to test the integrative link between self-evaluative emotions and achievement motivation as described by the proposed model. With regard to shame, it was hypothesized that mastery oriented 
children would demonstrate the lowest amount of shame, followed by attenuated-mastery oriented and performance oriented children. This hypothesis was supported by previous theoretical and empirical research, which has shown that more maladaptive motivation patterns, as well as factors associated with maladaptive patterns (e.g., decreased persistence), are associated with general negative affect and self-evaluative shame more specifically (Diener \& Dweck, 1978; Kelley et al., 2000; Pekrun et al., 2006, 2009; Smiley \& Dweck, 1994; Stipek et al., 1992). With regard to pride, it was hypothesized that differences in motivation orientation would not relate to pride during the puzzle task. Although previous research shows that more adaptive motivation patterns are associated with general positive affect and mood (Diener \& Dweck, 1978; Linnenbrink, 2005; Smiley \& Dweck, 1994), research with preschool-aged children has shown that, regardless of their motivation orientation, all children show similar amounts of pride in success (Kelley et al., 2000).

In sum, the examination of the proposed model will provide new information for better understanding how children's cognitive and self-evaluative emotional responses to challenge are related to their motivation orientation, which will provide important insights as to how these variables can best be supported in at-risk children from poverty. 


\section{METHOD}

\section{Participants}

A total of 76 preschool-aged children were initially recruited to participate in the current study. Children and their families were recruited from local Head Start sites by sending information fliers and consent forms home to parents and guardians. Children's qualifications for enrollment in the Head Start program were based on family income levels under Federal Poverty Guidelines, which ensures that a low-income sample was evaluated in the current study. No restrictions based on child gender or ethnicity were included.

The final sample size consisted of 66 children as a result of families moving out of the school prior to data collection, children not attending school for an extended period of time, video equipment malfunction, noncompletion of assessments, or other reasons associated with the data (i.e., the only performance oriented child was excluded from data analyses). Children ranged in age from 3.50 to 5.00 years $(M=4.35, S D=0.37)$ and included 30 boys and 36 girls. The children in the study were predominantly African American $(93.90 \%$; Caucasian $=4.50 \%$; other $=1.50 \%)$, which was representative of the Head Start sites from which participants were recruited. Consistent with Head Start enrollment requirements of meeting federal poverty guidelines, families reported a median income of $\$ 8,860-\$ 11,939$. 


\section{Procedure}

Data were collected by the primary researcher and trained research assistants during three assessment sessions. All sessions took place in a small, quiet room at the children's schools. During Session 1, children completed a measure of puzzle ability, which lasted approximately 5 minutes. Session 2 took place no less than 1 day and no more than 7 days later and lasted approximately 20 minutes. Children completed a series of puzzle tasks meant to measure their motivation orientation during this session. This task was videotaped for later coding of children's verbalizations and self-evaluative emotions. Finally, children completed a cognitive ability measure during Session 3 , which lasted approximately 45-60 minutes and took place within approximately four weeks of Session 2. These procedures were approved by the Institutional Review Board (IRB \# 607.06) and parental informed written consent and child verbal assent were obtained prior to data collection. Children were told they could end their participation at any time. All but one child in the initial sample of 76 participants completed all assessments; one child wanted to go back to class and refused to complete the motivation assessment.

\section{Measures}

Cognitive ability. The Differential Ability Scales-Second Edition (DAS-II;

Elliott, 2007) is a cognitive ability test that measures the general conceptual ability (GCA) of children ranging in age from 2:6 to 17:11. The Upper Early Years battery is administered to children ranging in age from 3:6 to 6:1 land includes subtests designed to measure children's verbal, nonverbal reasoning, and spatial abilities, which are combined to yield a single, standardized GCA score. The verbal ability subtest measures children's 
language comprehension and language expression, while the nonverbal reasoning subtest assesses children's ability to identify important aspects of visually presented stimuli and to determine relationships among these and future stimuli. The spatial ability subtest assesses children's "complex visual-spatial processing" (Elliott, 2007, p. 77) based on block-building and copying/drawing tests. The DAS-II has been shown to demonstrate good internal reliability, with reliability coefficients on the Upper Early Years subtests and GCA ranging from .87 to .95 (Elliott, 2007). The DAS-II has also been shown to demonstrate good internal, convergent, and divergent validity when compared to other assessments of cognitive ability (Elliott, 2007). This measure has also been shown to be highly positively correlated with other measures of children's academic achievement and emerging skills (Elliott, 2007). Children completed the DAS-II during Session 3 of the study. Although previous research with young children has continually shown that cognitive ability is not correlated with achievement motivation (e.g., Harris, Brown, et al., 2007; Harris, Robinson, et al., 2007; Gagné \& St. Père, 2002), this variable was measured in the current study to ensure that any verbalization or self-evaluative emotion differences found between motivation groups were not a function of cognitive ability differences.

Puzzle-solving ability. Children's general puzzle-solving abilities were assessed during Session 1. Children were first shown a black and white picture of an ageappropriate puzzle that depicted popular children's characters (Sesame Street characters) and were asked to identify the characters and the activities taking place. The picture was then removed from the child's view and the puzzle board and eight puzzle pieces were placed in front of the child (this same procedure was followed prior to children working 
on puzzles during the motivation assessment). The time required to complete the puzzle was recorded and used as a baseline measure of puzzle-solving ability, with higher times being indicative of lower puzzle-solving ability.

Achievement motivation. A series of puzzle tasks (see Figure 1; Smiley \& Dweck, 1994) were used to assess children's motivation orientation during Session 2. As part of the task, children were presented with opportunities to complete three unsolvable puzzles in two-minute segments and then one solvable puzzle and were asked several questions afterward to assess their motivation orientation. The unsolvable puzzles depicted popular cartoon characters (Sesame Street characters) and included eight pieces, three of which were incorrect, that were to be inserted by the child. Unsolvable puzzles differed only slightly from the solvable puzzle, in that similar puzzle pieces were exchanged for the required accurate pieces. The final, solvable puzzle contained the same number of pieces and characters as the unsolvable puzzles, but all of the correct puzzle pieces were included.

Children were permitted to work on each unsolvable puzzle for a maximum of two minutes, or until there was an indication that they had become aware that they are given incorrect puzzle pieces. After two minutes of working on the puzzle, the experimenter said, "Let's go on to the next puzzle". The experimenter then picked up the puzzle, leaving the correctly inserted pieces intact, and moved it across the table in the child's view. The number of correct insertions for each unsolvable puzzle was recorded by the experimenter. On the fourth (solvable) puzzle, the child was provided with as much time as was needed to successfully complete the puzzle; the amount of time needed was recorded by the experimenter. Once completed, the solvable puzzle was placed next 
to the three unsolvable puzzles and the child was asked a series of questions in order to categorize their achievement motivation orientation patterns.

Children were asked which of the four puzzles they would like to work on again and why (Smiley \& Dweck, 1994). The experimenter pointed to the puzzles in a random order and said, "You can do one of these again. Which one would you like to do?" After the child chose a puzzle, the experimenter responded by saying, "Good choice. Why did you pick that puzzle?" Regardless of whether the child chose an unsolvable or solvable puzzle, they were given the opportunity to solve the puzzle they chose. By quickly exchanging some pieces, the experimenter provided the child with all of the correct pieces and as much time as was needed to complete the puzzle. After completing their chosen puzzle, children's task-specific confidence was assessed by asking the child, "If you had lots of time right now, could you finish any of these [unsolvable] puzzles?" Low confidence was marked by "no" responses, whereas "yes" responses indicated high confidence.

Children's reasons for their puzzle choice were then categorized into one of four categories according to the response coding system used by Smiley and Dweck (1994). Responses were coded in the "Challenge" category if they demonstrated the child's interest in trying to solve the puzzle (e.g., "Because I want to try to finish it."). The "Want/Like" category consisted of responses indicating the child's desire or preference for a certain puzzle (e.g., "Because I like that one."). "No Challenge" reasons refer to how easy the child thought the task was (e.g., "Because that's an easy one.") or to the child's belief that they could easily complete the puzzle ("Because I already know how to do that one."). Finally, the "No Reason" category consisted of "I don't know" or "Just 
because" responses.

Children's puzzle choice and the reason for their choice were used to determine children's achievement goals (Smiley \& Dweck, 1994). Children were categorized as having a performance goal if they chose the solvable puzzle, regardless of their reason. The rationale being that by choosing a puzzle that they have already completed, children were actively avoiding a challenging task. Children who chose one of the three unsolvable puzzles, but provided a No Challenge reason were also classified as having performance goals, because they chose a puzzle based on their perception that it was going to be easy to complete. Children were categorized as having a learning goal if they chose an unsolvable puzzle and provided a Challenge, Want/Like, or No Reason response. The rationale being that their responses indicated that they recognized and approached a challenging task.

Finally, children's motivation orientation patterns were determined based on their achievement goals, as defined by their puzzle choice and reason for this choice, and their task-specific confidence (Smiley \& Dweck, 1994). Children with a performance goal who also demonstrate low task-specific confidence were categorized as having a performance oriented motivation pattern. However, children with a performance goal who had high task-specific confidence were categorized as having an attenuated-mastery oriented motivation pattern. Regardless of their task-specific confidence, children with a learning goal were categorized as having a mastery oriented motivation pattern (see Figure 2). All motivation orientation categorizations were independently coded by the first author and another researcher familiar with the coding task and system; coders reached independent agreement on the motivation categorizations of $100 \%$ of the sample. 
Self-evaluative emotions. The Self-Evaluative Emotions Coding System (SEECS;

Geppert et al., 1997) was used to code children's expressions of shame and pride while working on the motivation puzzle tasks. This coding system examines combinations of gaze, expression, gesture, posture, and verbalization patterns to identify the unique expressions of shame and pride (see Tables 2 and 3 for operational definitions and unique feature combinations, respectively). The SEECS was developed as a way to measure the self-evaluative emotions of children ranging in age from 2-5 years during competitive or challenging tasks and in reaction to successes and failures resulting from these tasks (Geppert et al., 1997). This particular coding system has been widely used by researchers studying preschool-aged children's self-evaluative emotions (e.g., Alessandri \& Lewis, 1996; Belsky, Domitrovich, \& Crnic, 1997; Kelley et al., 2000; Lewis et al., 1992). The SEECS has been shown to be a valid and reliable measure of self-evaluative emotions and has been used with children from various ethnic backgrounds (see Belsky et al., 1997; Geppert et al., 1997).

Interrater reliability was established on $20 \%$ of the videos coded for children's self-evaluative emotions. Two research assistants received extensive training in the use of the SEECS, with acceptable reliability coefficients of 80 or above. Coders were blind to participants' achievement goal and motivation orientations and performance on all assessments. Interrater reliability kappa scores ranged from .83 to .97 for individual videos, with a mean of .90 .

Verbalizations. Children's spontaneous verbalizations made while working on the motivation puzzle tasks were recorded and transcribed into one of 4 broad, mutually exclusive and exhaustive categories using a coding system that integrates and builds upon 
the work of Smiley and Dweck (1994), Chiu and Alexander (2000), and Manning and colleagues (1994). Based on these previous studies examining children's motivation and private speech, children's verbalizations made during the puzzle task were coded into one of the following categories: Task-Relevant Facilitative, Task-Relevant Nonfacilitative, Task-Irrelevant, and Ambiguous (see Table 4). Task-Relevant Facilitative statements were related to the task at hand and represented attempts by the child to focus his or her cognitive resources on the task, to plan or organize task-related activities, and to correct, cope, or motivate the child while working on the task. This category included strategy, self-motivating, task appropriate solution, task-appropriate difficulty, and challenge verbalizations. Task-Relevant Nonfacilitative statements included verbalizations that were related to the task, but "served to delay or stop accompanying task-related behavior" (Manning et al., 1994, p. 196), and included performance concern, negative ability evaluation, disengaged, and help-related statements. As their name suggests TaskIrrelevant verbalizations referred to statements that did not relate to the challenging puzzle task and included off-task statements. Any utterances and verbalizations that could not be understood were coded in the Ambiguous category. Definitions and specific examples of verbalization categories are provided in Table 4.

Interrater reliability was established on $20 \%$ of the transcriptions coded for children's verbalizations. To verify reliability, a research assistant received extensive training in the verbalization coding scheme and was blind to participants' achievement goals, motivation orientations, and performance on all assessments. Reliability coefficients were obtained for each participant by dividing the number of coding agreements by the total number of possible codes for that participant (Chiu \& Alexander, 
2000; Smiley \& Dweck, 1994), with acceptable reliability coefficients set at .80 or above.

Interrater reliability scores ranged from .96 to 1.00 , with a mean of .99 . 


\section{RESULTS}

\section{Preliminary Analyses}

Preliminary data exploration and analyses were first conducted to determine the overall pattern of children's motivation orientations, as well as any differences among these groups in terms of age, gender, cognitive ability, puzzle-solving ability, the amount of time required to complete the final puzzle in the puzzle task. Preliminary analyses were also conducted to determine whether these variables were related to children's verbalization proportions and their self-evaluative shame and pride expressions during the challenging puzzle tasks. All preliminary analyses were evaluated as two-tailed tests with significance levels set at $p<.05$.

Motivation orientation. As previously discussed, children's motivation orientations were determined based on their puzzle choices, reasons for those choices, and their confidence in their ability as assessed by the challenging puzzle task. Of the 67 children for which all assessments were completed and videos were available, 1 child had a performance oriented motivation pattern, 15 had an attenuated-mastery oriented motivation pattern, and 51 had a mastery oriented motivation pattern (Table 5, goalconfidence patterns). Because only one child had a performance oriented motivation pattern, this child was removed from the dataset. Thus, only children with mastery and attenuated-mastery oriented motivation patterns were included in all subsequent analyses.

Preliminary analyses were then conducted to examine differences between 
children categorized as having an attenuated-mastery versus mastery oriented motivation pattern. Independent $t$ tests showed that attenuated-mastery and mastery oriented children did not differ in terms of age $(t(63)=-1.10, p=.28)$, overall cognitive ability $(t(58)=-$ $0.60, p=.55)$, verbal cognitive ability $(t(64)=0.20, p=.98)$, nonverbal cognitive ability $(t(58)=-0.59, p=.56)$, spatial cognitive ability $(t(58)=-0.67, p=.51)$, puzzle ability $(t(63)=0.04, p=.97)$, or the amount of time required to complete the solvable puzzle $(t(64)=-1.24, p=.22)$ (see Table 6 for group means and standard deviations). A chisquare analysis showed that attenuated-mastery and mastery oriented children did not differ by gender (attenuated-mastery: 8 boys, 7 girls; mastery: 22 boys, 29 girls), $\chi^{2}(1, N$ $=66)=0.49, p=.49$.

Verbalizations. Pearson product moment correlation and independent $t$ test analyses were conducted to determine whether children's verbalization proportions during the puzzle task were related to age, cognitive ability, puzzle solving ability, the amount of time required to complete the solvable puzzle, or gender. Results showed that the total number of verbalizations children made during the puzzle task was negatively correlated with age and children's verbal ability, and was positively correlated with puzzle ability and the amount of time required to complete the solvable puzzle (see Table 7 for intercorrelations). Younger children, children with lower verbal ability scores, and children with lower puzzle ability made more total verbalizations during the puzzle task, while children who spent more time on the solvable puzzle made more verbalizations. A review of the raw verbalization data showed that there were 12 children who did not make any verbalizations during the puzzle task (see Appendix A for data histograms), all of whom were categorized as having a mastery oriented motivation pattern, $\chi^{2}(1)=4.31$, 
$p=.04$. Of the remaining children who made verbalizations, there were no differences between mastery $(M=30.33, S D=33.41)$ and attenuated-mastery $(M=27.73, S D=26.50)$ oriented children in terms of the total number of verbalizations made, $t(64)=-0.28, p=$ .78.

Correlation analyses examining children's proportions of Task-Irrelevant, TaskRelevant Nonfacilitative, Task-Relevant Facilitative, and Ambiguous verbalizations showed that these variables were not correlated with children's age, cognitive ability, puzzle solving ability, or the amount of time required to complete the solvable puzzle. Chi-square analyses showed that boys and girls did not differ from one another in any of the verbalization variables, $p s>.05$ (see Table 8 for verbalization means and standard deviations by gender).

Self-evaluative emotions. Pearson product moment correlation and independent $t$ test analyses were conducted to determine whether children's total shame and pride expressions exhibited during the puzzle tasks were related to age, cognitive ability, puzzle solving ability, the amount of time required to complete the solvable puzzle (puzzle 4), or gender. Results showed that children's total pride expressions were not correlated with age, cognitive ability, puzzle solving ability, or the amount of time required to complete the solvable puzzle (see Table 7 for intercorrleations and Appendix B for data histograms). Children's total shame expressions were not correlated with age, cognitive ability, or puzzle solving ability; however, shame was correlated with the amount of time children spent on the solvable puzzle, such that children who took more time to complete the puzzle exhibited more shame. Independent $t$ tests showed that boys and girls did not differ in the total number of self-evaluative behaviors $(t(63)=0.61, p=$ 
$.54)$, or in the total number of shame $(t(64)=-0.72, p=.48)$ or pride $(t(64)=1.15, p=$ .25) behaviors exhibited during the puzzle task (see Table 9 for self-evaluative emotion means and standard deviations by gender).

Main Analyses: Hypothesis Testing

Hypothesis 1. Mastery and attenuated-mastery oriented preschool-aged children from poverty will differ in the proportion of Task-Relevant Facilitative, Task-Relevant Nonfacilitative, and Task-Irrelevant verbalizations produced during the challenging puzzle tasks. To determine whether attenuated-mastery and mastery oriented children differed in their verbalizations during the puzzle task and regardless of puzzle trial, a $2 \times 3$ (Motivation Orientation [mastery, attenuated-mastery] $\times$ Verbalization Category [Task-Relevant Facilitative, Task-Relevant Nonfacilitative, and Task-Irrelevant]) analysis of variance (ANOVA) was conducted. Motivation orientation was included as the between-subjects variable and verbalization category served as the

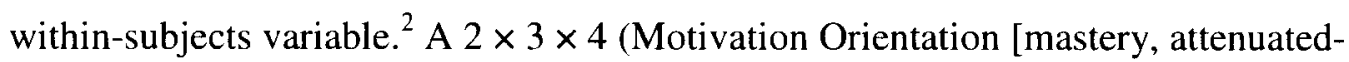
mastery] $\times$ Verbalization Category [Task-Relevant Facilitative, Task-Relevant Nonfacilitative, and Task-Irrelevant] $\times$ Puzzle Trial $[1,2,3,4])$ mixed ANOVA was also conducted in order to further examine children's verbalizations across individual puzzles. Motivation orientation was included as the between-subjects variable and verbalization category and puzzle served as the within-subjects variables. ${ }^{3}$

Statistical assumptions. Prior to conducting the analyses, all relevant statistical assumptions were examined. For both analyses, the independence of errors assumption

\footnotetext{
${ }^{2}$ This $2 \times 3$ analysis not taking into account puzzle was conducted in order to retain all participants who made any verbalizations during the puzzle task; some children did not make verbalizations during all four puzzles, and these children would not have been included in an analysis including puzzle as a variable. ${ }^{3}$ Hypothesis 1 main effect and interaction statistics not including puzzle are based on the 2-way ANOVA; main effect and interaction statistics including puzzle are based on the 3-way ANOVA.
} 
was met as a result of the study design. A visual and statistical examination showed that the verbalization proportion data were positively skewed (see Appendix A). A review of the $z$-scores for each verbalization proportion category showed that there were 3 outliers, as indicated by scores greater than $|3|$. After reviewing these outliers, however, it was determined that these data could be expected in the population and were not anomalous cases; taking this into consideration, along with the relatively large sample size and the robustness of the analysis, these cases were not removed from subsequent analyses. To reduce the effect of these outliers on the data, verbalization proportion scores were adjusted using a log transformation (Tabachnick \& Fidell, 2007). ${ }^{4}$ With regard to the 2way ANOVA, Mauchly's test indicated that the assumption of sphericity was violated for the verbalization category main effect $\left(\chi^{2}(2)=20.50, p<.001\right)$; therefore, degrees of freedom for this effect were corrected using Huynh-Feldt estimates of sphericity $(\varepsilon=$ .78). Additionally, Levene's tests showed that the log transformed Task-Irrelevant and Task-Relevant Facilitative proportion data met the homogeneity of variance assumption ( $p$ s $>.05$ ), but was significant for the Task-Relevant Nonfacilitative verbalizations $(p=$ .02). With regard to the 3-way ANOVA, Mauchly's test indicated that the assumption of sphericity was violated for the puzzle trial main effect $\left(\chi^{2}(5)=16.86, p=.005, \varepsilon=.73\right.$ ) and the Verbalization Category $\times$ Puzzle Trial interaction $\left(\chi^{2}(20)=69.31, p<.001, \varepsilon=\right.$ .62). Because all tests were significant and all $\varepsilon$ values were less than .75 , degrees of freedom were corrected using Greenhouse-Geisser estimates of sphericity. Levene's tests showed that the log transformed proportion data met the homogeneity of variance assumption at all levels of the repeated measures ( $p s>.05)$, except for Puzzle 1 Task-

\footnotetext{
${ }^{4}$ Untransformed means and standard errors are reported throughout the text and in all figures and tables associated with hypothesis 1; transformed values are reported in Appendix C.
} 
Irrelevant, Puzzle 1 Task-Relevant Nonfacilitative, and Puzzle 2 Task-Relevant Nonfacilitative verbalizations $(p s<.05)$.

Preliminary main effects and interactions. Results showed that there was a significant main effect of verbalization category, $F(1.57,81.50)=326.32, p<.001$, partial $\eta^{2}=.86,1-\beta=1.00$. Posthoc pairwise comparisons using Bonferroni adjustments indicated that overall, children made a significantly higher proportion of Task-Relevant Facilitative verbalizations than Task-Irrelevant $(p<.001,1-\beta=1.00)$ and TaskRelevant Nonfacilitative verbalizations $(p<.001,1-\beta=1.00)$, but did not differ in the proportion of Task-Irrelevant and Task-Relevant Nonfacilitative verbalizations $(p=.32,1$ $-\beta=.09 ;$ see Figure 3 ). Results showed that the main effect of motivation orientation was not statistically significant, suggesting that mastery $(M=.25, S E=.01,95 \%$ CI $[.23$, $.27])$ and attenuated-mastery oriented children $(M=.25, S E=.02,95 \%$ CI $[.22, .29])$ did not differ in their mean proportion of verbalizations during the puzzle task, $F(1,52)=$ $0.25, p=.62$, partial $\eta^{2}=.01,1-\beta=.08$. Finally, there was a significant main effect of puzzle trial, suggesting that the mean proportion of verbalizations differed across puzzles, $F(2.17,71.74)=6.26, p=.001$, partial $\eta^{2}=.16,1-\beta=.90$. Posthoc pairwise comparisons using Bonferroni adjustments showed that on average, children made a significantly greater mean proportion of verbalizations on puzzle 4 as compared to puzzle $1(p=.008)$; there were no other significant differences between puzzles ( $p s>.05$; see Figure 4).

Second-order interactions showed that the Verbalization Category $\times$ Puzzle Trial interaction was significant, suggesting that the mean proportion of Task-Relevant Facilitative, Task-Relevant Nonfacilitative, and Task-Irrelevant verbalizations children 
produced differed across puzzle trials, $F(3.74,123.35)=6.59, p<.001$, partial $\eta^{2}=.17$, $1-\beta=.99$ (see Figure 5). Follow-up analyses using Bonferroni adjustments were conducted to further examine this interaction. Results showed that children did not differ in terms of the mean proportion of Task Irrelevant verbalizations produced across the four puzzle trials of the puzzle task, $F(2.70,91.88)=1.40, p=.25$, partial $\eta^{2}=.04,1-\beta$ $=.34$, nor did they differ in the mean proportion of Task-Relevant Nonfacilitative verbalizations produced across puzzle trials, $F(1.64,55.68)=0.80, p=.43$, partial $\eta^{2}=$ $.02,1-\beta=.17$. Follow-up results did show, however, that children differed in the mean proportion of Task-Relevant Facilitative verbalizations produced across the 4 puzzle trials, $F(3,102)=6.64, p<.001$, partial $\eta^{2}=.16,1-\beta=.97$, making a significantly greater proportion of these verbalizations on the fourth, solvable as compared to the first 3 unsolvable puzzles $(p s \leq .05)$. The Motivation Orientation $\times$ Puzzle Trial interaction was not significant, suggesting that mastery and attenuated-mastery oriented children did not differ in the overall mean proportion of verbalizations produced across trials in the puzzle task, $F(2.17,71.74)=0.89, p=.42$, partial $\eta^{2}=.03,1-\beta=.20$ (see Figure 6).

Hypothesis testing results. In order to examine the verbalization differences between mastery and attenuated-mastery oriented children (hypothesis 1), two interactions were examined: Verbalization Category $\times$ Motivation Orientation and Verbalization Category $\times$ Motivation Orientation $\times$ Puzzle Trial. Results showed that the Verbalization Category $\times$ Motivation Orientation interaction was not significant, suggesting that mastery and attenuated-mastery oriented children did not differ in the mean proportion of Task-Relevant Facilitative, Task-Relevant Nonfacilitative, and Task- 
Irrelevant verbalizations produced during the puzzle task (see Figure 7$), F(1.57,81.50)=$ $0.28, p=.70$, partial $\eta^{2}=.01,1-\beta=.09$.

Results did show, however, that the Verbalization Category $\times$ Motivation Orientation $\times$ Puzzle Trial interaction was significant $(F(3.74,123.35)=2.98, p=.02$, partial $\eta^{2}=.08,1-\beta=.76$ ), indicating that mastery and attenuated-mastery oriented children demonstrated different verbalization patterns across puzzle trials during the challenging puzzle task (see Figure 8). Simple effects analyses showed that mastery oriented children made a significantly smaller proportion of Task Irrelevant verbalizations during puzzle $1(F(1,33)=7.35, p=.01,1-\beta=.75)$, significantly fewer Task-Relevant Nonfacilitative verbalizations during puzzle $2(F(1,33)=5.43, p=.03,1$ $-\beta=.62$ ), and slightly less Task-Relevant Facilitative verbalizations during puzzle 4 $(F(1,33)=4.49, p=.04,1-\beta=.54)$. Mastery and attenuated-mastery oriented children did not differ in any verbalizations during puzzle $3\left(p s>.05,1-\beta_{\mathrm{TI} \text {. TRNF. TRI }} \leq .31\right)$. As can be seen by the graphs in Figure 8, the pattern of verbalizations across puzzles remained fairly consistent for mastery oriented children. The verbalization patterns of attenuatedmastery oriented children, however, show a different pattern; there was a near-significant trend $(p=.06)$, such that attenuated-mastery oriented children were producing a greater proportion of Task-Relevant verbalizations by the end of the task (puzzle 4) as compared to the beginning of the task (puzzle 1).

Hypothesis 2.The self-evaluative shame and pride responses to challenge by preschool-aged children from poverty will differ across puzzles on the puzzle task, such that children will demonstrate increasing shame across subsequent puzzles, and more pride on the solvable puzzle than on the unsolvable puzzles. Hypothesis 2 
was tested by examining a mixed analysis of covariance (ANCOVA) including selfevaluative emotions (shame, pride) and motivation orientation (mastery, attenuatedmastery) as within-subjects variables. ${ }^{5}$ Based on preliminary analyses, the amount of time children spent on the solvable puzzle was entered as the covariate to ensure that any potential differences related to children's self-evaluative emotions were not simply an effect of the amount of time spent working on the motivation puzzle tasks.

Statistical assumptions. Prior to conducting the analysis, all assumptions were examined. The independence of errors assumption was met as a result of the study design. A visual and statistical examination showed that the self-evaluative emotion data were positively skewed (see Appendix B), although a review of the z-scores for shame and pride showed that there were no outliers. However, to reduce the effect of the skewed distribution, shame and pride scores were adjusted using a log transformation. ${ }^{6}$

Mauchly's test indicated that the assumption of sphericity was violated for the SelfEvaluative Emotion $\times$ Puzzle Trial interaction $\left(\chi^{2}(5)=15.22, p=.01\right)$; therefore, degrees of freedom for this interaction were corrected using Huynh-Feldt estimates of sphericity $(\varepsilon=.93)$. Levene's tests showed that the data met the homogeneity of variance assumption at all levels of the repeated measures ( $p \mathrm{~s}>.05$ ). The homogeneity of regression slopes assumption was also met $(F(1,62)=0.08, p=.78)$.

Preliminary main effects and interactions. Results showed that the selfevaluative emotion main effect was not statistically significant, suggesting that after controlling for the amount of time spent on the final puzzle, children exhibit similar

\footnotetext{
${ }^{5}$ Hypothesis 2 was tested by examining a portion of the larger $2 \times 2 \times 4$ (Self-Evaluative Emotion $\times$ Motivation Orientation $\times$ Puzzle Trial) mixed ANCOVA described later in hypothesis 3 .

${ }^{6}$ Untransformed means and standard errors are reported throughout the text and in all figures and tables associated with hypotheses 2 and 3; transformed values are reported in Appendix D.
} 
amounts of shame $(M=6.98, S E=0.74,95 \% \mathrm{CI}[5.51,8.46])$ and pride $(M=6.70, S E=$ $0.95,95 \% \mathrm{CI}[4.80,8.60])$ during the puzzle task, $F(1,63)=1.70, p=.197$, partial $\eta^{2}=$ $.03,1-\beta=.25$. There was also a non-significant main effect of puzzle trial, indicating that children did not differ in the mean number of self-evaluative emotion behaviors produced across different puzzles, $F(3,189)=0.15, p=.927$, partial $\eta^{2}=.002,1-\beta=$ .08 (see Table 10 for combined self-evaluative emotion means and standard errors by puzzle).

\section{Hypothesis testing results. The Self-Evaluative Emotion $\times$ Puzzle Trial} interaction was examined to evaluate hypothesis 2 : whether children showed increasing shame across puzzles and an increase in pride on the final, solvable puzzle. Results showed that this interaction was significant, indicating that the amount of self-evaluative shame and pride expressions children exhibited differed across puzzle trials, $F(2.58$, $162.68)=15.00, p<.001$, partial $\eta^{2}=.19,1-\beta=1.00$. Planned contrasts were conducted separately for shame and pride to further examine this interaction. Polynomial contrasts showed significant linear and quadratic trends for shame across puzzles (linear, $F(1,64)=11.43, p=.001$, partial $\eta^{2}=.15,1-\beta=.92 ;$ quadratic, $F(1,64)=13.22, p=$ .001 , partial $\eta^{2}=.17,1-\beta=.95$ ). As can be seen in Figure 9 , there was a significant increase in the number of shame expressions exhibited from puzzle 1 to puzzle 2 , with no change observed between puzzles 2 and 3 , followed by a significant increase between puzzles 3 and 4 . With regard to pride, simple contrasts showed that children demonstrated significantly more pride on puzzle 4 as compared to puzzle $1(F(1,64)=$ $10.28, p=.002$, partial $\left.\eta^{2}=.14,1-\beta=.88\right)$, puzzle $2 F(1,64)=9.35, p=.003$, partial $\eta^{2}$ $=.13,1-\beta=.85$ ), and puzzle $3 F(1,64)=10.82, p=.002$, partial $\left.\eta^{2}=.15,1-\beta=.90\right)$. 
The Self-Evaluative Emotion $\times$ Puzzle Trial interaction was also examined in terms of the relationship between the amount of shame versus pride exhibited across puzzles. Simple contrasts were performed comparing self-evaluative shame versus pride across puzzles. Contrasts revealed significant interactions when comparing shame versus pride in puzzle 1 compared to puzzle $4\left(F(1,63)=19.18, p<.001\right.$, partial $\eta^{2}=.23,1-\beta$ $=.99))$, in puzzle 2 compared to puzzle $4\left(F(1,63)=24.15, p<.001\right.$, partial $\eta^{2}=.28,1-$ $\beta=1.00))$, and in puzzle 3 compared to puzzle $4\left(F(1,63)=28.95, p<.001\right.$, partial $\eta^{2}=$ $.32,1-\beta=1.00)$ ). Examining Figure 9, these results show children demonstrated more shame than pride behaviors in puzzles 1,2 , and 3 , but more pride than shame behaviors in puzzle 4 . This suggests that children demonstrated significantly more shame than pride on unsolvable puzzles, but significantly more pride than shame on the solvable puzzle.

Hypothesis 3. The self-evaluative shame responses by preschool-aged children from poverty during the challenging puzzle task will differ between motivation orientation groups, while self-evaluative pride responses will not differ between children of different motivation orientations. A $2 \times 2 \times 4$ (Self-Evaluative Emotion [shame, pride] $\times$ Motivation Orientation [mastery, attenuated-mastery] $\times$ Puzzle Trial $[1,2,3,4])$ mixed ANCOVA was conducted to examine hypothesis 3 . Motivation orientation was included as the between-subjects variable and self-evaluative emotion and puzzle were the within-subjects variables. The amount of time children took to complete the fourth, solvable puzzle was included as a covariate. As previously discussed, all analysis assumptions were examined and shame and pride scores were adjusted using a log transformation.

Preliminary main effects and interactions. As previously reported, the self- 
evaluative emotion and puzzle trial main effects were not significant. Results showed, however, that there was a significant main effect of motivation orientation, $F(1,63)=$ $15.65, p<.001$, partial $\eta^{2}=.20,1-\beta=.97$. Overall, children with a mastery motivation orientation $(M=11.19, S E=1.16,95 \% \mathrm{CI}[8.87,13.51])$ demonstrated significantly fewer self-evaluative emotion expressions than did children with an attenuated-mastery motivation orientation $(M=21.03, S E=2.13,95 \% \mathrm{CI}[16.78,25.28])$. This pattern between mastery and attenuated-mastery oriented children remained consistent across individual puzzles, as indicated by the non-significant Motivation Orientation $\times$ Puzzle Trial interaction $\left(F(3,189)=2.20, p=.090\right.$, partial $\left.\eta^{2}=.03,1-\beta=.55\right)($ see Table 10 for means and standard errors). It is important to note, however, that the main effect of motivation was qualified by a significant Self-Evaluative-Emotion $\times$ Motivation Orientation interaction.

Hypothesis testing results. Consistent with hypothesis 3 and the proposed model, children with different motivation orientations demonstrated different patterns of selfevaluative shame and pride expressions during the puzzle task, as indicated by the significant Self-Evaluative Emotion $\times$ Motivation Orientation interaction, $F(1,63)=$ 7.91, $p=.01$, partial $\eta^{2}=.11,1-\beta=.79$. Follow-up ANCOVAs were conducted separately for shame and pride to further examine this interaction and the hypothesized differences in these variables between mastery and attenuated-mastery oriented children. ${ }^{7}$ As hypothesized, analyses showed that mastery oriented children demonstrated significantly less shame than did attenuated-mastery oriented children, $F(1,63)=31.05$, $p<.001$, partial $\eta^{2}=.33,1-\beta=1.00$ (see Figure 10). Also consistent with hypothesis 3 ,

\footnotetext{
${ }^{7}$ Follow-up analyses were not corrected using Bonferroni adjustments because the specific hypotheses regarding shame and pride were made a priori.
} 
mastery and attenuated-mastery oriented children did not differ in the number of pride expressions exhibited during the puzzle task, $F(1,63)=1.26, p=.27$, partial $\eta^{2}=.02,1-$ $\beta=.20$ (see Figure 10). Third-order interactions showed that these self-evaluative emotion patterns between mastery and attenuated-mastery oriented children remained consistent across individual puzzles, as indicated by the non-significant Self-Evaluative Emotion $\times$ Motivation Orientation $\times$ Puzzle Trial interaction, $(F(3,189)=1.32, p=.273$, partial $\left.\eta^{2}=.02,1-\beta=.35\right)$ (see Figure 11$)$

The Self-Evaluative Emotion $\times$ Motivation Orientation interaction was also interpreted in terms of the relationship between the amount of shame versus pride demonstrated by mastery versus attenuated-mastery oriented children. The interaction results show that for mastery oriented children, the mean number of shame versus pride behaviors are similar, but attenuated- mastery oriented children demonstrate significantly more shame versus pride behaviors (see Figure 10). 


\section{DISCUSSION}

Achievement motivation is an influential variable affecting children's academic achievement and outcomes and, as such, understanding the factors related to its development in early childhood has important implications for learning, particularly among children from low-income families. Children from low-income environments are at an increased risk of entering school with academic skills below those of children from more advantaged backgrounds (Arnold \& Doctoroff, 2003; Barbarrin et al., 2006; Bryant et al., 1994; National Center for Education Statistics, 2001; Smith et al., 1997; Stipek \& Ryan, 1997), with negative effects persisting throughout their academic careers (see Axinn et al., 1997; Bettler et al., 2006; Pagani et al., 1997). Given the role of achievement motivation in learning and academic success, it is important to understand its early development and its related factors in children from low-income environments to address the achievement gap. Taking this into consideration, the current study sought to better understand low-income preschoolers' responses to challenge by building on two areas of research: (1) children's achievement motivation and their related cognitions (as assessed by their verbalizations) and (2) their self-evaluative emotion behaviors during challenge.

The current findings showed that, when examining children's overall verbalizations combined across a series of challenging tasks, no differences were found between mastery and attenuated- mastery oriented children. However, when their 
verbalizations across individual puzzles were examined, it was found that mastery and attenuated-mastery oriented children made different patterns of verbalizations, which were indicative of their cognitive processes while working on the tasks. More specifically, mastery oriented children showed a more stable verbalization pattern across the puzzles. They made very few off-task, negative verbalizations and, from the very start of the task, made a high percentage of Task-Relevant Facilitative verbalizations; these children were more focused throughout the entire task and were engaging in more strategy-related cognitions while working on the challenging tasks. Attenuated- mastery children, however, showed a more inconsistent verbalization pattern during the tasks. During the early portions of the task (puzzles 1 and 2), they were less focused and more negative as compared to the mastery kids, but by the end of the final challenging task (puzzle 4), they were making more Task-Relevant Facilitative verbalizations, engaging in more strategy-related cognitions from the beginning to the end of the challenging puzzle tasks.

With regard to self-evaluative emotions, it was found that regardless of their motivation orientation, children demonstrated increasing amounts of shame behaviors across subsequent puzzles, and demonstrated more pride on the final, solvable puzzle as compared to previous puzzles during the puzzle task. In support of the proposed model, results showed that mastery oriented children demonstrated significantly fewer shame behaviors throughout the challenging puzzle task than did attenuated-mastery oriented children. These findings suggest that when faced with challenging tasks, mastery and attenuated-mastery oriented children differed in terms of their views of themselves and their abilities. As hypothesized, no differences were found between mastery and 
attenuated-mastery children in terms of pride. For both groups of children, the number of pride behaviors exhibited was low during the first three, unsolvable puzzles (although children did show some pride when individual puzzle pieces were correctly inserted) and highest during the fourth, solvable puzzle. It is interesting to note that, although the difference was not significant, attenuated-mastery oriented children demonstrated a numerically greater number of pride behaviors on the final puzzle. Finally, there was not a significant Self-Evaluative Emotion $\times$ Motivation Orientation $\times$ Puzzle Trial interaction, indicating that the shame and pride relationships between mastery and attenuated-mastery oriented children remained consistent across all four puzzles.

\section{Achievement Motivation and Verbalizations}

Although no verbalization differences were found between mastery and attenuated-mastery oriented children across the entire puzzle task, these children did show different patterns of verbalizations across individual puzzles within the task. The finding that mastery oriented children began and remained focused and planful throughout the entire series of challenging tasks, as suggested by their verbalizations, was consistent with what is to be expected of these children who, by definition, remain more persistent and tend to demonstrate more effective problem solving strategies when faced with challenge (Diener \& Dweck, 1978, 1980; Smiley \& Dweck, 1994). Based on previous work describing attenuated-mastery oriented children (Diener \& Dweck, 1978 1980; Smiley \& Dweck, 1994), it was expected that these children would show a moderate level of task-focus and problem solving strategies. What was unexpected, however, was the finding that attenuated-mastery oriented children became more focused and productive in their cognitions by the final challenging task. 
These verbalization findings are particularly important to the understanding of early motivation patterns in children, as children's private speech is reflective of their cognitions and provides insights into their attempts to direct and regulate their behavioral actions during difficult tasks (Vygotsky, 1934/1986; also see Feigenbaum, 2002). Also important for interpreting these findings, research with young children from a variety of socioeconomic and ethnic backgrounds has shown that the occurrence of private speech verbalizations increases during cognitively demanding, moderately difficult, and novel tasks (Berk \& Garvin, 1984; Duncan \& Pratt, 1997; Fernyhough \& Fradley, 2005; Frauenglass \& Diaz, 1999). Taking this into consideration, one can speculate that attenuated-mastery oriented children needed to increase their verbalizations in order to keep themselves focused and on the task, whereas mastery oriented children started out and remained appropriately focused from the very beginning of the task. This idea may also help to explain why attenuated-mastery oriented children demonstrated increases in Task-Relevant Facilitative verbalizations as the task progressed, but mastery oriented children did not. Although not assessed in the current study, it is important to consider the possibility that the increased Task-Irrelevant statements made during the first puzzle by attenuated-mastery oriented children may be, at least partly, a result of biologicallybased attention factors or distractibility aspects of temperament, on which children with more and less adaptive motivation orientations have been shown to differ (e.g., Chang $\&$ Burns, 2005; Harris, Robinson, et al., 2007); additional research is needed to more fully examine the relationships among these variables and their role in children's TaskIrrelevant verbalizations. As examined in the current study, however, the verbalization findings suggest that mastery oriented children possess more solidly learned focused and 
facilitative cognitive patterns when faced with challenge, while such a pattern is not as established in attenuated-mastery children, who began the tasks with less focus and negativity, but became more focused and facilitative by the end of the tasks.

The finding that mastery and attenuated-mastery oriented children did not differ in their verbalizations combined across puzzles is largely consistent with previous work using the same puzzle task assessment of achievement motivation (Harris, Brown, et al., 2007; Smiley \& Dweck, 1994), although studies measuring motivation on a continuum have produced mixed findings (e.g., Chiu \& Alexander, 2000). Similar previous work conducted with preschool children from middle- and upper-income backgrounds found that mastery and attenuated-mastery oriented children did not differ in the types of combined verbalizations made during the puzzle task, with both groups tending to remain focused and planful during the puzzle task (Smiley \& Dweck, 1994). Previous work has shown, however, that performance oriented children tend to make significantly more offtask and negative statements and fewer facilitative statements than mastery oriented children (Harris, Brown, et al., 2007; Smiley \& Dweck, 1994). It is important to note that the inclusion of only one performance oriented child in the current study prevented the statistical comparison of this group to mastery and attenuated-mastery oriented children, although such differences were predicted in the initial model and hypothesis.

Previous studies with young children have examined the relationship between achievement motivation and verbalizations by examining single verbalization scores, whether it be combined across multiple tasks (e.g., Harris, Brown, et al., 2007; Smiley \& Dweck, 1994) or during a single task (e.g., Chiu \& Alexander, 2000). By differentiating the verbalization scores, the current study adds to the literature by also examining 
children's verbalizations across multiple challenging tasks. This is especially important because children rarely encounter a given challenge only one time, especially in school; they are presented with the same challenging task, such as learning to read, numerous times before the task is mastered. Examining children's verbalizations across individual puzzles within the puzzle task allowed for a more detailed examination of children's verbalization patterns across multiple challenges. Importantly, and contrary to previous research, the current study showed that mastery and attenuated-mastery oriented children's task-related cognitions during challenge do, in fact, differ in important ways.

\section{Achievement Motivation and Self-Evaluative Emotions}

The finding that all children generally demonstrated increasing amounts of shame as the puzzle task progressed is consistent with previous research. According to the cognitive attribution model of self-evaluative emotions (Lewis \& Sullivan, 2005) and empirical research with young children, shame is experienced when errors are made and personal standards of success are not met (Alessandri \& Lewis, 1996; Lewis et al., 1992; Stipek et al., 1992, Study 2). The presence of shame behaviors across the puzzles suggests that children were perceiving their errors inserting puzzle pieces (unsolvable and solvable puzzles) and/or their inability to complete the puzzles (unsolvable puzzles) in a negative way and that these negative feelings increased as they experienced continued challenges. The finding that children made significantly more pride expressions on the solvable puzzle is also supported by the cognitive-attribution model and previous research, which has found that pride is experienced when standards of success are met (Alessandri \& Lewis, 1996; Lewis et al., 1992; Lewis \& Sullivan, 2005; Stipek et al., 1992, Study 2; Tracy \& Robins, 2004). Children were experiencing lower 
amounts of pride on the unsolvable tasks because they had fewer opportunities to insert correct puzzle pieces and were not able to complete the puzzle, whereas there were more correct pieces and the experience of completing the final puzzle. Given that the first three puzzles were unsolvable, children were likely meeting their standards of success and experiencing pride when individual puzzle pieces were correctly inserted, but the most positive feelings of the self resulted when they were able to complete the final puzzle.

Shame. The finding that mastery oriented children demonstrated significantly fewer shame behaviors in response to challenge than did attenuated-mastery oriented children provides important insights into how they were interpreting these situations. Although the frequency of possible errors (incorrect pieces and unsolvable puzzles) was the same for both groups, mastery and attenuated-mastery oriented children were each responding in distinct ways, indicating that they were interpreting these errors, or challenges, differently. The low frequency of shame behaviors exhibited by mastery oriented children suggests that their standards and goals were likely more focused on the process associated with trying to solve the task, and that they were not interpreting their errors as failures reflective of their ability or self-worth, but as a normal part of learning. The fact that attenuated-mastery oriented children made significantly more shame behaviors, however, suggests that they possessed different standards of what it meant to succeed or fail, with goals specifically focusing on task outcome, and that they were interpreting their error and challenging experiences in a less adaptive way that reflected negatively on themselves and their abilities.

The fact that mastery oriented children were showing some shame suggests that these children were not impervious to negative self-evaluations when exposed to 
challenge and errors, but the fact that they were demonstrating low, and significantly fewer, shame behaviors suggests that their thought processes in such situations were more adaptive than those of attenuated-mastery oriented children. Geppert and colleagues (1997, p. 11) stated that, "if the child can quickly avoid the self-evaluation process through a new action, in which the positive or negative effects mean no interruption for the child, self-evaluative emotions [such as shame] may fail to appear." Taking this into consideration, it is possible that mastery oriented children may be more skilled at adopting new or different strategies or foci of attention that redirect any potential negative emotions into more productive task-related behaviors, while attenuated-mastery oriented children, in addition to having different standards of success and failure, may not have the necessary skills to redirect their efforts and attention in such a productive manner.

Although previous research generally supports the idea that individuals with more adaptive motivation-related variables and patterns experience and report fewer instances of negative affect and shame, this relationship has only been found between those with the most and least adaptive motivation patterns (mastery and performance, or comparable, orientations; Diener \& Dweck, 1978; Elliott \& Dweck, 1988; Pekrun et al., 2006, 2009; Smiley \& Dweck, 1994) and when motivation or persistence were measured on a continuum (Kelley et al., 2000); differences in shame have not previously been reported between mastery and attenuated-mastery oriented individuals at any age. As such, the present findings extend upon previous research in important ways. First, the results clarify the relationship between negative affect and motivation, motivation-related variables, and self-evaluative shame in young children from poverty, a group previously 
overlooked in this line of research. The findings also provide new evidence demonstrating that the relationship among achievement motivation and self-evaluative shame, previously found with adults, is already established during the preschool years when these variables are developing.

Pride. The finding that mastery and attenuated-mastery oriented children demonstrated similar amounts of pride throughout the puzzle task suggests that both groups of children were interpreting their successes, whether they included inserting puzzle pieces correctly or solving the final puzzle, in a way that reflected positively on their sense of self. Although the feeling of pride was a positive experience, it likely encouraged children to continue to maintain their current standards and goals that led to the success experience (Lewis \& Sullivan, 2005; Stipek et al., 1992; Tracy \& Robins, 2004, 2007a). The current findings are supported by previous work with preschoolers and fifth graders, which showed that children with mastery and attenuated-mastery oriented motivation (or comparable categorizations) did not differ from one another in terms of the level of positive affect reported after a challenging task (Diener \& Dweck, 1978; Smiley \& Dweck, 1994), as well as work showing that toddlers' persistence during a difficult task was not correlated with subsequent pride (Kelley et al., 2000); work with adults has reported similar findings (Pekrun et al., 2009).

\section{Limitations of Current Study}

An unexpected limitation of the current work had to do with the distribution of children falling into the mastery, attenuated-mastery, and performance oriented motivation categories. There was only one performance oriented child in this sample, making it impossible to examine differences related to this group and to fully test this 
portion of the proposed model. This was unexpected, as previous studies using the motivation puzzle task assessment (e.g., Chang \& Burns, 2007; Harris, Brown, et al., 2007; Smiley \& Dweck, 1994) generally found that about one-third to one-half of preschool children in a given sample were categorized as having performance oriented motivation. In addition to limiting our analysis of the proposed model, not having this motivation orientation group represented also made it difficult to fully compare the current findings to those of previous research. Studies including performance oriented individuals (or three motivation groups defined in different motivation terms) only found verbalization and emotion differences between mastery and performance oriented motivation groups (Diener \& Dweck, 1978; Elliott \& Dweck, 1988; Harris, Brown, et al., 2007; Pekrun et al., 2006, 2009; Smiley \& Dweck, 1994). Despite this limitation and contrary to previous research, this more stringent test of the model, including children with more similar mastery and attenuated-mastery oriented patterns, resulted in significant differences between the groups in terms of their verbalizations and shame behaviors in this sample. It is important to note that previous research was conducted exclusively with children and adults from middle- and upper-SES backgrounds, while the current study examined children in poverty. The fact that the current study found differences between mastery and attenuated-mastery oriented children when other studies did not is intriguing, and suggests that within a low-income sample, attenuated-mastery oriented children are not as similar to mastery oriented children, but may be more similar to performance oriented children; additional research is needed to further examine this relationship.

The findings of the current study do not provide an explanation as to why there 
was only one performance oriented child in the current sample, when other studies have reported a more even distribution of mastery, attenuated-mastery, and performance oriented children A possible explanation may to attributed to the fact that the Head Start curriculum is designed support children's school readiness skills, which includes taking a mastery approach to challenge by focusing on the process and not the product of such tasks. Teacher and classroom structure variables were not collected in the current study, but it is possible that certain teachers may have been especially supportive of masteryrelated cognitions and behaviors. It may also be the case that just attending a preschool program, such as Head Start, better supports early mastery patterns as compared to not attending such a program (see Malakoff et al., 1998). Finally, there may even be important differences between low-income parents who enroll their children in preschool and/or Head Start programs versus those who do not, such as differences in parent involvement, academic support, or stressful home circumstances, all of which have important implications for motivation and emotional development (Brooks-Gunn \& Duncan, 1997; Pomerantz et al., 2005). Future research should include teacher, school, and parent variables to better understand the influence of these variables on the relationship between verbalizations, self-evaluative emotions, and achievement motivation.

The current study is limited in terms of its generalizability across ethnicity. Almost $94 \%$ of the sample was comprised of African American children. Although some studies have found evidence for motivation differences between adolescents of different ethnicities (e.g., Graham, Taylor, \& Hudley, 1998; Graham \& Taylor, 2002), research with elementary and middle school children suggests that these differences are not 
evident until early adolescence (Graham, 2001; Graham \& Taylor, 2002). Research also suggests that children's private speech verbalizations may be uniquely influenced by their social and cultural contextual experiences inside and outside of the home (Berk \& Spuhl, 1995; Berk \& Winsler, 1995; Hart \& Risely, 1995; Hoffman, Crnic, \& Baker, 2006;

Robinson, Burns, \& Davis, 2009; Vygotsky, 1934/1986). While the physical manifestation of self-evaluative emotion expressions are universal, the learned standards, rules, and goals that determine when and why these emotions are experienced vary depending on the cultural context (Goetz \& Keltner, 2007; Wong \& Tsai, 2007). It is important to note, however, that research reports significant cultural differences primarily when comparing collectivistic and individualistic cultures (see Wong \& Tsai for review).

Finally, the proposed model provides a theoretical description of the developmental relationship between self-evaluative shame and achievement motivation in young children. Given the nature of the current study design, it was only possible to examine the correlational relationship between these variables, and a causal relationship was not able to be tested. Future longitudinal or structural equation modeling research is needed to fully understand and verify the causal relationships described in the model.

\section{Theoretical and Research Implications}

The current study is the first line of research to jointly examine the relationship between preschool-aged children's achievement motivation, verbalizations, and selfevaluative emotions, and is also the only study to jointly examine these variables in children from poverty. Theoretical work has discussed the importance of self-evaluative emotions as "important motivators of behavior" (e.g., Stipek, 1983; Lewis \& Sullivan, 2005), yet the only empirical work examining the relationship between these two 
variables was conducted with college students (Pekrun et al., 2006, 2009; except see Kelley et al., 2000 for related work with toddlers). From a basic, developmental point of view, the current findings provide new and important information demonstrating an already-formed relationship between achievement motivation and self-evaluative shame by 3.5 to 5 years of age. Taking these findings into consideration, and also considering the fact that these factors begin developing at approximately the same age (Elliot \& Dweck, 2005b; Lewis \& Sullivan, 2005), longitudinal research is needed to fully test the proposed model to more fully understand and to determine how early this relationship is formed.

Another contribution of the current work is its focus on young children from poverty. As previously discussed, these children often find themselves on the negative side of the achievement gap and are faced with numerous risk factors that can negatively impact achievement motivation (e.g., Brooks-Gunn et al., 2005; McLoyd, 1998) and emotion-regulation, particularly the ability to regulate negative emotions such as shame (Brooks-Gunn \& Duncan, 1997; Garner \& Spears, 2000; Gershoff et al., 2007; Turner \& Waugh, 2007). The current findings provide evidence that motivation and shame are related to one another in preschool-aged children from low-income backgrounds, and provide new information about the patterns of verbalizations and shame that differentiate mastery and attenuated-mastery children. These findings provide more support for the suggestion that attenuated-mastery oriented patterns may be even less adaptive in poverty samples than in more economically advantaged samples. Given the importance of these variables to children's academic achievement and their relationship to one another in a preschool-aged, low-income sample, future research needs to focus on understanding 
their earlier development to better support these factors in children from poverty.

This research also has important implications for methodological issues associated with assessing children's responses to challenge. Previous studies of motivation, even those including multiple trials or tasks, have examined motivation and important associated factors, such as verbalizations and emotions, with a single composite score or rating (e.g., Harris, Brown, et al., 2007; Elliott \& Dweck, 1988; Kelley et al., 2000; Pekrun et al., 2006, 2009; Smiley \& Dweck, 1994; except see Diener \& Dweck, 1978). While the current study did include such examinations, responses across individual puzzles were also analyzed, which led to important findings. For example, it was found that mastery and attenuated-mastery oriented children did not differ in their verbalizations when considering their composite scores combined across the entire task, but important differences were found between the groups when their responses across individual puzzles were examined. As previously discussed, children are rarely, if ever, presented with a challenging or difficult task only once, particularly in school. As such, examining the changes in their behaviors or cognitions in the face of continued challenge provides important, practical information about how we can best support mastery responses to such challenges. Finally, given that children's verbalizations and self-evaluative shame were distinctly related to mastery and attenuated-mastery orientations, these variables may also serve as early measures that can allow researchers to examine children's responses to challenge on a continuum, in addition to the categorical approach used in the achievement motivation research.

\section{Applied Implications}

The current findings of the relationships of children cognitions, as assessed by 
their verbalizations, and their self-evaluative emotions to achievement motivation have important and practical implications that can inform early interventions in home and educational settings (see Pekrun \& Schutz, 2007). According to Vygotsky's sociocultural theory (see van der Veer \& Valsiner, 1994), children's higher cognitive processes are largely influenced by their social context and the interactions children have with those in their environment. When adults are sensitive to children's needs, engage in scaffolding, and support their sense of initiative and autonomy, children's psychological needs are met and they are better able to adopt a mastery approach to challenge (Eccles et al., 1998; Pomerantz et al., 2005).

As children continue to interact with other people, including their parents, they come to adopt others' statements by incorporating them into their private speech. Taking this into consideration, it stands to reason that children whose parents are insensitive and provide negative feedback to their children are supporting children's development of negative private speech verbalizations and cognitions (Heyman et al., 1992), which the current study shows are also related to children's unique motivation orientations. Similarly, children adopt their standards, rules, and goals from those in their immediate environment, which determine when and why children will experience shame and pride (Lewis \& Sullivan, 2005).

Kelley and colleagues (2000) provide important research that illustrates the role of parent feedback on children's motivation-related and self-evaluative emotion responses to challenge. They found that two-year-olds whose mothers engaged in gentle guidance, as opposed to controlling behaviors, when interacting with them during challenging tasks were less likely to avoid challenges when they were three-years-old. 
This same study showed that the type of feedback mothers give their children plays an important role in their later persistence. Generally, mothers' positive feedback directed toward the product or action (e.g., "Good job!"), and corrective feedback (e.g., "Try turning the piece the other way.") positively predicted children's persistence one year later when they were three years old. Kelley and colleagues and others (Alessandri \& Lewis, 1996) have also found a relationship between parent evaluation and feedback and children's shame and pride behaviors. Generally, both studies found that negative and specific feedback (e.g., "You're not very good at that.") was related to children's increased shame behaviors during challenge.

For many of the same reasons that parents are important to children's development of achievement motivation, teachers and classroom structure also play a key role in achievement motivation. Similar to parents, teachers who support autonomy and praise children's efforts positively influence motivation (Guthrie, Wigfield, \& VonSecker, 2000; Oliver, Markland, Hardy, \& Petherick, 2008; Stipek, Givvin, Salmon, \& Macgyvers, 1998). Consistent with parental feedback findings, teachers' feedback that focuses on the task process and children's efforts supports mastery motivation at various ages (Cimpian et al., 2007; Heyman et al., 1992; Kamins \& Dweck, 1999). Several studies have shown that the type of instructions, feedback, or information children receive can influence their reaction to challenge and, more broadly, their achievement motivation (e.g., Burns \& Hagerman, 1989; Diener \& Dweck, 1978; Kamins \& Dweck, 1999; Schunk, 1996).

In a particularly interesting intervention study with seventh graders, Blackwell and colleagues (2007) manipulated students' achievement motivation by providing them 
with incremental theory training. Students in the experimental groups received one 25minute training sessions per week for eight weeks, during which they were presented with research suggesting that intelligence was malleable and that learning changes the physiological structure of the brain. Students participating in this training demonstrated positive changes in motivation and an increased trajectory in grades as compared to a control group. By emphasizing an incremental theory of intelligence, the idea that individuals can change their intelligence and abilities, the researchers were able to positively impact students' motivation. It is important to note, however, that similar research examining college students' implicit theories of intelligence and motivation has produced mixed findings (e.g., Aronson, Fried, \& Good, 2002; Crocker, Olivier, \& Nuer, 2009; Furnham, Chamorro-Premuzic, \& McDougall, 2002). Although it is unclear why the findings with adults are inconsistent, the research with middle-school children suggests that targeting the implicit theories of intelligence in this age group may have important intervention applications. Studies have shown that it is also possible to positively influence children motivation in more subtle ways. For example, changing the ways teachers talk about success in the classroom (Cimpian et al., 2007; Heyman, 2008) and adopting a class structure that supports learning goals via teaching styles, academic feedback, and assignment formats can lead children to adopt a more mastery oriented approach to challenges (Miller \& Meece, 1997; Schunk, 1996; Self-Brown \& Matthews, 2003; Stipek et al., 1995; also see Ames, 1992 and Dweck, 2000 for reviews).

Taken together, research with parents and teachers suggests that providing sensitive care and instruction that supports children's autonomy and sense of self via positive feedback can support the development of mastery motivation. Although causal 
relationships were not established in this study, the current findings and those of others suggest that warm, sensitive parent-child relationships and classroom environments may support mastery motivation by influencing children's self-talk, as well as the standards and goals influencing their experiences of self-evaluative emotions during challenge. As such, encouraging parents and teachers to engage in sensitive interactions with children guided by positive, task-specific and corrective feedback is an important step to supporting children's positive cognitive/verbal, emotional, and, thus, motivation development. Given that low-income families experience many stressors that can strain these relationships, it is especially important to support such relationships with these children, who are at an increased risk of developing less adaptive attenuated-mastery and performance oriented motivation patterns.

\section{Future Directions}

Based on the theoretical and empirical work guiding the current study, we have developed and implemented a classroom-based intervention program with eight local Head Start classrooms (four intervention classes, four control classes; Day, Harris, Carter, \& Burns, 2008). The motivation intervention curriculum was designed to promote a mastery oriented approach to learning by encouraging positive self-task, positive emotional reactions to challenge and success, and the mindset that errors are a normal and useful part of learning. Throughout the intervention, children were introduced to songs (Kisor, 2009), books, games, and activities focused on initiative, self-control, and persistence. Trained research assistants went to each of the four intervention classrooms two days a week for three months to model the motivation intervention and to facilitate teachers' implementation of the intervention into their own curriculum. In addition to 
assessing their cognitive ability, pre- and post-intervention measures of children's achievement motivation orientations, verbalizations, and self-evaluative shame and pride were gathered from Smiley and Dweck's (1994) puzzle task assessment. While preliminary analyses have shown that children's achievement motivation orientations were not changed as a result of the intervention (Burns, 2008; Day, Harris, Carter, et al., 2008), future analyses will examine whether the intervention had an impact on children's verbalizations and self-evaluative emotions.

\section{Conclusion}

The current study provides the first analysis of the early relationships between achievement motivation, verbalizations, and self-evaluative emotions in preschool-aged children and children in poverty. Integrating achievement motivation and self-evaluative emotion research into a new and more complete model has yielded new information that will allow us to better understand the early development of these variables in young children. Based on the current verbalization and self-evaluative emotion findings, we now have more detailed evidence that at-risk children with mastery and attenuatedmastery oriented motivation patterns interpret and respond to challenge differently as early as 3.5 years of age. Understanding why and how children respond to challenging tasks as they do will, in turn, provide important information that can be used to develop more effective early interventions to support their developing achievement motivation, which is especially important given that neuropsychological research has shown that the emotional and behavioral/motivational systems become linked together and these response patterns become solidified as children get older (Pessoa, 2009; Schutter et al., 2008). Finally, being able to better assess, predict, and intervene with regard to children's 
response to challenge may be especially important for children from poverty who, due to the effects of numerous risk factors on community, family, and self structures, are at increased risk for developing negative behavioral and emotional response patterns to challenge. 


\section{REFERENCES}

Aber, J. L. (1994). Poverty, violence, and child development: Untangling family and community level effects. In C. A. Nelson (Ed.), Threats to optimal development: Integrating biological, psychological, and social risk factors (pp. 229-272). Hillsdale, NJ: Erlbaum.

Aber, J. L., Jones, S., \& Cohen, J. (2000). The impact of poverty on the mental health and development of very young children. In C. H. Zeanah, Jr. (Ed.), Handbook of infant mental health (2nd ed., pp. 113-128). New York: Guilford.

Alessandri, S. M., \& Lewis, M. (1996). Differences in pride and shame in maltreated and nonmaltreated preschoolers. Child Development, 67, 1857-1869.

Alexander, K. L., Entwisle, D. R., \& Dauber, S. L. (2003). On the success of failure: A reassessment of the effects of retention in the primary grades ( $2 \mathrm{nd}$ ed.). New York: Cambridge University Press.

Alexander, P. A., White, C. S., \& Daugherty, M. (1997). Analogical reasoning and early mathematics learning. In L. D. English (Ed.), Mathematical reasoning: Analogies, metaphors, and images (pp. 117-147). Mahwah, NJ: Erlbaum.

Ames, C. (1992). Classrooms: Goals, structures, and student motivation. Journal of Educational Psychology, 84, 261-271.

Anderson, E. S., \& Keith, T. Z. (1997). A longitudinal test of a model of academic 
success for at-risk high school students. International Journal of Educational Research, 90, 259-268.

Arnold, D. H., \& Doctoroff, G. L. (2003). The early education of socioeconomically disadvantaged children. Annual Review of Psychology, 54, 517-545.

Aronson, J., Fried, C. B., \& Good, C. (2002). Reducing the effects of stereotype threat on African American college students by shaping theories of intelligence. Journal of Experimental Social Psychology, 38, 113-125.

Arrighi, B. A., \& Maume, D. J. (Eds.). (2007a). Child poverty in America today: Health \& medical care (Vol. 2). Westport, CT: Praeger.

Arrighi, B. A., \& Maume, D. J. (Eds.). (2007b). Child poverty in America today: The promise of education (Vol. 3). Westport, CT: Praeger.

Asmus, E. P. (1986). Student beliefs about the causes of success and failure in music: A study of achievement motivation. Journal of Research in Music Education, 34, $262-278$.

Axinn, W., Duncan, G. J., \& Thornton, A. (1997). The effects of parents' income, wealth, and attitudes on children's completed schooling and self-esteem. In G. J. Duncan \& J. Brooks-Gunn (Eds.), Consequences of growing up poor (pp. 518-540). New York: Sage.

Bakermans-Kranenburg, M. J., Van IJzendoorn, M. H., \& Kroonenberg, P. M. (2004). Differences in attachment security between African-American and white children: Ethnicity or socio-economic status? Infant Behavior \& Development, 27, 417-433. Barbarin, O., Bryant, D., McCandies, T., Burchinal, M., Early, D., Clifford, R., et al. (2006). Children enrolled in public pre-K: The relation of family life, 
neighborhood quality, and socioeconomic resources to early competence. American Journal of Orthopsychiatry, 76, 265-276.

Baumeister, R. F., Campbell, J. D., Krueger, J. I., \& Vohs, K. D. (2003). Does high selfesteem cause better performance, interpersonal success, happiness, or healthier lifestyles? Psychological Science in the Public Interest, 4, 1-44.

Belsky, J., Domitrovich, C., \& Crnic, K. (1997). Temperament and parenting antecedents of individual difference in three-year-old boys' pride and shame reactions. Child Development, 68(3), 456-466.

Berk, L. E., \& Garvin, R. A. (1984). Development of private speech among low-income Appalachian children. Developmental Psychology, 20, 271-286.

Berk, L. E., \& Spuhl, S. T. (1995). Maternal interaction, private speech, and task performance in preschool children. Early Childhood Research Quarterly, 10, 145 169.

Berk, L. E., \& Winsler, A. (1995). Scaffolding children's learning: Vygotsky and early Childhood education. Washington, DC: National Association for the Education of Young Children.

Bettler, R. F., Jr., Miles, S. S., \& Burns, B. M. (2006). Methodological and Conceptual Innovations in Student Achievement Research. In A. Columbus (Ed.), Advances in psychology research (Vol. 45, pp. 145-157). Hauppauge, NY: Nova Science.

Blackwell, L. S., Trzesniewski, K. H., \& Dweck, C. S. (2007). Implicit theories of intelligence predict achievement across an adolescent transition: A longitudinal study and an intervention. Child Development, 78, 246-263.

Bransford, J. D., Brown, A. L., \& Cocking, R. R. (1999). How people learn: Brain, mind, 
experience, and school. Washington, DC: National Academy Press.

Brooks-Gunn, J., \& Duncan, G. J. (1997). The effects of poverty on children. The Future of Children, 7(2), 55-71.

Brooks-Gunn, J., Linver, M. R., \& Fauth, R. C. (2005). Children's competence and socioeconomic status in the family and neighborhood. In A. J. Elliot \& C. S. Dweck (Eds.), Handbook of competence and motivation (pp. 414-435). New York: Guilford.

Brophy, J. (2004). Motivating students to learn (2nd ed.). Mahwah, NJ: Erlbaum.

Bryant, D. M., Burchinal, M., Lau, L. B., \& Sparling, J. J. (1994). Family and classroom correlates of Head Start children's developmental outcomes. Early Childhood Research Quarterly, 9, 289-304.

Burns, B. (2008, March) Classroom-based motivation intervention in Head Start classrooms: What can I learn vs. Will I look smart? Southern Early Childhood Association, Cincinnati, $\mathrm{OH}$.

Burns, B. \& Hagerman, A. (1989). Computer experience, self-concept and problemsolving: The effects of LOGO on children's ideas of themselves as learners. Journal of Educational Computing Research,5, 199-212.

Cain, K. M., \& Dweck, C. S. (1995). The relation between motivational patterns and achievement cognitions through the elementary school years. Merrill-Palmer Quarterly, 41, 25-52.

Castenell, L. A. (1983). Achievement motivation: An investigation of adolescents' achievement patterns. American Educational Research Journal, 20, 503-510.

Chang, F., \& Burns, B. M. (2005). Attention in preschoolers: Associations with effortful 
control and motivation. Child Development, 76, 247-263.

Chiu, S., \& Alexander, P. A. (2000). The motivational function of preschoolers' private speech. Discourse Processes, 30, 133-152.

Cimpian, A., Arce, H-M., Markman, E. M., and Dweck, C. S. (2007). Subtle linguistic cues impact children's motivation. Psychological Science, 18, 314-316.

Covert, M. V., Tangney, J. P., Maddux, J. E., \& Heleno, N. M. (2003). Shame-proneness, guilt-proneness, and interpersonal problem solving: A social cognitive analysis. Journal of Social \& Clinical Psychology, 22, 1-12.

Crocker, J., Olivier, M-A., \& Nuer, N. (2009). Self-image goals and compassionate goals: Costs and benefits. Self Identity, 8, 251-269.

Cutting, A. L., \& Dunn, J. (2002). The cost of understanding other people: Social cognition predicts young children's sensitivity to criticism. Journal of Child Psychology and Psychiatry, 43, 849-860.

Day, C. A., \& Burns, B. M. (2011). Characterizing the achievement motivation orientation of children from low- and middle-income families. Early Education and Development, 22, 105-127.

Day, C. A., Harris, R. C., Carter, K., \& Burns, B. M. (2008, June). Evaluation of a classroom-based intervention on mastery motivation outcomes in children in Head Start. Paper presented at the 9th Head Start National Research Conference, Washington, D.C.

Day, C. A., Harris, R. C., Ford, A., \& Burns, B. M. (2008, June). Examining the relation of the Preschool Learning Behaviors Scale to children's motivation orientation in Head Start. Paper presented at the 9th Head Start National Research Conference, 
Washington, D. C.

Deci, E. L., \& Ryan, R. M. (2000). The 'what' and 'why' of goal pursuits: Human needs and the self-determination of behavior. Psychological Inquiry, 11, 227-268.

Diener, C. I., \& Dweck, C. S. (1978). An analysis of learned helplessness: Continuous changes in performance, strategy, and achievement cognitions following failure. Journal of Personality and Social Psychology, 36, 451-462.

Diener, C. I., \& Dweck, C. S. (1980). An analysis of learned helplessness: The processing of success. Journal of Personality and Social Psychology, 39, 940-952.

Diener, M. L., Nievar, M. A., \& Wright, C. (2003). Attachment security among mothers and their young children living in poverty: Associations with maternal, child, and contextual characteristics. Merrill-Palmer Quarterly, 49, 154-182.

Duncan, R. M., \& Pratt, M. W. (1997). Microgenetic change in the quantity and quality of preschoolers' private speech. International Journal of Behavioral Development, 20, 367-383.

Dweck, C. S. (1986). Motivational processes affecting learning. American Psychologist, $41,1040-1048$

Dweck, C. S., (2000). Self theories: Their role in personality, motivation and development. Philadelphia, PA: Taylor and Francis.

Dweck, C. S., \& Bempechat, J. (1983). Children's theories of intelligence. In S. Paris, G. Olsen \& H. Stevenson (Eds.), Learning and motivation in the classroom (pp. 239256). Hillsdale, NJ: Erlbaum.

Dweck, C. S., \& Leggett, E. L. (1988). A social-cognitive approach to motivation and personality. Psychological Review, 95, 256-273. 
Eccles, J. S., Adler, T. F., Futterman, R., Goff, S. B., Kaczala, C. M., Meece, J. L., et al. (1983). Expectancies, values, and academic behaviors. In J. T. Spence (Ed.), Achievement and achievement motivation (pp. 75-146). San Francisco, CA: W. H. Freeman.

Eccles, J. S., Wigfield, A., \& Schiefele, U. (1998). Motivation to succeed. In N. Eisenberg \& W. Damon (Eds.), Handbook of child psychology: Social, emotional, and personality development (5th ed., Vol. 3, pp. 1017-1095). Hoboken, NJ: Wiley.

Eid, , M., \& Diener, E. (2001). Norms for experienceing emotions in different cultures: Inter and intranational differences. Journal of Personality and Social Psychology, $81,869-885$.

Elliot, A. J. (2005). A conceptual history of the achievement goal construct. In A. J. Elliot \& C. S. Dweck (Eds.), Handbook of competence and motivation (pp. 52-72). New York: Guilford.

Elliot, A. J., \& Church, M. A. (1997). A hierarchical model of approach and avoidance achievement motivation. Journal of Personality and Social Psychology, 72, 218232.

Elliot, A. J., \& Dweck, C. S. (2005a). Competence and motivation: Competence as the core of achievement motivation. In A. J. Elliot \& C. S. Dweck (Eds.), Handbook of competence and motivation (pp. 3-12). New York: Guilford.

Elliot, A. J., \& Dweck, C. S. (2005b). Handbook of competence and motivation. New York: Guilford.

Elliot, A. J., \& McGregor, H. A. (2001). A $2 \times 2$ achievement goal framework. Journal 
of Personality and Social Psychology, 80, 501-519.

Elliot, A. J., \& Thrash, T. M. (2001). Achievement goals and the hierarchical model of achievement motivation. Educational Psychology Review, 13, 139-156.

Elliott, C. D. (2007). Differential Ability Scales, Second Edition. San Antonio, TX: Psychological Corporation.

Elliott, E. S., \& Dweck, C. S. (1988). Goals: An approach to motivation and achievement. Journal of Personality and Social Psychology, 54, 5-12.

Feigenbaum, P. (2002). Private speech: Cornerstone of Vygotsky's theory of the development of higher psychological processes. In D. Robbins \& A. Stetsenko (Eds.), Voices within Vygotsky's non-classical psychology: Past, present, future (pp. 161-174). Hauppauge, NY: Nova Science Publishers.

Ferguson, T. J., Brugman, D., White, J., \& Eyre, H. L. (2007). Shame and guilt as morally warranted experiences. In J. L. Tracy, R. W. Robins \& J. P. Tangney (Eds.), The self-conscious emotions: Theory and research (pp. 330-348). New York: Guilford.

Ferguson, T. J., Stegge, H., Eyre, H. L., Vollmer, R., \& Ashbaker, M. (2000). Context effects and the (mal)adaptive nature of guilt and shame in children. Genetic, Social, and General Psychology Monographs, 126, 319-345.

Fernyhough, C., \& Fradley, E. (2005). Private speech on an executive task: Relations with task difficulty and task performance. Cognitive Development, 20, 103-120.

Frauenglass, M. H., \& Diaz, R. M. (1999). Self-regulatory funtions of children's private speech: A critical analysis of recent challenges to Vygotsky's theory. In P. Lloyd \& C. Fernyhough (Eds.), Lev Vygotsky: Critical assessments: Thought and 
language (Vol. II, pp. 371-383). Florence, KY: Taylor \& Francis.

Fredricks, J. A., Blumenfeld, P. C., \& Paris, A. H. (2004). School engagement: Potential of the concept, state of the evidence. Review of Educational Research, 74, 59-109.

Furnham, A., Chamorro-Premuzic, T., \& McDougall, F. (2002). Personality, cognitive ability, and beliefs about intelligence as predictors of academic performance. Learning and Individual Differences, 14, 47-64.

Gagné, F., \& St. Père, F. (2002). When IQ is controlled, does motivation still predict achievement? Intelligence, 30, 71-100.

Garbarino, J., Hammond, W. R., Mercy, J., \& Yung, B. R. (2004). Community violence and children: Preventing exposure and reducing harm. In K. I. Maton, C. J. Schellenbach, B. J. Leadbeater, \& A. L. Solarz (Eds.), Investing in children, youth, families, and communities: Strengths-based research and policy (pp. 303320). Washington, DC: American Psychological Association.

Garner, P. W., \& Spears, F. M. (2000). Emotion regulation in low-income preschoolers. Social Development, 9, 246-264.

Geppert, U., Schmidt, D., \& Galinowski, I. (1997). Self-evaluative emotions coding system (SEECS). Unpublished Technical Manual. Max Planck Institute for Psychological Research.

Gershoff, E. T., Aber, J. L., Raver, C. C., \& Lennon, M. C. (2007). Income is not enough: Incorporating material hardship into models of income associations with parenting and child development. Child Development, 78, 70-95.

Gilmore, L., Cuskelly, M., \& Purdie, N. (2003). Mastery motivation: Stability and predictive validity from ages two to eight. Early Education and Development, 14, 
411-424.

Goetz, J. L. \& Keltner, D. (2007). Shifting meaning of self-conscious emotions across cultures: A social-funtional approach. In J. L. Tracy, R. W. Robins \& J. P. Tangney (Eds.), The self-conscious emotions: Theory and research (pp. 153-173). New York: Guilford.

González, N., Moll, L. C., \& Amanti, C. (2005). Funds of knowledge: Theorizing practices in households, communities, and classrooms. Mahwah, NJ: Erlbaum.

Gottfried, A. E., Gottfried, A. W., Morris, P. E., \& Cook, C. R. (2008). Low academic intrinsic motivation as a risk factor for adverse educational outcomes: A longitudinal study from early childhood through early adulthood. In C. Hudley \& A. E. Gottfried (Eds.), Academic motivation and the culture of school in childhood and adolescence (pp. 36-69). New York: Oxford University Press.

Graham, S. (2001). Inferences about responsibility and values: Implication for academic motivation. In F. Salili, C. Chiu, \& Y. Hong (Eds.), Student motivation: The culture and context of learning (pp. 31-59). New York: Plenum Publishers.

Graham, S., \& Taylor, A. Z. (2002). Ethnicity, gender, and the development of achievement values. In A. Wigfield \& J. S. Eccles (Eds.), Development of achievement motivation (pp. 121-146). San Diego, CA: Academic Press.

Graham, S., Taylor, A. Z., \& Hudley, C. (1998). Exploring achievement values among ethnic minority early adolescents. Journal of Educational Psychology, 90, 606620.

Grant, H., \& Dweck, C. S. (2003). Clarifying achievement goals and their impact. Journal of Personality and Social Psychology, 85, 541-553. 
Gupta, S., Rosenthal, M. Z., Mancini, A. D., Cheavens, J. S., \& Lynch, T. R. (2008). Emotion regulation skills mediate the effects of shame on eating disorder symptoms in women. Eating Disorders: The Journal of Treatment \& Prevention, $16,405-417$.

Guthrie, J. T., Wigfield, A., \& VonSecker, C. (2000). Effects of integrated instruction on motivation and strategy use in reading. Journal of Educational Psychology, 92, $331-341$.

Harris, R. C., Brown, D. D., Day, C. A., \& Burns, B. M. (2007, March). The relation of spontaneous verbalizations to motivation orientation. Paper presented at the biennial meeting of the Society for Research in Child Development, Boston, MA.

Harris, R. C., Robinson, J. B., Chang, F., \& Burns, B. M. (2007). Characterizing preschool children's attention regulation in parent-child interactions: The roles of effortful control and motivation. Journal of Applied Developmental Psychology, $28,25-39$.

Hart, B., \& Risley, T. R. (1995). Meaningful differences in the everyday experience of young American children. Baltimore: Brookes.

Heckhausen, H. (1987). Emotional components of action: Their ontogeny as reflected in achievement behavior. In D. Görlitz \& J. F. Wohlwill (Eds.), Curiosity, imagination, and play: On the development of spontaneous cognitive motivational processes (pp. 326-348). Hillsdale, NJ: Erlbaum.

Heerey, E. A., Keltner, D., \& Capps, L. M. (2003). Making sense of self-conscious emotion: Linking theory of mind and emotion in children with autism. Emotion, 3, 394-400. 
Heine, S. J. (2004). Positive self-views: Understanding universals and variability across cultures. Journal of Cultural and Evolutionary Psychology, 21, 109-122.

Heine, S. J., Lehman, D. R., Markus, H. R., \& Kitayama, S. (1999). Is there a universla need for positive self-regard? Psychological Review, 106, 766-794.

Heyman, G. D., Dweck, C. S., \& Cain, K. M. (1992). Young children's vulnerability to self-blame and helplessness: Relationship to beliefs about goodness. Child Development, 63, 401-415.

Hoffman, C., Crnic, K. A., \& Baker, J. K., (2006). Maternal depression and parenting: Implications for children's emergent emotion regulation and behavioral functioning. Parenting: Science and Practice, 6, 271-295.

Howse, R. B., Lange, G., Farran, D. C., \& Boyles, C. D. (2003). Motivation and selfregulation as predictors of achievement in economically disadvantaged young children. Journal of Experimental Education, 71, 151-174.

Hwa-Froelich, D. A., Cook, C. A. L., \& Flick, L. H. (2008). Maternal sensitivity and communication styles: Mothers with depression. Journal of Early Intervention, 31, 44-66.

Kagan, J. (1981). The second year. Cambridge, MA: Harvard University Press.

Kamins, M. L., \& Dweck, C. S. (1999). Person versus process praise and criticism: Implications for contingent self-worth and coping. Developmental Psychology, $35,835-847$.

Kelley, S. A., Brownell, C. A., \& Campbell, S. B. (2000). Mastery motivation and selfevaluative affect in toddlers: Longitudinal relations with maternal behavior. Child Development, 71, 1061-1071. 
Kisor, D. (2009). Tough stuff: Songs for mastery motivation. Covington, KY: Growing Sound.

Lagattuta, K. H., \& Thompson, R. A. (2007). The development of self-conscious emotions: Cognitive processes and social influences. In J. L. Tracy, R. W. Robins \& J. P. Tangney (Eds.), The self-conscious emotions: Theory and research (pp. 91-113). New York: Guilford.

Lange, G., MacKinnon, C. E., \& Nida, R. E. (1989). Knowledge, strategy, and motivational contributions to preschool children's object recall. Developmental Psychology, 25, 772-779.

Lever, J. P., Piñol, N. L., \& Uralde, J. H. (2005). Poverty, psychological resources and subjective well-being. Social Indicators Research, 73, 375-408.

Lewis, M. (1992). Shame: The exposed self. New York: Free Press.

Lewis, M. (2001). Origins of the self-conscious child. In W. R. Crozier \& L. E. Alden (Eds.), International handbook of social anxiety: Concepts, research and interventions relating to the self and shyness (pp. 101-118). New York: Wiley.

Lewis, M. (2007). Self-conscious emotional development. In J. L. Tracy, R. W. Robins \& J. P. Tangney (Eds.), The self-conscious emotions: Theory and research (pp. 134149). New York: Guilford.

Lewis, M., Alessandri, S. M., \& Sullivan, M. W. (1992). Differences in shame and pride as a function of children's gender and task difficulty. Child Development, 63, 630638.

Lewis, M., \& Brooks-Gunn, J. (1979). Social cognition and the acquisition of self. New York: Plenum Press. 
Lewis, M., \& Ramsay, D. (2004). Development of self-recognition, personal pronoun use, and pretend play during the 2nd year. Child Development, 75, 1821-1831.

Lewis, M., \& Sullivan, M. W. (2005). The development of self-conscious emotions. In A. J. Elliot \& C. S. Dweck (Eds.), Handbook of competence and motivation (pp. 185201). New York: Guilford.

Lewis, M., Sullivan, M. W., Stanger, C., \& Weiss, M. (1989). Self development and selfconscious emotions. Child Development, 60, 146-156.

Li, J., Wang, L., \& Fischer, K. W. (2004). The organization of Chinese shame concepts. Cognition and Emotion, 18, 767-797.

Linnenbrink-Garcia, L., \& Fredricks, J. A. (2008). Developmental perspectives on achievement motivation: Personal and contextual influences. In J. Y. Shah \& W. L. Gardner (Eds.), Handbook of motivation science (pp. 448-464). New York: Guilford.

Linnenbrink, E. A. (2005). The dilemma of performance-approach goals: The use of multiple goal contexts to promote students' motivation and learning. Journal of Educational Psychology, 97, 197-213.

Lloyd, J., \& Barenblatt, L. (1984). Intrinsic intellectuality: Its relations to social class, intelligence, and achievement. Journal of Personality and Social Psychology, 46, 646-654.

Maehr, M. L., \& Meyer, H. A. (1997). Understanding motivation and schooling: Where we've been, where we are, and where we need to go. Educational Psychology Review, 9, 371-409.

Malakoff, M. E., Underhill, J. M., \& Zigler, E. (1998). Influence of inner-city 
environment and Head Start experience on effectance motivation. American Journal of Orthopsychiatry, 68, 630-638.

Manning, B. H., White, C. S., \& Daugherty, M. (1994). Young children's private speech as a precursor to metacognitive strategy use during task engagement. Discourse Processes, 17, 191-211.

McLoyd, V. C. (1990). The impact of economic hardship on Black families and children: Psychological distress, parenting, and socioemotional development. Child Development, 61, 311-346.

McLoyd, V. C. (1998). Socioeconomic disadvantage and child development. American Psychologist, 53, 185-204.

Miller, S. D., \& Meece, J. L. (1997). Enhancing elementary students' motivation to read and write: A classroom intervention study. Journal of Educational Research, 90, 286-299.

Murphy, P. K., \& Alexander, P. A. (2000). A motivated exploration of motivation terminology. Contemporary Educational Psychology, 25, 3-53.

National Center for Education Statistics (2001). Entering kindergarten: A portrait of American children when they begin school: Findings from the condition of education 2000 (NCES 2001-035). Washington, DC: US Government Printing Office.

Normandeau, S., \& Gobeil, A. (1998). A developmental perspective on children's understanding of causal attributions in achievement-related situations. International Journal of Behavioral Development, 22, 611-632.

Oliver, E. J., Markland, D., Hardy, J., \& Petherick, C. M. (2008). The effects of 
autonomy-supportive versus controlling environments on self-talk. Motivation and Emotion, 32, 200-212.

Op't Eynde, P., De Corte, E., \& Verschaffel, L. (2007). Students' emotions: A key component of self-regulated learning? In P. A. Schutz \& R. Pekrun (Eds.), Emotion in education (pp. 185-204). San Diego, CA: Elsevier Academic Press.

Pagani, L., Boulerice, B., \& Tremblay, R. E. (1997). The influence of poverty on children's classroom placement and behavior problems. In G. J. Duncan \& J. Brooks-Gunn (Eds.), Consequences of growing up poor (pp. 311-339). New York: Sage.

Parsons, J. E., \& Ruble, D. N. (1977). The development of achievement-related expectancies. Child Development, 48, 1075-1079.

Pekrun, R. (2000). A social-cognitive, control-value theory of achievement emotions. In J. Heckhausen (Ed.), Motivational psychology of human development: Developing motivation and motivating development (pp. 143-163). New York: Elsevier Science.

Pekrun, R. (2006). The control-value theory of achievement emotions: Assumptions, corollaries, and implications for educational research and practice. Educational Psychology Review, 18, 315-341.

Pekrun, R., Elliot, A. J., \& Maier, M. A. (2006). Achievement goals and discrete achievement emotions: A theoretical model and prospective test. Journal of Educational Psychology, 98, 583-597.

Pekrun, R., Elliot, A. J., \& Maier, M. A., (2009). Achievement goals and achievment emotions: Testing a model of their joint relations with academic performance. 
Journal of Educational Psychology, 101, 115-135.

Pekrun, R., Frenzel, A. C., Goetz, T., \& Perry, R. P. (2007). The control-value theory of achievement emotions: An integrative approach to emotions in education. In P. A. Schutz \& R. Pekrun (Eds.), Emotion in education (pp. 13-36). San Diego, CA: Elsevier Academic Press.

Pekrun, R., Goetz, T., Titz, W., \& Perry, R. P. (2002). Academic emotions in students' self-regulated learning and achievement: A program of qualitative and quantitative research. Educational Psychologist, 37, 91-106.

Pekrun, R., \& Schutz, P. A. (2007). Where do we go from here? Implications and future directions for inquiry on emotions in education. In P. A. Schutz \& R. Pekrun (Eds.), Emotion in education (pp. 313-331). San Diego, CA: Elsevier Academic Press.

Pessoa, L. (2009). How do emotion and motivation direct executive control? Trends in Cognitive Sciences, 13, 160-166.

Pomerantz, E. M., Grolnick, W. S., \& Price, C. E. (2005). The role of parents in how children approach achievement: A dynamic process perspective. In A. J. Elliot \& C. S. Dweck (Eds.), Handbook of competence and motivation (pp. 229-278). New York: Guilford.

Riley, A. W., Coiro, M. J., Broitman, M., Colantuoni, E., Hurley, K. M., Bandeen-Roche, K., et al. (2009). Mental health of children of low-income depressed mothers: Influences of parenting, family environment, and raters. Psychiatric Services, 60 , 329-336.

Robins, R. W., Noftle, E. E., \& Tracy, J. L. (2007). Assessing self-conscious emotions: A 
review of self-report and nonverbal measures. In J. L. Tracy, R. W. Robins \& J. P. Tangney (Eds.), The self-conscious emotions: Theory and research (pp. 443-467). New York: Guilford.

Robinson, J. B., Burns, B.M. \& Davis, D.W. (2009). Maternal scaffolding and attention regulation in children living in poverty. Journal of Applied Developmental Psychology, 30, 82-91.

Rouse, H. L., \& Fantuzzo, J. W. (2008). Competence motivation in Head Start: An early childhood link to learning. In C. Hudley \& A. E. Gottfried (Eds.), Academic motivation and the culture of school in childhood and adolescence (pp. 15-35). New York: Oxford University Press.

Rozin, P. (2003). Five potential principles for understanding cultural differences in relation to individual differences. Journal of Research in Psychology, 37, 273283.

Schiffman, R. F., Omar, M. A., \& McKelvey, L. M. (2003). Mother-infant interaction in low-income families. The American Journal of Maternal/Child Nursing, 28, 246251.

Schultz, G. F. (1993). Socioeconomic advantage and achievement motivation: Important mediators of academic performance in minority children in urban schools. The Urban Review, 25, 221-232.

Schunk, D. H. (1996). Goal and self-evaluative influences during children's cognitive skill learning. American Educational Research Journal, 33, 359-382.

Schutter, D. J. L. G., de Weijer, A. D., Meuwese, J. D. I., Morgan, B., \& van Honk, J. (2008). Interrelations between motivational stance, cortical excitability, and the 
frontal electroencephalogram asymmetry of emotion: A transcranial magnetic stimulation study. Human Brain Mapping, 29, 574-580.

Schutz, P. A., Hong, J. Y., Cross, D. I., \& Osbon, J. N. (2006). Reflections on investigating emotion in educational activity settings. Educational Psychology Review, 18, 343-360.

Schutz, P. A., \& Pekrun, R. (2007). Emotion in education. San Diego, CA: Elsevier Academic Press.

Self-Brown, S. R., \& Matthews, S. (2003). Effects of classroom structure on student achievement goal orientation. Journal of Educational Research, 97, 106-111.

Sideridis, G. D. (2007). Why are students with LD depressed? A goal orientation model of depression vulnerability. Journal of Learning Disabilities, 40, 526-539.

Skinner, E. A., \& Belmont, M. J. (1993). Motivation in the classroom: Reciprocal effects of teacher behavior and student engagement across the school year. Journal of Educational Psychology, 85, 571-581.

Smiley, P. A., \& Dweck, C. S. (1994). Individual differences in achievement goals among young children. Child Development, 65, 1723-1743.

Smith, J. R., Brooks-Gunn, J., \& Klebanov, P. K. (1997). Consequences of living in poverty for young children's cognitive and verbal ability and early school achievement. In G. J. Duncan \& J. Brooks-Gunn (Eds.), Consequences of growing up poor (pp. 132-189). New York: Sage.

Sternberg, R. J. (2005). Intelligence, competence, and expertise. In A. J. Elliot \& C. S. Dweck (Eds.), Handbook of competence and motivation (pp. 15-30). New York: Guilford. 
Stipek, D. J. (1983). A developmental analysis of pride and shame. Human Development, $26,42-54$.

Stipek, D. J. (1995). The development of pride and shame in toddlers. In J. P. Tangney \& K. W. Fischer (Eds.), Self-conscious emotions: The psychology of shame, guilt, embarrassment, and pride (pp. 237-252). New York: Guilford.

Stipek, D. J. (1998). Difference between Americans and Chinese in the circumstances evoking pride, shame, and guilt. Journal of Cross-Cultural Psychology, 29,616630.

Stipek, D. J. (2002). Motivation to learn: Integrating theory and practice (4th ed.). Boston: Allyn \& Bacon.

Stipek, D. J., \& DeCotis, K. M. (1988). Children's understanding of the implications of causal attributions for emotional experiences. Child Development, 59, 1601-1610.

Stipek, D. J., Feiler, R., Daniels, D., \& Milburn, S. (1995). Effects of different instructional approaches on young children's achievement and motivation. Child Development, 66, 209-223.

Stipek, D. J., Givvin, K. B., Salmon, J. M., \& Macgyvers, V. L. (1998). Can a teacher intervention improve classroom practices and student motivation in mathematics? Journal of Experimental Education, 66, 319-337.

Stipek, D. J., Recchia, S., \& McClintic, S. (1992). Self-evaluation in young children. Monographs of the Society for Research in Child Development, 57(1), 1-95.

Stipek, D. J., \& Ryan, R. H. (1997). Economically disadvantaged preschoolers: Ready to learn but further to go. Developmental Psychology, 33, 711-723.

Tabachnick, B. G., \& Fidell, L. S. (2007). Experimental designs using ANOVA.Belmont, 


\section{$C A$, Duxbury Press.}

Tangney, J. P., \& Dearing, R. L. (2002). Shame and guilt. New York: Guilford.

Terrell, G., Jr., Durkin, K., \& Wiesley, M. (1959). Social class and the nature of the incentive in discrimination learning. The Journal of Abnormal and Social Psychology, 59, 270-272.

Thompson, R. A., \& Meyer, S. (2007). Socialization of emotion regulation in the family. In J. J. Gross (Ed.), Handbook of emotion regulation (pp. 249-268). New York: Guilford.

Tracy, J. L., \& Robins, R. W. (2004). Show your pride: Evidence for a discrete emotion expression. Psychological Science, 15, 194-197.

Tracy, J. L., \& Robins, R. W. (2007a). The nature of pride. In J. L. Tracy, R. W. Robins \& J. P. Tangney (Eds.), The self-conscious emotions: Theory and research (pp. 263-282). New York: Guilford.

Tracy, J. L., \& Robins, R. W. (2007b). The self in self-conscious emotions: A cognitive appraisal approach. In J. L. Tracy, R. W. Robins \& J. P. Tangney (Eds.), The selfconscious emotions: Theory and research (pp. 3-20). New York: Guilford.

Tracy, J. L., Robins, R. W., \& Tangney, J. P. (2007). The self-conscious emotions: Theory and research. New York: Guilford.

Turner, J. E., \& Waugh, R. M. (2007). A dynamical systems perspective regarding students' learning processes: Shame reactions and emergent self-organizations. In P. A. Schutz \& R. Pekrun (Eds.), Emotion in education (pp. 125-145). San Diego, CA: Elsevier Academic Press.

Turner, L. A., \& Johnson, B. (2003). A model of mastery motivation for at-risk 
preschoolers. Journal of Educational Psychology, 95, 495-505.

Urdan, T., \& Turner, J. C. (2005). Competence motivation in the classroom. In A. J. Elliot \& C. S. Dweck (Eds.), Handbook of competence and motivation (pp. 297317). New York: Guilford.

van der Veer, R., \& Valsiner, J. (Eds.). (1994). The Vygotsky reader. Cambridge, MA: Blackwell.

Vygotsky, L. S. (1934/1986). Thought and language. Cambridge, MA: MIT Press.

Wallbott, H. G., \& Scherer, K. R. (1995). Cultural determinants in experienceing shame and guilt. In J. P. Tangney \& K. W. Fischer (Eds.), Self-conscious emotions: The psychology of shame, guilt, embarrassment, and pride (pp. 465-487). New York: Guilford.

Weiner, B. (1985). An attributional theory of achievement motivation and emotion. Psychological Review, 92, 548-573.

Weiner, B. (2000). Intrapersonal and interpersonal theories of motivation from an attributional perspective. Educational Psychology Review, 12, 1-14.

Weiner, B. (2001). Intrapersonal and interpersonal theories of motivation from an attribution perspective. In F. Salili, C. Chiu \& Y. Hong (Eds.), Student motivation: The culture and context of learning (pp. 17-30). Dordrecht, Netherlands: Kluwer Academic Publishers.

Weiner, B., \& Kukla, A. (1970). An attributional analysis of achievement motivation. Journal of Personality and Social Psychology, 15, 1-20.

Weiner, B., Russell, D., \& Lerman, D. (1979). The cognition-emotion process in achievement-related contexts. Journal of Personality and Social Psychology, 37, 
$1211-1220$.

Wigfield, A., \& Eccles, J. S. (1992). The development of achievement task values: A theoretical analysis. Developmental Review, 12, 265-310.

Wong, Y., \& Tsai, J. (2007). Cultural models of shame and guilt. In J. L. Tracy, R. W. Robins \& J. P. Tangney (Eds.), The self-conscious emotions: Theory and research (pp. 209-223). New York: Guilford.

Ziegert, D. I., Kistner, J. A., Castro, R., \& Robertson, B. (2001). Longitudinal study of young children's responses to challenging achievement situations. Child Development, 72, 609-624.

Zigler, E., \& De Labry, J. (1962). Concept-switching in middle-class, lower-class, and retarded children. Journal of Abnormal and Social Psychology, 65, 267-273.

Zill, N., \& West, J. (2001). Entering kindergarten: A portrait of American children when they begin school: Findings from the condition of education, 2000 (No. NCES 2001-035). Washington, DC: U.S. Department of Education, National Center for Education Statistics. 
Table 1

Proposed Integrative Model

\begin{tabular}{|c|c|c|c|c|}
\hline $\begin{array}{l}\text { Achievement } \\
\text { Standard }\end{array}$ & $\begin{array}{c}\text { Achievement } \\
\text { Goal }\end{array}$ & $\begin{array}{c}\text { SE Emotion } \\
\text { Response }\end{array}$ & $\begin{array}{c}\text { Response to } \\
\text { Challenge }\end{array}$ & $\begin{array}{l}\text { Motivation } \\
\text { Orientation }\end{array}$ \\
\hline \multirow[t]{2}{*}{$\begin{array}{l}\text { Outcome is key; } \\
\text { Success: correct } \\
\text { completion of task; } \\
\text { Failure: non- } \\
\text { completion of task }\end{array}$} & Performance & High Shame & $\begin{array}{l}\text { Performance } \\
\text { decline; ineffective } \\
\text { problem solving; } \\
\text { low/decreased } \\
\text { persistence; } \\
\text { low/decreased } \\
\text { effort; low } \\
\text { confidence }\end{array}$ & Performance \\
\hline & & $\begin{array}{l}\text { Moderate to } \\
\text { Low Shame }\end{array}$ & $\begin{array}{l}\text { Some performance } \\
\text { decline; moderately } \\
\text { effective problem } \\
\text { solving; moderate } \\
\text { persistence; } \\
\text { moderate effort; } \\
\text { high confidence }\end{array}$ & $\begin{array}{l}\text { Attenuated- } \\
\text { Mastery }\end{array}$ \\
\hline $\begin{array}{l}\text { Process is key; } \\
\text { Success: learning } \\
\text { during a task; } \\
\text { Failure: N/A }\end{array}$ & Learning & $\begin{array}{l}\text { Very Low to } \\
\text { No Shame }\end{array}$ & $\begin{array}{l}\text { No performance } \\
\text { decline; effective } \\
\text { problem solving; } \\
\text { high persistence; } \\
\text { high effort; low or } \\
\text { high confidence }\end{array}$ & Mastery \\
\hline
\end{tabular}

Note. Children are expected to demonstrate equal amounts of pride in success, regardless of their motivation orientation. 
Table 2

SEECS Operational Definitions

\begin{tabular}{|c|c|}
\hline Feature category & Operational definition \\
\hline \multicolumn{2}{|l|}{ Gaze } \\
\hline Downward & Child's eyes are downward \\
\hline Experimenter & Child looks up at experimenter or camera \\
\hline Other/off-task & Child is looking anywhere expect downward or at experimenter \\
\hline \multicolumn{2}{|l|}{ Expression } \\
\hline Smile & Cheek raise and lip corner pull (mouth can be opened or closed) \\
\hline Frown & Corners of mouth turned downward \\
\hline Lip bite/suck & Lower lip or both upper and lower lips tucked between teeth \\
\hline \multicolumn{2}{|l|}{ Gesture } \\
\hline Pointing at outcome & Child points to, taps/pats, or presents puzzle, pieces, or outcome \\
\hline Pointing at self & Child points to self \\
\hline Raising arms & Child raises one or both arms above their shoulders \\
\hline Clapping hands & Child claps hands together one or more times \\
\hline Dancing & Child makes dancing movements \\
\hline \multicolumn{2}{|l|}{ Posture } \\
\hline Erect posture & Body erect with back straight and shoulders back \\
\hline Collapsed posture & Body collapsed with back and shoulders hunched over \\
\hline Head raised & Head up with chin higher than $90^{\circ}$ or above a level position \\
\hline Head lowered & Head down with chin at or below $45^{\circ}$ or at least halfway down \\
\hline Shoulder raise & One or both shoulders pulled up \\
\hline \multicolumn{2}{|l|}{ Verbalization } \\
\hline Negative self-evaluation & $\begin{array}{l}\text { Statements reflecting the child's negative opinion of their ability } \\
\text { and/or performance (e.g., "I'm no good at this.") }\end{array}$ \\
\hline Positive self-evaluation & $\begin{array}{l}\text { Statements reflecting the child's positive opinion of their ability } \\
\text { and/or performance (e.g., "I did it!") }\end{array}$ \\
\hline \multicolumn{2}{|l|}{ Task period } \\
\hline Puzzle 1-4 & $\begin{array}{l}\text { Marks the beginning of coding for each puzzle; start when the } \\
\text { experimenter removes hands from spreading out puzzle pieces }\end{array}$ \\
\hline Break 1-3 & $\begin{array}{l}\text { Marks the beginning of coding for the period immediately after } \\
\text { child works on each puzzle; start when experimenter touches } \\
\text { puzzle pieces/puzzle to remove them (code for } 25 \text { seconds) }\end{array}$ \\
\hline Break 4 & $\begin{array}{l}\text { Start after the child inserts the last piece in the puzzle (code for } \\
15 \text { seconds) }\end{array}$ \\
\hline
\end{tabular}


Table 3

SEECS Feature Combinations for Coding Shame and Pride

\begin{tabular}{ll}
$\begin{array}{c}\text { Self-Evaluative } \\
\text { Emotion }\end{array}$ & \multicolumn{1}{c}{ Feature Combination } \\
\hline Shame & $\begin{array}{l}\text { Gaze downward + head lowered/collapsed posture } \\
\text { Gaze downward + frown + head lowered/collapsed posture } \\
\end{array}$ \\
& Gaze downward + lip bite/suck \\
& Gaze downward + shoulder raise \\
& Negative self-evaluation statements \\
& $\begin{array}{l}\text { Smiling + raised head/erect posture } \\
\text { Pmiling + victorious gestures (pointing at self/outcome, raising arms, clapping, } \\
\text { dancing) } \\
\text { Positive self-evaluation statements }\end{array}$ \\
\hline
\end{tabular}


Table 4

Verbalization Categorization Definitions and Examples

\begin{tabular}{|c|c|c|}
\hline Category & Definition & Example \\
\hline Task-Relevant Facilitative & $\begin{array}{l}\text { Statements are related to the task at } \\
\text { hand and represent attempts by the } \\
\text { child to focus his or her cognitive } \\
\text { resources on the task, to plan or } \\
\text { organize task-related activities, and } \\
\text { to correct, cope, or motivate the } \\
\text { child while working on the task }\end{array}$ & \\
\hline Strategy & $\begin{array}{l}\text { Statements reflecting children's } \\
\text { plans and hypotheses about specific } \\
\text { pieces and their potential locations }\end{array}$ & $\begin{array}{l}\text { "I make my colors } \\
\text { match right here." }\end{array}$ \\
\hline Self-motivating & $\begin{array}{l}\text { Statements meant to encourage or } \\
\text { praise their work on the task }\end{array}$ & "I can do it!" \\
\hline Task-appropriate solution & $\begin{array}{l}\text { Statements related to searches for } \\
\text { appropriate pieces or (not) fitting a } \\
\text { puzzle piece }\end{array}$ & $\begin{array}{l}\text { "This piece goes right } \\
\text { here." }\end{array}$ \\
\hline Task-appropriate difficulty & $\begin{array}{l}\text { Statements indicating that the child } \\
\text { is having difficulty completing the } \\
\text { puzzle or fitting a piece }\end{array}$ & $\begin{array}{l}\text { "Oh, this piece is } \\
\text { backwards." }\end{array}$ \\
\hline Challenge & $\begin{array}{l}\text { Statements indicating that the child } \\
\text { wants to continue working on the } \\
\text { challenging task, is enjoying the } \\
\text { task, or wants to attempt an } \\
\text { additional task }\end{array}$ & $\begin{array}{l}\text { "Can we come back to } \\
\text { this puzzle? I'm not } \\
\text { done." }\end{array}$ \\
\hline Task-Relevant Nonfacilitative & $\begin{array}{l}\text { Statements that are related to the } \\
\text { task, but "serve to delay or stop } \\
\text { accompanying task-related } \\
\text { behavior" }\end{array}$ & \\
\hline Performance concern & $\begin{array}{l}\text { Statements concerning adequate } \\
\text { performance on the task }\end{array}$ & $\begin{array}{l}\text { "I bet that puzzle is } \\
\text { going to be too hard." }\end{array}$ \\
\hline Negative ability evaluation & $\begin{array}{l}\text { Statements that the child thinks } \\
\text { they lack the ability and skills } \\
\text { needed to complete the task }\end{array}$ & $\begin{array}{l}\text { "I'm not smart at } \\
\text { puzzles." }\end{array}$ \\
\hline Disengaged & $\begin{array}{l}\text { Statements that the child does not } \\
\text { want to continue working on the } \\
\text { task or wants to work on some } \\
\text { other task }\end{array}$ & $\begin{array}{l}\text { "I don't want to do } \\
\text { this puzzle anymore." }\end{array}$ \\
\hline Help & $\begin{array}{l}\text { Statements in which the child tells } \\
\text { the experimenter to help them or } \\
\text { asks the experimenter for help }\end{array}$ & "Help me do this." \\
\hline
\end{tabular}


Task-Irrelevant

Off-task

Ambiguous

Ambiguous/unintelligible
Statements that do not relate to the challenging puzzle task

Statements about the immediate environment, free associations about the puzzles, or some comments about the child's personal life

Incomplete or unintelligible utterances

Sentence fragments that did not provide enough information to assign a code or were otherwise unintelligible
"What's that noise?"

Humming sounds 
Table 5

Summary of Goal-Confidence and Motivation Orientation Patterns

\begin{tabular}{lccc}
\hline \multicolumn{1}{c}{ Goal-Confidence Pattern } & Performance & $\begin{array}{c}\text { Attenuated- } \\
\text { Mastery } \\
(n=15)\end{array}$ & $\begin{array}{c}\text { Mastery } \\
(n=51)\end{array}$ \\
\hline Performance goal, low confidence & 1 & - & - \\
Performance goal, high confidence & - & 15 & - \\
Learning goal, low confidence & - & - & 3 \\
Learning goal, high confidence & - & - & 48 \\
\hline
\end{tabular}


Table 6

Motivation Orientation Group Differences in Age, Cognitive Ability, and Puzzle Task Variables

\begin{tabular}{lrrrrrrr}
\hline & \multicolumn{2}{c}{$\begin{array}{c}\text { Attenuated- } \\
\text { Mastery }\end{array}$} & & \multicolumn{2}{c}{ Mastery } & \\
\cline { 2 - 3 } \multicolumn{1}{c}{ Variable } & \multicolumn{1}{c}{$M$} & $S D$ & & $M$ & $S D$ & $95 \%$ CI \\
\hline Age (years) & 4.26 & 0.42 & & 4.38 & 0.35 & {$[-0.33,0.10]$} \\
DAS GCA & 90.00 & 10.48 & & 91.73 & 9.49 & {$[-7.54,4.08]$} \\
DAS verbal & 92.60 & 8.02 & & 92.56 & 7.18 & {$[-4.28,4.37]$} \\
DAS nonverbal & 92.53 & 12.63 & & 94.53 & 11.00 & {$[-8.81,4.81]$} \\
DAS spatial & 91.60 & 10.41 & & 93.73 & 10.85 & {$[-8.55,4.28]$} \\
Puzzle ability (min) & 5.32 & 1.62 & & 5.29 & 2.90 & {$[-1.54,1.60]$} \\
P4 time (min) & 3.95 & 1.28 & & 4.61 & 2.98 & {$[-2.25,0.93]$} \\
\hline
\end{tabular}

Note . $\mathrm{CI}=$ confidence interval. DAS GCA $=$ Differential Ability Scales General Conceptual Ability; DAS Verbal $=$ Differential Ability Scales Verbal subscale score; DAS NonVerbal = Differential Ability Scales Nonverbal subscale score; DAS Spatial = Differential Ability Scales Spatial subscale score; Puzzle Ability $=$ time required to complete pretest puzzle; P4 Time $=$ time required to complete the solvable puzzle.

${ }^{*} p<.05 .{ }^{* *} p<.01$. 
Table 7

Summary of Intercorrelations. Means, and Standard Deviations for Age. Cognitive Abilin: Puzzle Variables. Self-Evaluative Emotions, and Verbalization Proportions

\begin{tabular}{|c|c|c|c|c|c|c|c|c|c|c|c|c|c|c|c|}
\hline Measure & 1 & 2 & 3 & 4 & 5 & 6 & 7 & 8 & 9 & 10 & 11 & 12 & 13 & 14 & 15 \\
\hline 1. Age & - & -.05 & .01 & .02 & -.13 & -.17 & $-.32 *$ & -.22 & -.18 & $-.28 *$ & $-.31 *$ & .00 & .20 & .08 & -.14 \\
\hline 2. DAS GCA & & - & $.74 * *$ & $.78 * *$ & $.84 * *$ & $-.42 * *$ & $-.42 * *$ & -.09 & -.11 & -.14 & -.20 & -.04 & -.29 & -.19 & .28 \\
\hline 3. DAS Verbal & & & - & $.34 * *$ & $.54 * *$ & $-.44 * *$ & $-.44 * *$ & .13 & -.18 & -.06 & $-.35 * *$ & .25 & -.24 &. .24 & .22 \\
\hline 4. DAS Nonverbal & & & & - & $.43 * *$ & -.14 & -.19 & -.21 & .04 & -.09 & .01 & -.10 & -.24 & -.13 & .24 \\
\hline 5. DAS Spatial & & & & & - & $-.47 * *$ & $-.39 * *$ & -.06 & -.17 & -.17 & -.19 & -.17 & -.22 & -.09 & .22 \\
\hline 6. Puzzle Ability & & & & & & - & $.55 * *$ & .02 & .20 & .17 & $.27 *$ & -.02 & .23 & .10 & -.16 \\
\hline 7. P4 Time & & & & & & & - & $.37 * *$ & .18 & $.38 * *$ & $.48 * *$ & .02 & .18 & .06 & -.12 \\
\hline 8. Shame & & & & & & & & - & -.03 & $.64 * *$ & -.08 & .02 & .05 & -.03 & .01 \\
\hline 9. Pride & & & & & & & & & - & $.75 * *$ & $.69 * *$ & .05 & .05 & .20 & -.23 \\
\hline 10.SE Emotions & & & & & & & & & & - & $.49^{* *}$ & .06 & .07 & .14 & -.18 \\
\hline 11.Total Verbs. & & & & & & & & & & & - & .13 & .07 & .15 & -.22 \\
\hline $12 . \%$ TI Verbs. & & & & & & & & & & & & - & -.05 & -.18 &. .18 \\
\hline $13 . \%$ TRNF Verbs. & & & & & & & & & & & & & - & -.07 & -.23 \\
\hline $14 . \%$ TRF Verbs. & & & & & & & & & & & & & & - & $-.88 * *$ \\
\hline $15 . \%$ A Verbs. & & & & & & & & & & & & & & & - \\
\hline$M$ & 4.35 & 91.30 & 92.55 & 94.03 & 93.20 & 5.30 & 4.46 & 6.98 & 6.70 & 13.46 & 29.74 & 0.05 & 0.03 & 0.68 & 0.25 \\
\hline$S D$ & 0.37 & 9.68 & 7.68 & 11.35 & 10.70 & 2.65 & 2.70 & 6.39 & 7.75 & 9.80 & 31.80 & 0.08 & 0.07 & 0.21 & 0.21 \\
\hline
\end{tabular}

Note. DAS GCA = Differential Ability Scales General Conceptual Ability: DAS Verbal = Differential Ability Scales Verbal subscale score; DAS Nonverbal = Differential Ability Scales Nonverbal subscale score: DAS Spatial = Differential Ability Scales Spatial subscale sc ore; Puzzle Ability = time required to complete pretest puzzle: $P 4$ Time $=$ time required to complete the sol vable puzzle: Shame $=$ total shame expressions; Pride $=$ total pride expressions: SE Emotions $=$ total self-evaluative shame and pride expressions: Total Verbs. $=$ Total verbalizations: \% II Verbs. = Proportion Task-Irrelevant verbalizations; \% TRNF Verbs. = Proportion Task-Relevant Nonfacilitative verbalizations; \% TRF Verbs. $=$ Propontion Task-Relevant Facilitative verbalizations; \% A Verbs. = Proportion Ambiguous verbalizations.

${ }^{*} p<.05 .{ }^{* *} p<.01$. 
Table 8

Verbalization Means and Standard Deviations by Gender.

\begin{tabular}{|c|c|c|c|c|c|}
\hline \multirow[b]{2}{*}{ Variable } & \multicolumn{2}{|c|}{ Boys } & \multicolumn{2}{|c|}{ Girls } & \multirow[b]{2}{*}{$95 \% \mathrm{CI}$} \\
\hline & $M$ & $S D$ & $M$ & $S D$ & \\
\hline Total Verbs. & 33.77 & 30.47 & 26.39 & 32.92 & {$[-8.34,23.10]$} \\
\hline$\%$ TI Verbs. & .05 & .05 & .06 & .10 & {$[-0.05,0.03]$} \\
\hline$\%$ TRNF Verbs. & .01 & .03 & .04 & .09 & {$[-0.06,0.01]$} \\
\hline$\%$ TRF Verbs. & .70 & .20 & .65 & .21 & {$[-0.07,0.16]$} \\
\hline$\%$ A Verbs. & .24 & .20 & .25 & .22 & {$[-0.13,0.10]$} \\
\hline
\end{tabular}

Note. $\mathbf{C I}=$ confidence interval.

$*_{p}<.05$. ${ }^{*} p<.01$. 
Table 9

Self-Evaluative Emotion Means and Standard Deviations by Gender.

\begin{tabular}{lcccccc}
\hline \multirow{2}{*}{ Variable } & \multicolumn{3}{c}{ Boys } & & \multicolumn{3}{c}{ Girls } \\
\cline { 2 - 3 } \cline { 5 - 6 } \cline { 5 - 6 } & $M$ & $S D$ & & $M$ & $S D$ & $95 \%$ CI \\
\hline Total SE Emotions & 14.27 & 10.17 & & 12.77 & 9.57 & {$[-3.40,6.39]$} \\
Shame & 6.37 & 6.47 & & 7.50 & 6.36 & {$[-4.30,2.03]$} \\
Pride & 7.90 & 7.28 & & 5.69 & 8.09 & {$[-1.61,6.02]$} \\
\hline
\end{tabular}

Note. $\mathrm{CI}=$ confidence interval.

$* p<.05 . * *<.01$. 
Table 10

Total Self-Evaluative Emotion Means and Standard Errors by Puzzle and Motivation Orientation.

\begin{tabular}{cccccccccc}
\hline & \multicolumn{2}{c}{ Attenuated-Mastery } & & \multicolumn{2}{c}{ Mastery } & & \multicolumn{2}{c}{ Combined } \\
\cline { 2 - 3 } \cline { 8 - 9 } \cline { 8 - 9 } Puzzle & $M$ & $S E$ & & $M$ & $S E$ & & $M$ & $S E$ \\
\hline 1 & 2.97 & 0.43 & & 1.62 & 0.23 & & 1.92 & 0.22 \\
2 & 3.76 & 0.47 & & 1.74 & 0.25 & & 2.20 & 0.24 \\
3 & 3.58 & 0.55 & & 2.26 & 0.30 & & 2.56 & 0.27 \\
4 & 10.63 & 1.38 & & 5.93 & 0.75 & & 7.00 & 0.70 \\
\hline
\end{tabular}


Figure 1. Puzzles used in challenging puzzle task to assess achievement motivation orientation.

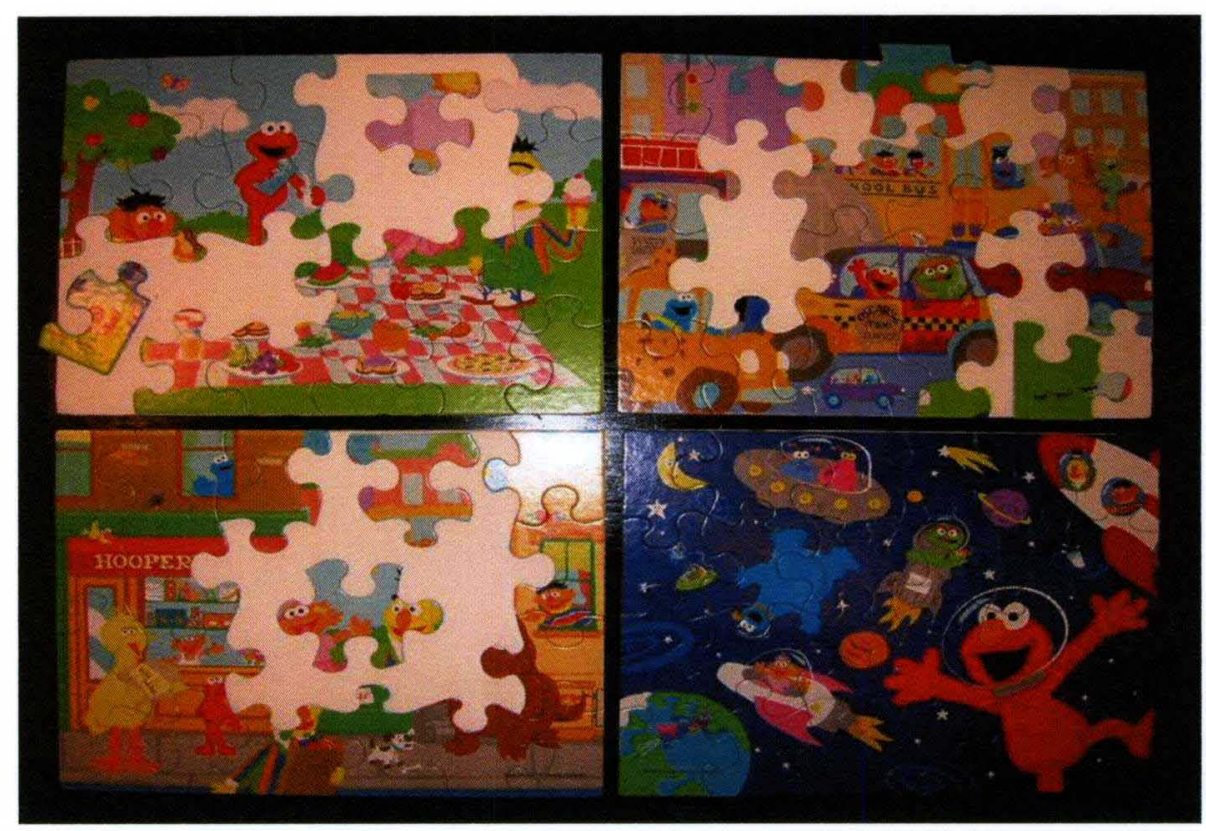


Figure 2. Motivation orientation categorizations based on challenging puzzle task.

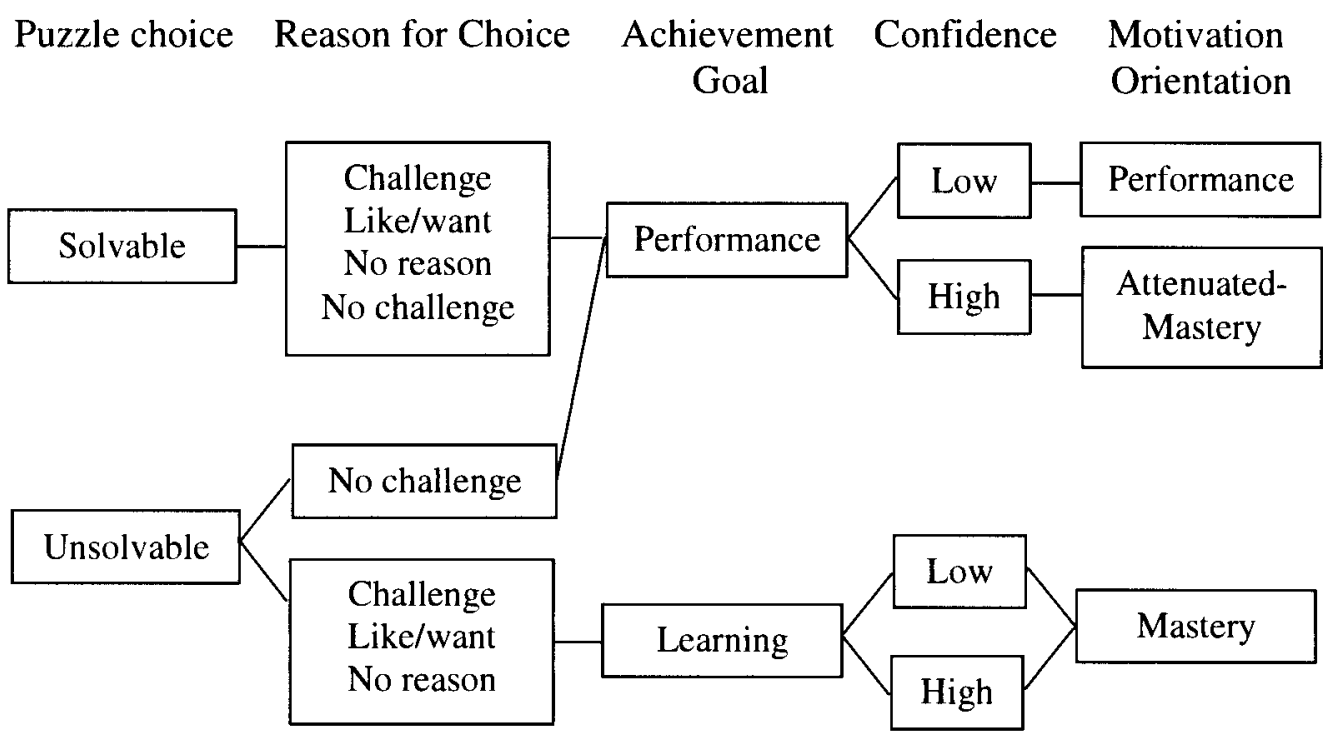


Figure 3. Mean proportion of verbalizations for each verbalization category across all children. Error bars represent standard errors.

$* p<.05 . * * p<.01$.

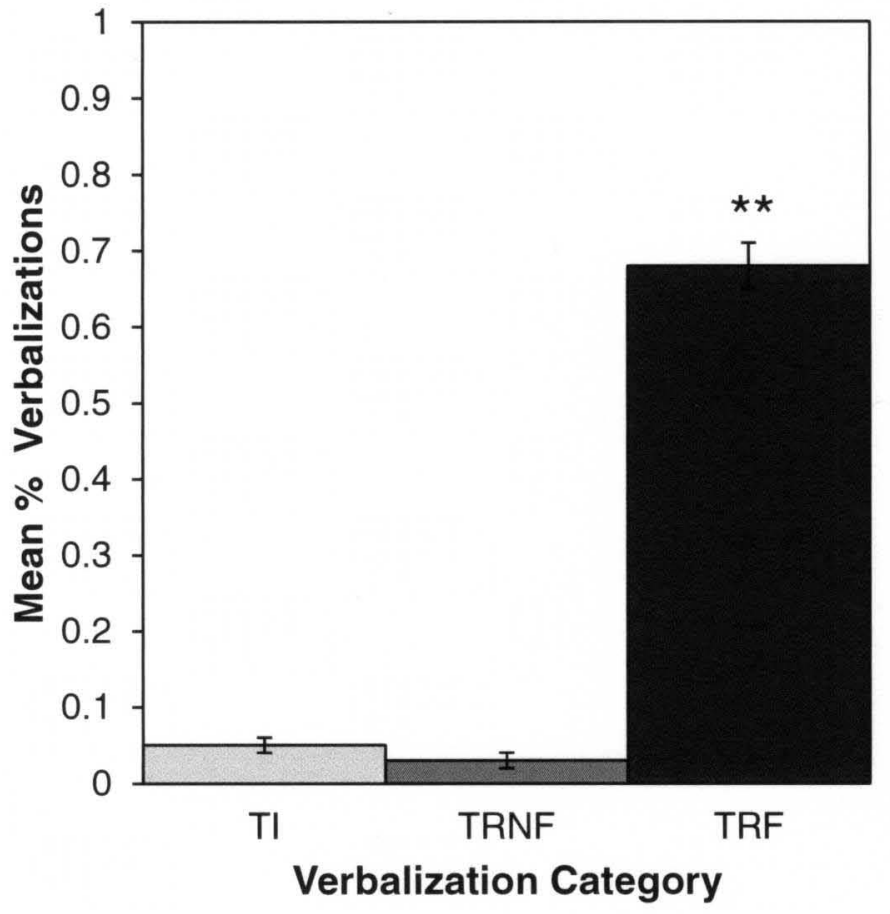


Figure 4. Mean proportion of overall verbalizations across all children by puzzle. Error bars repersent standard errors.

$* p<.05 . * * p<.01$.

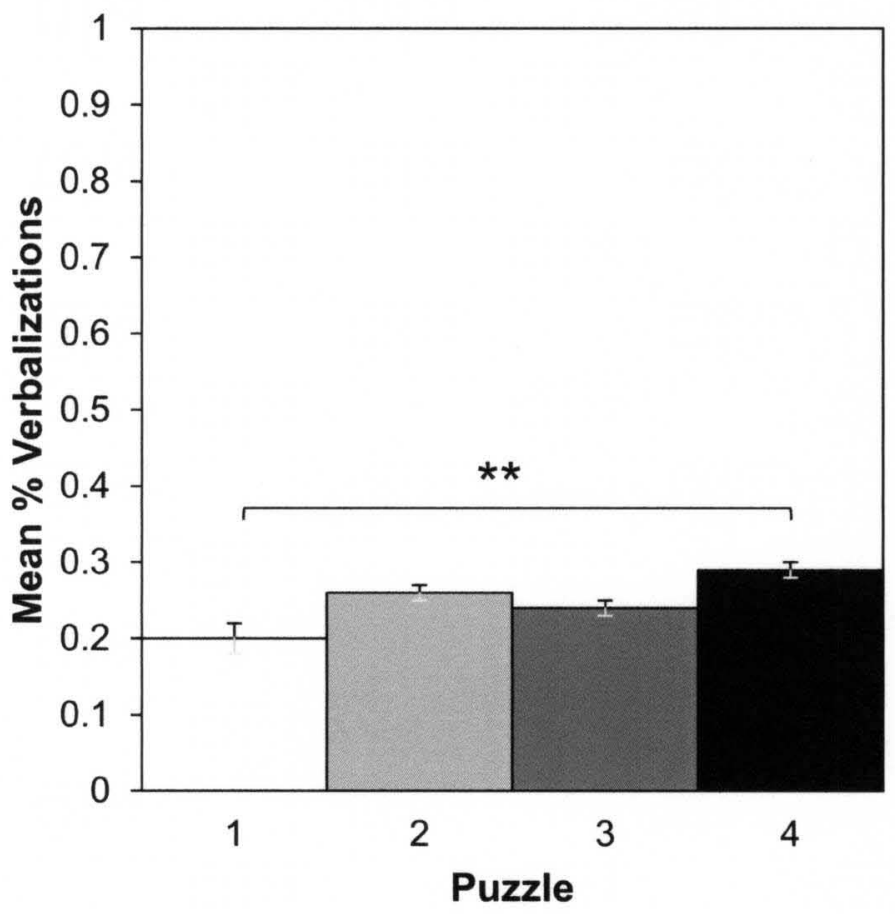


Figure 5. Mean proportion of verbalizations produced by all children by puzzle. Error bars represent standard errors.

${ }^{*} p<.05 . * * p<.01$.

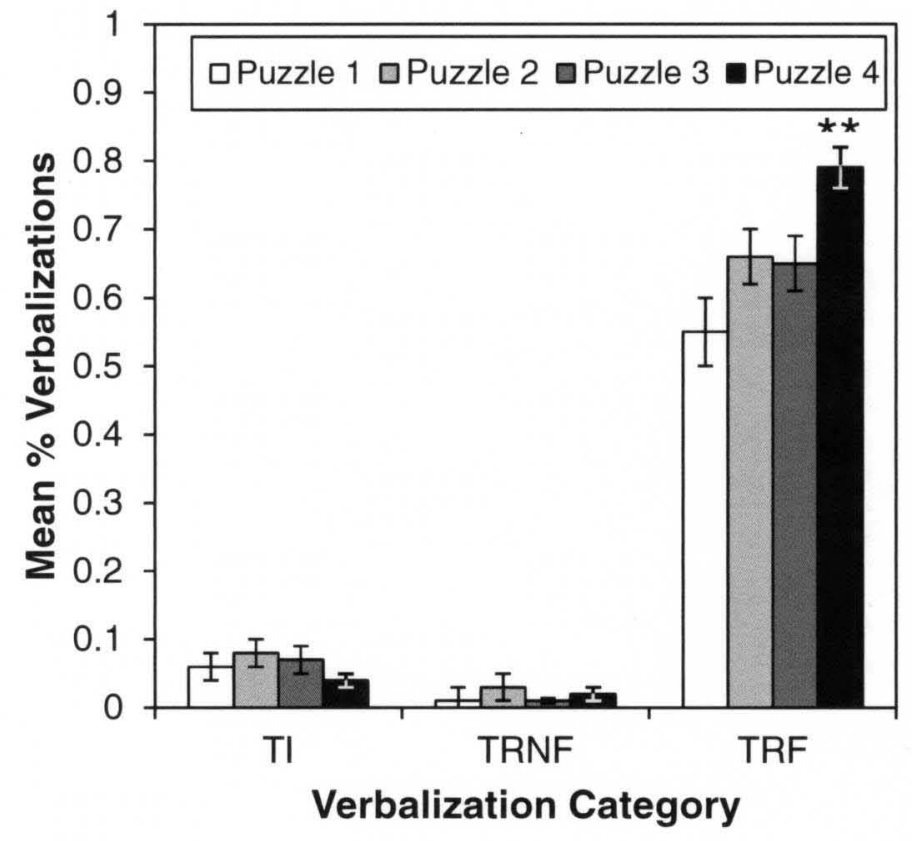


Figure 6. Mean proportion of overall verbalizations produced by attenuated-mastery and mastery oriented children by puzzle. Error bars represent standard errors.

$* p<.05$. $* * p<.01$.

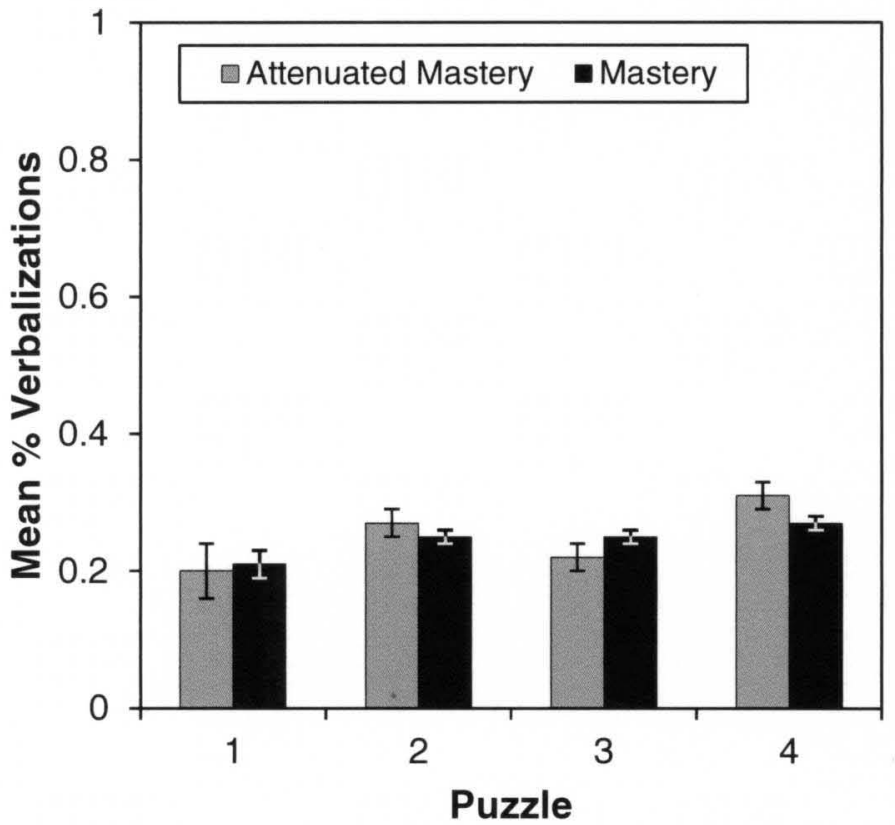


Figure 7. Mean proportion of verbalizations for each verbalization category produced by attenuated-mastery and mastery oriented children. Error bars represent standard errors. ${ }^{*} p<.05$. ${ }^{*} p<<.01$.

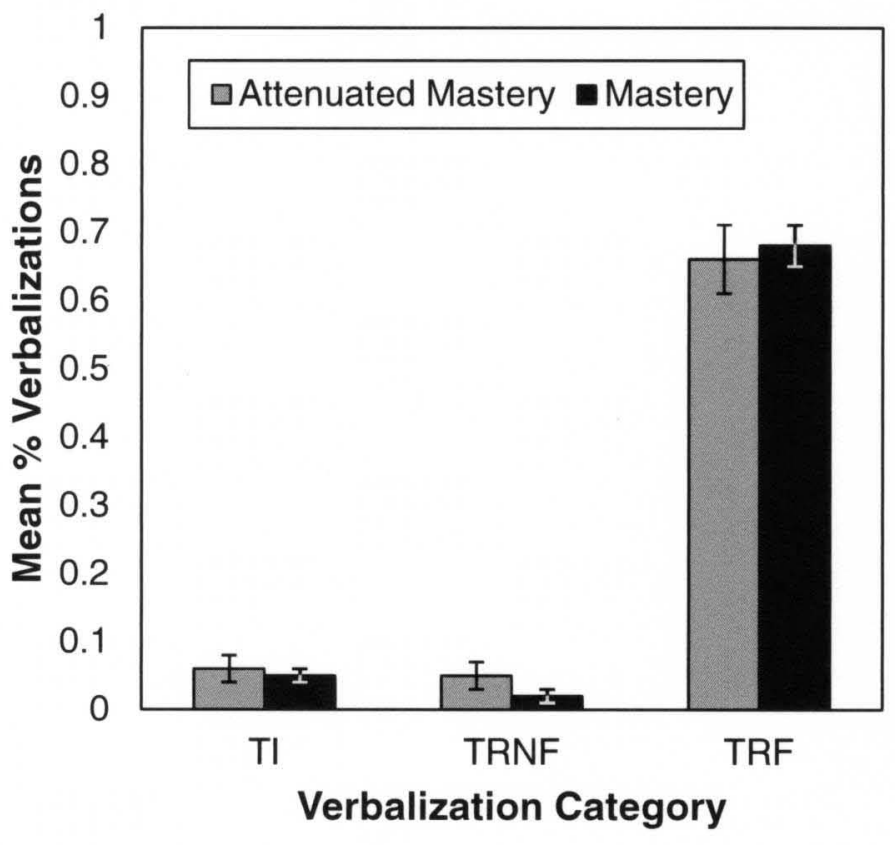


Figure 8. Mean proportion of verbalizations for each verbalization category produced by attenuated-mastery and mastery oriented children by puzzle. Error bars represent standard errors.

$* p<.05 . * * p<.01$.
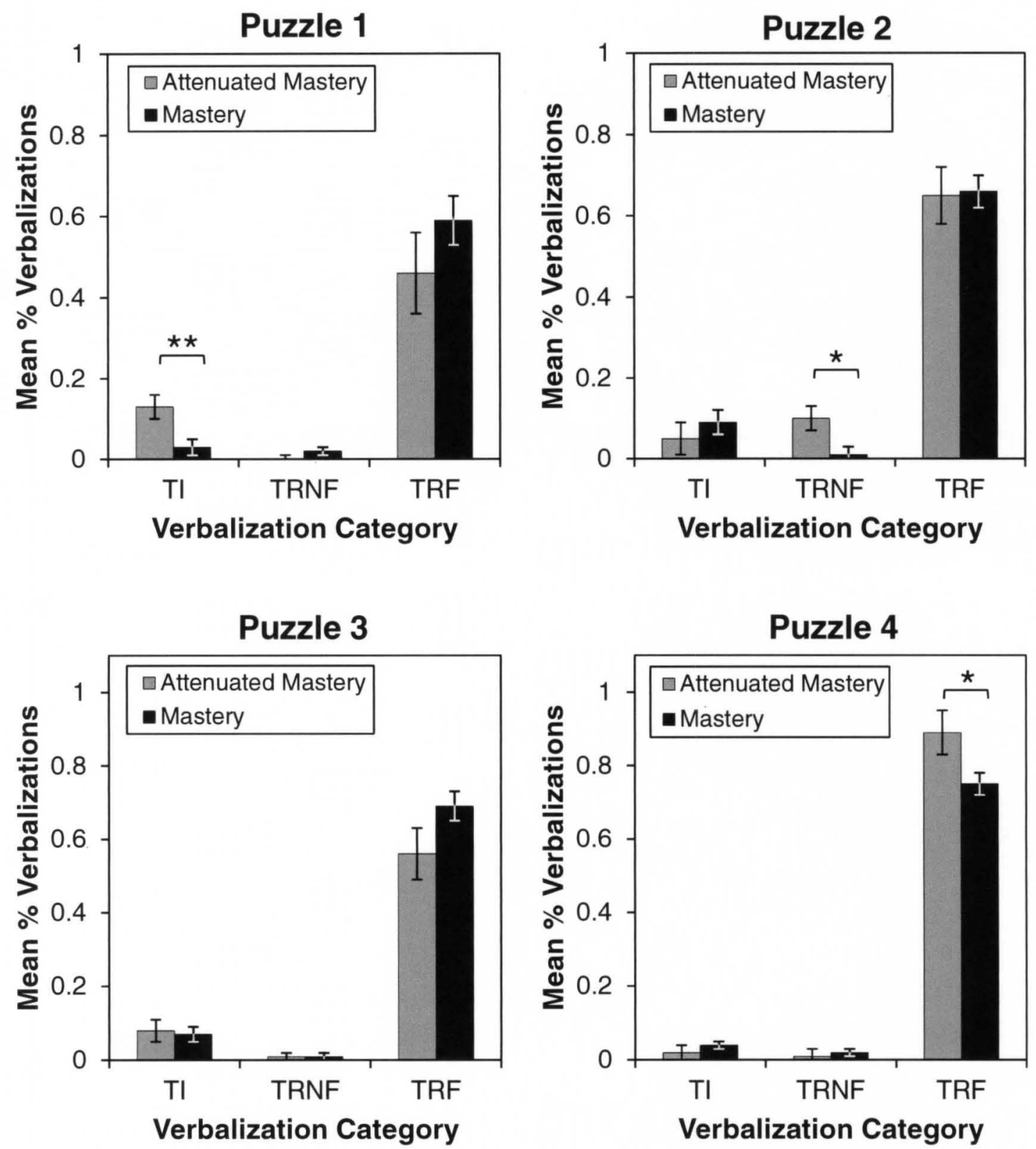
Figure 9. Mean number of shame and pride behaviors produced by puzzle. Error bars represent standard errors.

$* p<.05 . * * p<.01$.

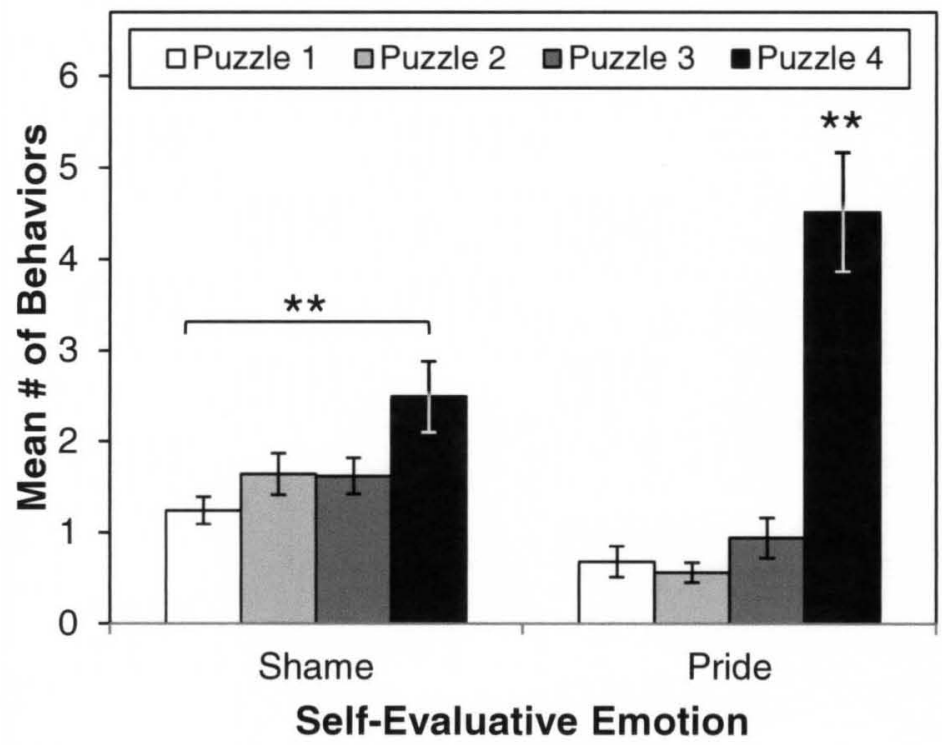


Figure 10. Mean number of self-evaluative shame and pride behaviors produced by attenuated- mastery and mastery oriented children. Error bars represent standard errors. ${ }^{*} p<.05$. ${ }^{* *} p<.01$.

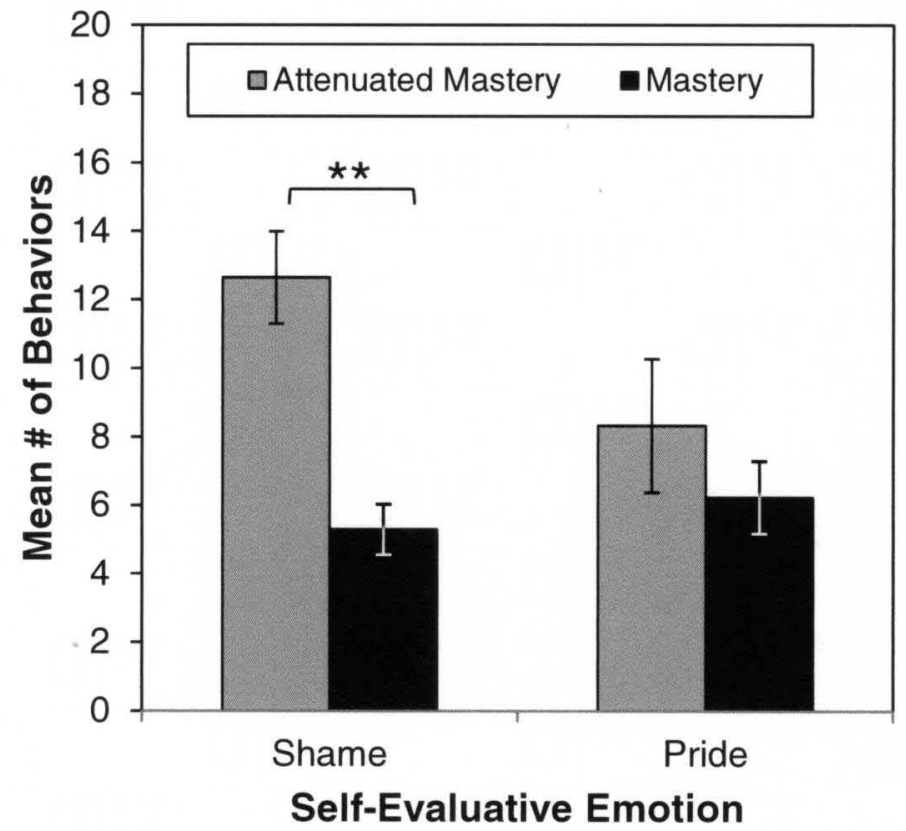


Figure 11. Mean number of shame and pride behaviors produced by attenuated-mastery and mastery oriented children by puzzle. Error bars represent standard errors.

$* p<.05 . * * p<.01$.
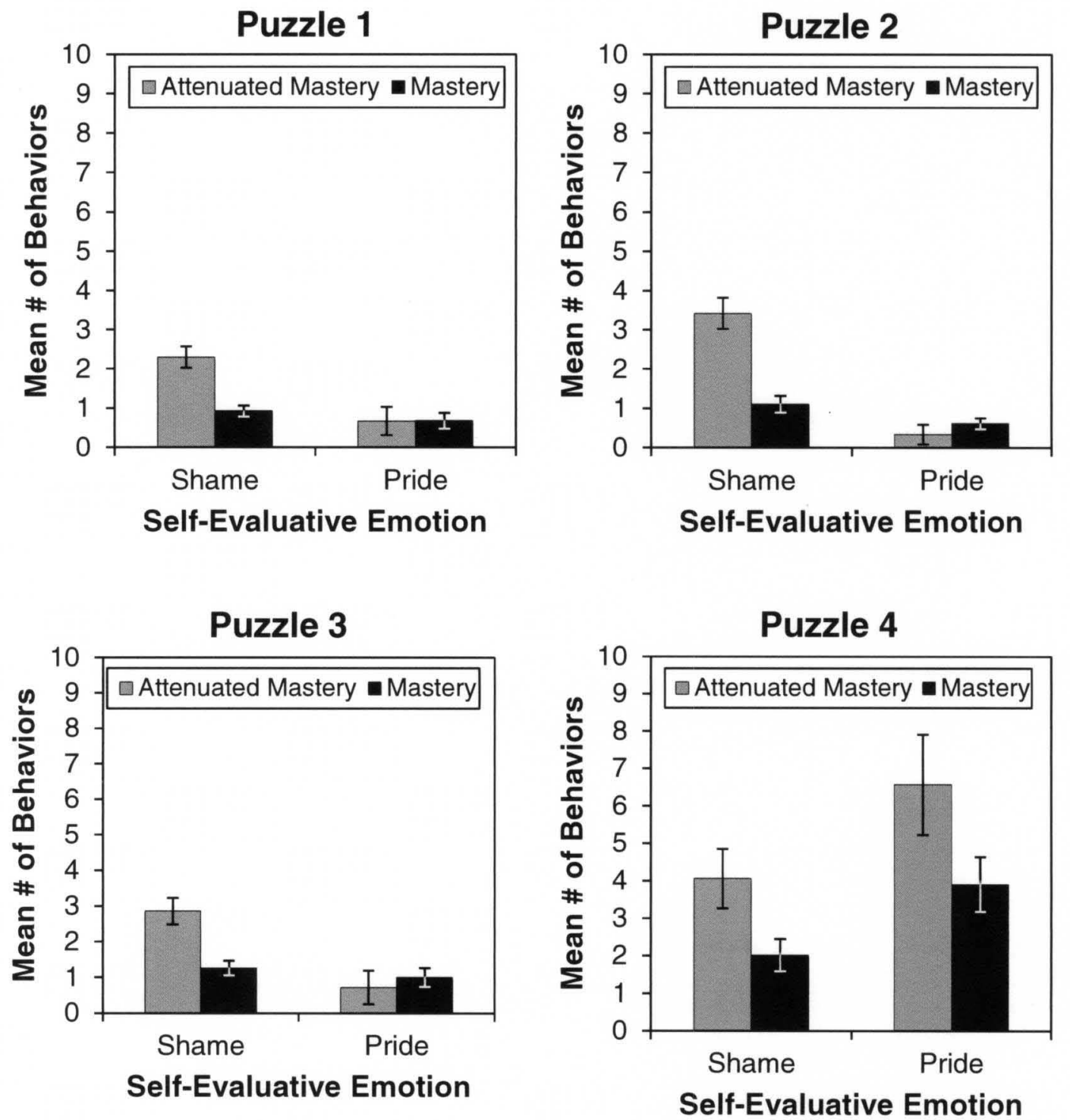
Appendix A

Histograms depicting the distributions of children's untransformed verbalizations.
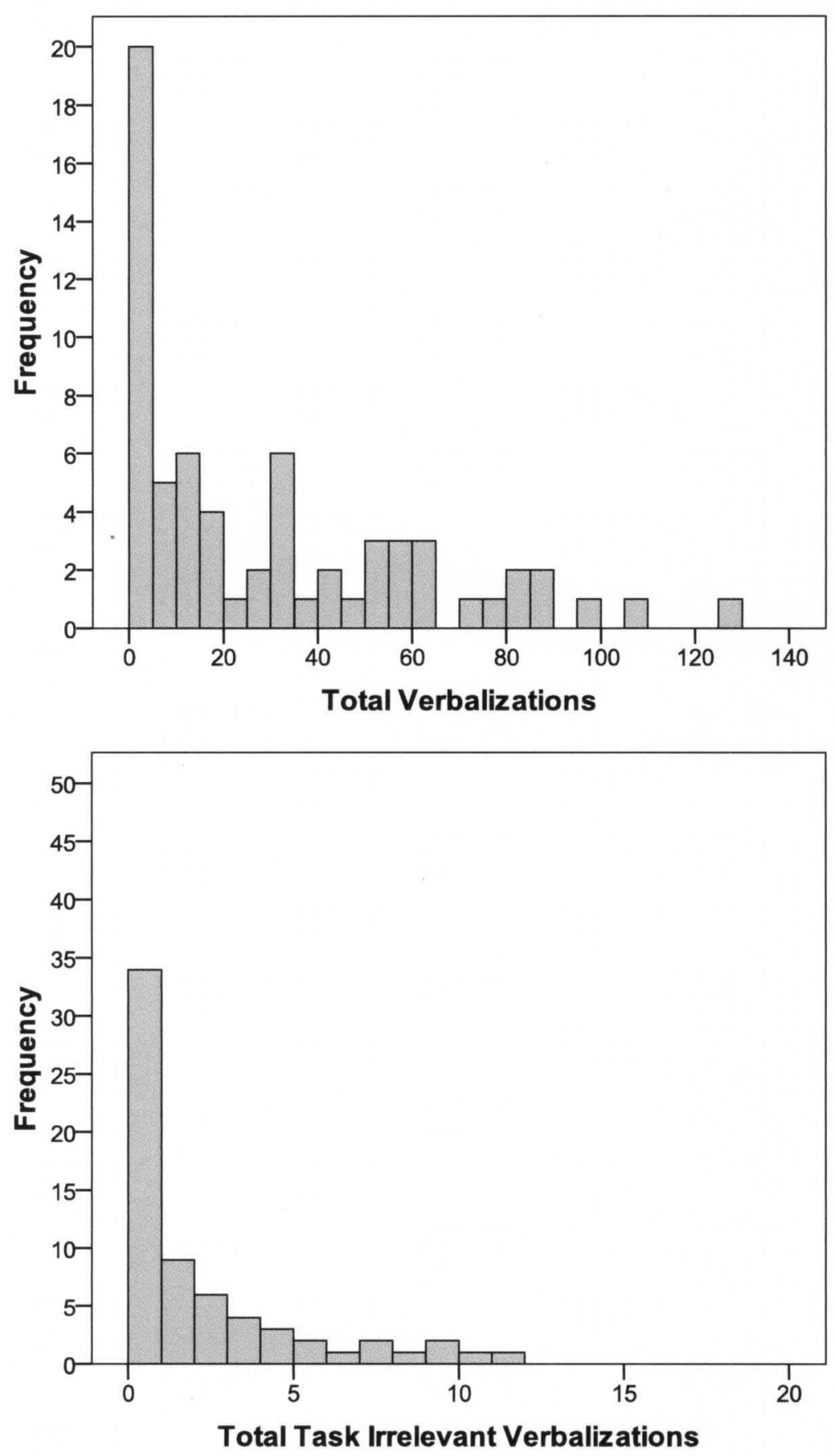

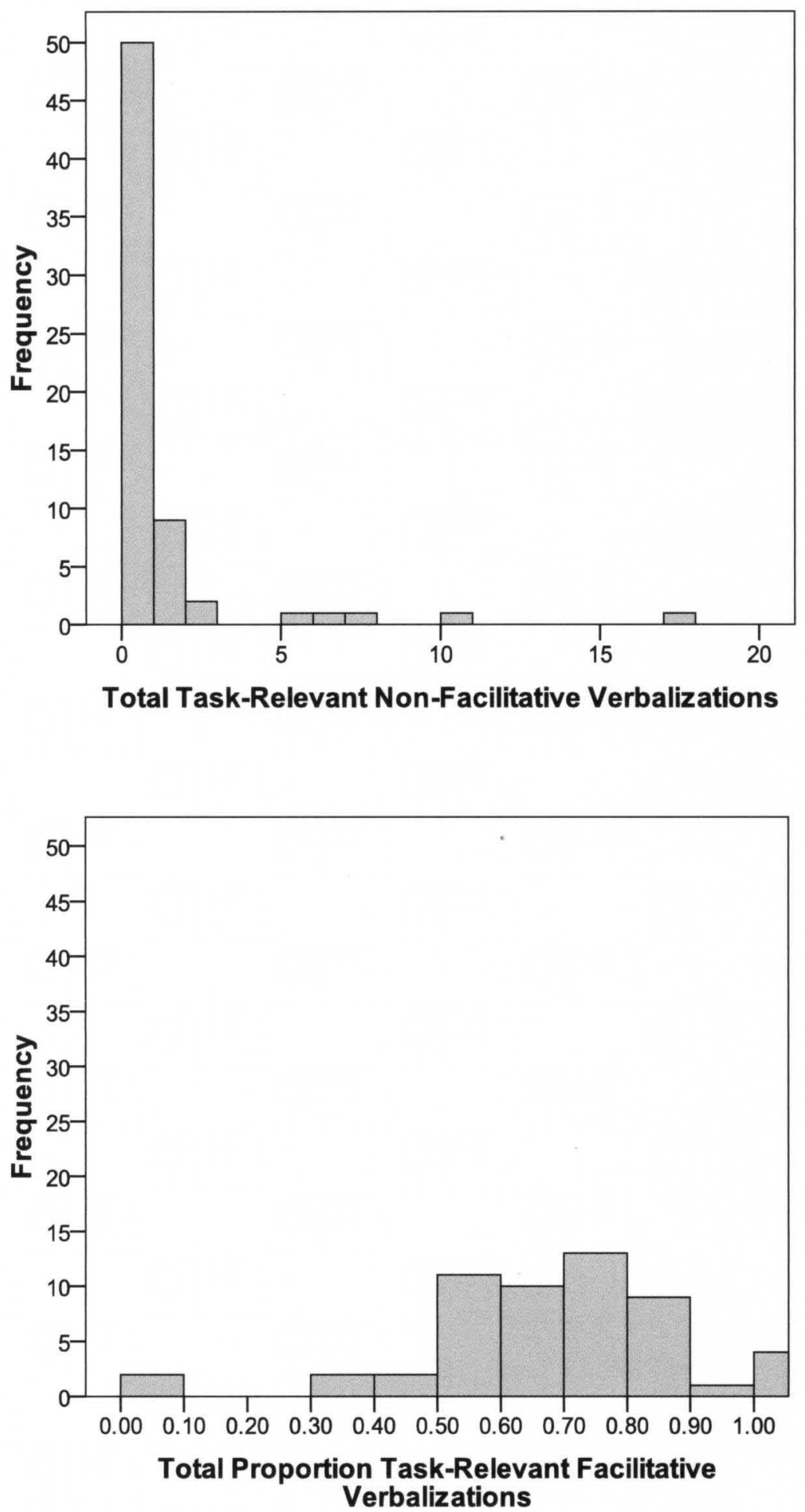


\section{Appendix B}

Histograms depicting the distributions of children's untransformed self-evaluative emotions.
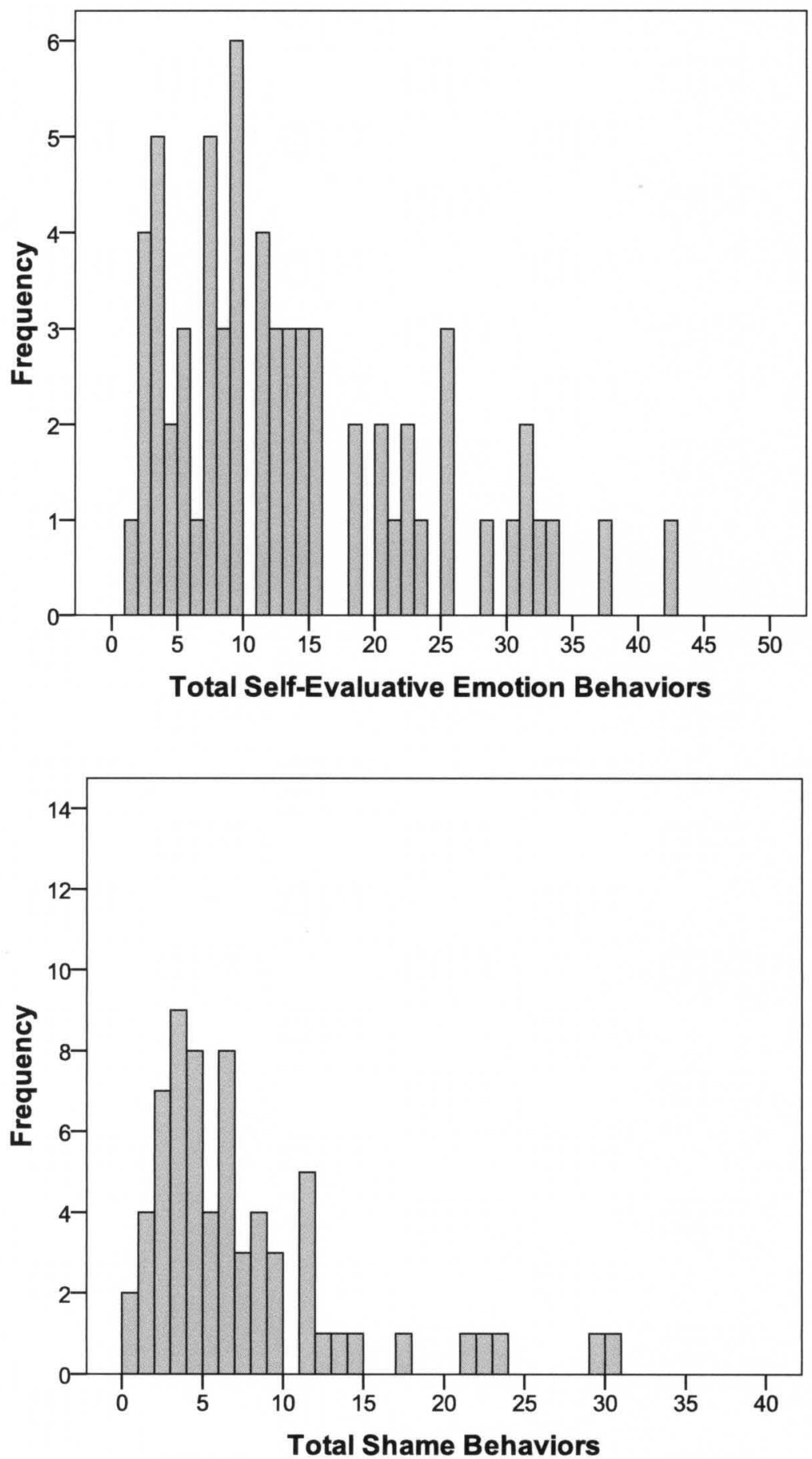


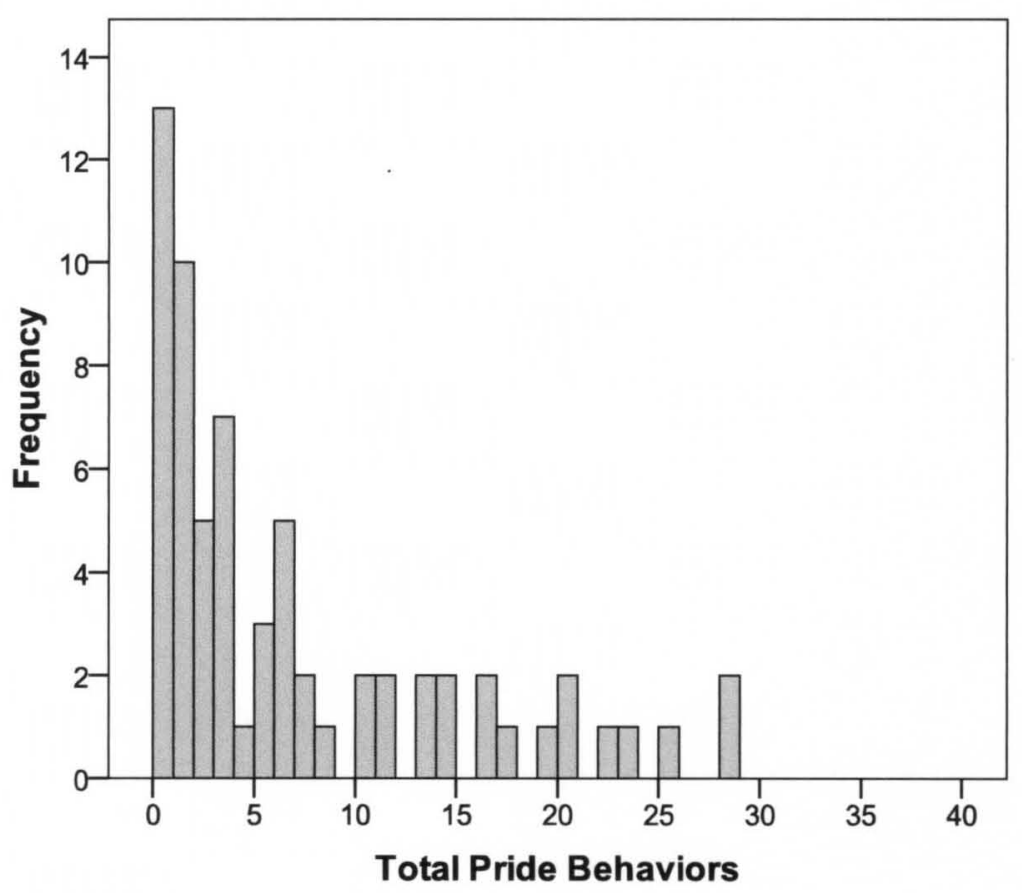




\section{Appendix C}

Log-transformed verbalization proportion means and standard errors as a function of motivation orientation and puzzle.

\begin{tabular}{|c|c|c|c|}
\hline & Attenuated-Mastery & Mastery & Total \\
\hline Verbalization Category & $M(S E)$ & $M(S E)$ & $M(S E)$ \\
\hline \multicolumn{4}{|c|}{ Puzzle $1^{a}$} \\
\hline Task-Irrelevant & $.05(.012)$ & $.01(.007)$ & $.03(.007)$ \\
\hline Task-Relevant Nonfacilitative & $.00(.005)$ & $.01(.003)$ & $.004(.003)$ \\
\hline Task-Relevant Facilitative & $.15(.031)$ & $.19(.018)$ & $.17(.018)$ \\
\hline Combined Verbalizations & $.07(.011)$ & $.07(.007)$ & $.07(.007)$ \\
\hline \multicolumn{4}{|c|}{ Puzzle $2^{\mathrm{a}}$} \\
\hline Task-Irrelevant & $.02(.016)$ & $.04(.010)$ & $.03(.009)$ \\
\hline Task-Relevant Nonfacilitative & $.04(.012)$ & $.003(.007)$ & $.02(.007)$ \\
\hline Task-Relevant Facilitative & $.21(.021)$ & $.22(.012)$ & $.21(.012)$ \\
\hline Combined Verbalizations & $.09(.007)$ & $.09(.004)$ & $.09(.004)$ \\
\hline \multicolumn{4}{|c|}{ Puzzle $3^{\mathrm{a}}$} \\
\hline Task-Irrelevant & $.03(.012)$ & $.03(.007)$ & $.03(.007)$ \\
\hline Task-Relevant Nonfacilitative & $.01(.004)$ & $.003(.002)$ & $.004(.002)$ \\
\hline Task-Relevant Facilitative & $.19(.021)$ & $.22(.012)$ & $.21(.012)$ \\
\hline Combined Verbalizations & $.08(.007)$ & $.09(.004)$ & $.08(.004)$ \\
\hline \multicolumn{4}{|c|}{ Puzzle $4^{\mathrm{a}}$} \\
\hline Task-Irrelevant & $.01(.007)$ & $.02(.004)$ & $.01(.004)$ \\
\hline Task-Relevant Nonfacilitative & $.01(.007)$ & $.01(.004)$ & $.01(.004)$ \\
\hline Task-Relevant Facilitative & $.28(.015)$ & $.24(.009)$ & $.26(.008)$ \\
\hline Combined Verbalizations & $.10(.004)$ & $.09(.003)$ & $.09(.003)$ \\
\hline \multicolumn{4}{|c|}{ Total $^{b}$} \\
\hline Task-Irrelevant & $.02(.008)$ & $.02(.005)$ & $.02(.004)$ \\
\hline Task-Relevant Nonfacilitative & $.02(.006)$ & $.01(.004)$ & $.01(.004)$ \\
\hline Task-Relevant Facilitative & $.22(.015)$ & $.22(.010)$ & $.22(.009)$ \\
\hline Combined Verbalizations & $.09(.006)$ & $.08(.004)$ & $.09(.003)$ \\
\hline
\end{tabular}




\section{Appendix D}

Log-transformed self-evaluative emotion means and standard errors as a function of motivation orientation and puzzle, controlling for time spend on puzzle 4 .

\begin{tabular}{|c|c|c|c|}
\hline & Attenuated-Mastery & Mastery & Total \\
\hline Self-Evaluative Emotion & $M(S E)$ & $M(S E)$ & $M(S E)$ \\
\hline \multicolumn{4}{|c|}{ Puzzle 1} \\
\hline Shame & $.47(.050)$ & $.25(.027)$ & $.36(.028)$ \\
\hline Pride & $.13(.065)$ & $.14(.035)$ & $.13(.037)$ \\
\hline Combined SE Emotions & $.30(.041)$ & $.20(.022)$ & $.25(.023)$ \\
\hline \multicolumn{4}{|c|}{ Puzzle 2} \\
\hline Shame & $.58(.064)$ & $.26(.034)$ & $.42(.036)$ \\
\hline Pride & $.09(.054)$ & $.15(.029)$ & $.12(.031)$ \\
\hline Combined SE Emotions & $.33(.043)$ & $.21(.023)$ & $.27(.024)$ \\
\hline \multicolumn{4}{|c|}{ Puzzle 3} \\
\hline Shame & $.55(.058)$ & $.29(0.32)$ & $.42(.033)$ \\
\hline Pride & $.17(.070)$ & $.19(.038)$ & $.18(.040)$ \\
\hline Combined SE Emotions & $.36(.043)$ & $.24(.023)$ & $.30(.024)$ \\
\hline \multicolumn{4}{|c|}{ Puzzle 4} \\
\hline Shame & $.60(.071)$ & $.31(.038)$ & $.45(.040)$ \\
\hline Pride & $.69(.109)$ & $.50(.059)$ & $.59(.062)$ \\
\hline Combined SE Emotions & $.65(.057)$ & $.40(.031)$ & $.52(.032)$ \\
\hline \multicolumn{4}{|c|}{ Total } \\
\hline Shame & $.55(.039)$ & $.28(.021)$ & $.41(.022)$ \\
\hline Pride & $.27(.060)$ & $.24(.032)$ & $.26(.034)$ \\
\hline Combined SE Emotions & $.41(.033)$ & $.26(.018)$ & $.34(.019)$ \\
\hline
\end{tabular}




\title{
CURRICULUM VITAE
}

\author{
Crystal A. Day \\ Early Intervention for Families Lab \\ Department of Psychological and Brain Sciences \\ University of Louisville
}

317 Life Sciences Building

Louisville, KY 40292

Lab: (502) 852-2348

Fax: (502) 852-8904
7109 Bur Oak Court \#4

Louisville, KY 40291

Cell: (513) 646-6996

Email : crystal.day@louisville.edu

\section{EDUCATION}

Ph.D., Experimental Psychology, May 2011

University of Louisville, Department of Psychological and Brain Sciences,

Cognitive and Developmental Sciences

Dissertation: "Achievement Motivation and Self-Evaluative Emotions in

Preschool Children from Low-Income Families"

Dissertation committee: Drs. Barbara Burns, Cara Cashon, Janet Woodruff-

Borden, Paul Salmon, and Kathleen Rudasill

Mentor: Barbara Burns, Ph.D.

Early Intervention for Families Lab

M.S., Experimental Psychology, August 2008

University of Louisville, Department of Psychological and Brain Sciences,

Cognitive and Developmental Sciences

Mentor: Barbara Burns, Ph.D.

Early Intervention for Families Lab

B.S., Psychology, May 2006

Northern Kentucky University, Department of Psychology

Honors Thesis: "Exposure to Marital Conflict and Memory for Conflict-Related

Words"

Mentors: Robin Bartlett, Ph.D. and Cyndi McDaniel, Ph.D.

Summa cum laude

\section{HONORS AND AWARDS}

2011, Guy Stevenson Award for Excellence in Graduate Studies

2010, School of Interdisciplinary and Graduate Studies Doctoral Dissertation Completion Award

2009, 2010, Kentucky Psychological Association Paul Hager Graduate Research Award 
2006-2008, University Fellowship, University of Louisville

2002-2006, University Honors, Northern Kentucky University

2002-2006, Presidential Scholarship, Northern Kentucky University

\section{PROFESSIONAL ORGANIZATIONS}

Society for Research in Child Development, Graduate Student Member

Kentucky Psychological Association, Graduate Student Affiliate

Kentucky Association for Psychology in the Schools, Graduate Student Member

American Psychological Association, Graduate Student Affiliate

National Head Start Association

\section{TEACHING EXPERIENCE}

Spring 2011, Instructor, Honors Lifespan Developmental Psychology (PSYC 363-02).

Department of Psychological and Brain Sciences, University of Louisville.

Louisville, KY.

2006-present, Undergraduate student training and supervision of 2 to 5 undergraduate research assistants per semester in the Early Intervention for Families Lab in collaboration with Dr. Barbara Burns (PSYC 401, 402, 405, 406). University of Louisville, Louisville, KY.

Spring 2010, Graduate Teaching Assistant, Writing Seminar in Infancy (PSYC 435).

Department of Psychological and Brain Sciences, University of Louisville, Louisville, KY.

Fall 2009, Graduate Teaching Assistant, Social Psychology (PSYC 372). Department of Psychological and Brain Sciences, University of Louisville. Louisville, KY.

Spring 2007, Graduate Teaching Assistant, Overcoming the Odds (HON 336).

Department of Psychological and Brain Sciences, University of Louisville.

Louisville, KY.

Spring 2004, Practicum Teacher, Kindergarten. Fourth Street Elementary School.

Newport, KY.

Spring 2004, Practicum Teacher, Grade 3. Fourth Street Elementary School. Newport, $\mathrm{KY}$.

Fall 2003, Honors Mentor, University Honors Program. Northern Kentucky University, Highland Heights, KY.

\section{Guest Lecture}

February 2007, Psi Chi Meeting (Preparing for Graduate School). University of Louisville, Louisville, KY.

\section{RESEARCH EXPERIENCE}

2006-present, Research Assistant to Dr. Barbara Burns, Early Intervention for Families Lab. Department of Psychological and Brain Sciences, University of Louisville, Louisville KY. (research projects described below)

2004-2006, Undergraduate Research Assistant to Drs. Robin Bartlett and Cyndi McDaniel. Department of Psychology, Northern Kentucky University, Highland Heights, KY. 


\section{RESEARCH GRANTS}

Burns, B. M., \& Day, C. A. "The Relation of Self-Evaluative Emotions to Achievement Motivation in Children Attending Head Start." University of Louisville College of Arts and Sciences. 2009-2010.

\section{RESEARCH PROJECTS}

2009-Present, Family College Intervention and Research Program

Mentor: Dr. Barbara M. Burns (University of Louisville)

The program is designed to promote maternal sensitivity and secure attachments within mother-child dyads as a way to promote children's social, emotional, and cognitive skills and later school readiness. The Baby Learning, Family Learning portion of this program was adapted from our previous research and includes a six week intervention program that promotes maternal sensitivity of at-risk families with children 0 to 3 years of age.

\section{8-2009, An Examination of the Parents and Children Together Program}

Mentor: Dr. Barbara M. Burns (University of Louisville)

The project expanded upon a previous pilot study that implemented the "Promoting First Relationships" program. We developed the Parents and Children Together (PACT) program, which incorporates educational and guidance components, including handouts and videotaped feedback, to support caregiver sensitivity in families attending a social services program. The goal of the study was to examine the impact of the PACT program on caregiver sensitivity and how changes in sensitivity relate to various caregiver and child outcomes.

\section{8-2009, An Evaluation of an Early Childhood Curriculum Program}

Mentors: Dr. Barbara M. Burns \& Dr. Lora Haynes (University of Louisville) The project included approximately 238 early childhood classrooms in the Early Childhood Program in the local public school system. The project examined the role of dialogic reading and parent involvement enrichment programs in promoting positive child outcomes in a variety of domains.

\section{7-Present, The Relation of Self-Evaluative Emotions to Motivation Orientation} Mentor: Dr. Barbara M. Burns (University of Louisville)

This project examines the relation between the expressions of shame and pride to motivation orientation in preschool-aged children from varying income backgrounds. Children's motivation orientation was assessed using a challenging task, which was videotaped for later coding of behaviors indicative of shame and pride. The results of the project have important implications for the evaluation of motivation in young children and the development of motivation interventions.

\section{7-2010, Characterizing Achievement Motivation Orientation in Low-and Middle-} Income Children

Mentor: Dr. Barbara M. Burns (University of Louisville)

This project examined the differences between low- and middle-income children in terms of their motivation orientation and private speech patterns. Children's motivation and 
private speech patterns were assessed with a challenging puzzle task. Videotapes of the task were then transcribed and children's verbalizations were coded. The results have important implications for research focusing on the development of motivation in children from various backgrounds.

2006-Present, Mastery Motivation Training in Head Start Children: Musical Motivation Mentor: Dr. Barbara M. Burns (University of Louisville) This project examines how a 10 week motivation intervention influences adaptive motivation outcomes in children attending Head Start. Researchers developed a motivation-focused intervention program that incorporated books, songs, and activities to encourage mastery motivation in Head Start classrooms. The study compares the motivation orientation, private speech patterns, self-evaluative emotions, and learning behaviors of children receiving the intervention to those of a control group. The results will provide important information on the impact teacher practices and instructional changes can have on supporting more adaptive motivation orientations in preschoolers.

\section{6-2008, Early Intervention on Maternal Sensitivity in Low-Income Families}

Mentor: Dr. Barbara M. Burns (University of Louisville)

This project was a pilot study that implemented a nationally recognized early intervention program entitled "Promoting First Relationships" aimed at enhancing maternal sensitivity in families attending Early Head Start. The goal of the study was to establish the utility of a 16 week intervention program for Early Head Start families. The results of the study provided the basis for a longitudinal study based on this early intervention protocol with mothers and their infants from low-income families, which will identify (1) the impact of the intervention on maternal sensitivity and (2) how changes in maternal sensitivity and attachment status relate to a range of child outcome measures related to self-regulation and school readiness.

2005-2006, The Impact of Marital Conflict on Social Information Processing Mentors: Drs. Robin M. Bartlett and Cyndi McDaniel (Northern Kentucky University)

The study examined the influence of exposure to conflict on social information processing in college students. Participants in the experimental group listened to an audiotape simulating parental conflict, while those in the control group were not exposed to the conflict simulation. All participants then completed emotional Stroop and memory tasks as measures of information processing. Participants also completed multiple questionnaires regarding their previous exposure to and perceptions of interparental conflict in the home.

\section{4-2005, Exposure to Marital Conflict and Memory for Conflict-Related Words} Mentors: Drs. Robin M. Bartlett and Cyndi McDaniel (Northern Kentucky University)

The study examined the influence of exposure to marital conflict on the false recall and recognition of conflict- and violence-related words in late adolescence. Participants were exposed to 4 standard DRM lists that were shown to produce high levels of false recall and recognition. Participants were also randomly presented with 2 additional word lists that consisted of constructive and destructive or ambiguous words. Participants also completed questionnaires designed to measure exposure to interparental conflict in the home. 


\section{PUBLICATIONS \& TECHNICAL REPORTS}

Day, C. (2011). Parenting children in high-risk environments: An examination of maternal sensitivity in poverty. In D. W. Davis \& M. C. Logsdon (Eds.), Maternal sensitivity: A scientific foundation for practice (pp. 195-214). New York: Nova Science.

Day, C., \& Burns, B. M. (2011). Characterizing the achievement motivation orientation of children from low- and middle-income families. Early Education \& Development, 22, 105-127.

Day, C., Flores, P. A., Gordon, M., Richard, H., \& Burns, B. M. (2008). Early intervention on maternal sensitivity in low-income families: Pilot study (Technical Report). Louisville, KY: University of Louisville, Department of Psychological and Brain Sciences.

Day, C. (2007). Attachment and early language development: Implications for early intervention. NHSA Dialog: A Research-to-Practice Journal for the Early Intervention Field, 10, 143-150.

Flores, P. A., Day, C., Richard, H., \& Horace, A. (2007). Promoting mother-child attachment: Review of the past and recommendations for future interventions. NHSA Dialog: Research-to-Practice Journal for the Early Intervention Field, 10, 129-142.

Burns, B. M., Chang, F., Snyder, E., Day, C. A., Davis, D. et al. (under revision). Attention skills and achievement in young children of poverty.

Brown, D. D., Day, C. A., \& Burns, B. M. (in preparation). Characterizing attention network skills of children from middle- and low-income families.

Day, C. A., \& Burns, B. M. (in preparation). Characterizing the cognitive ability profiles of children attending Head Start using the Differential Ability Scales-Second Edition.

Snyder, E., Day, C. A., \& Burns, B. M. (in preparation). Relating maternal and child temperament to early achievement.

\section{BOOK REVIEWS}

Day, C. (2008) [Review of the book Social and emotional development: Connecting science and practice in early childhood settings, by D. Riley, R. R. San Juan, J. Klinker, \& A. Ramminger]. NHSA Dialog: Research-to-Practice Journal for the Early Intervention Field, 11(3), 187-188.

Day, C. (2008). [Review of the book Songs of resilience: Tips for teachers, by T. J. Lottman \& Review of the CD Songs of resilience, by D. Kisor]. NHSA Dialog: Research-to-Practice Journal for the Early Intervention Field, 11(2), 133-134.

Day, C. (2007). [Review of the book Early intervention with multi-risk families: An integrative approach, by S. Landy \& R. Menna]. NHSA Dialog: Research-toPractice Journal for the Early Intervention Field, 10(4), 210-211.

\section{RESEARCH PRESENTATIONS}

Day, C. A., \& Burns, B. M. (2010, June). Characterizing achievement motivation orientation of children from low- and middle-income families. Poster session presented at Head Start's $10^{\text {th }}$ National Research Conference. Washington, D.C.

Brown, D. D., Day, C. A., \& Burns, B. M. (2010, April). Characterizing attention 
network skills of children from middle- and low-income families. Poster session presented at the $21^{\text {st }}$ Biennial Conference on Human Development. New York, NY.

Day, C. A., \& Burns, B. M. (2010, March). Characterizing achievement motivation orientation of children from low- and middle-income families. Poster session presented at the Kentucky Psychological Association Academic Conference. Louisville, KY.

Haynes, L., Payne, J., \& Day, C. (2009, July). Dialogic reading, family-school connections, \& FSP sing \& read materials for school readiness: Use and effects in early childhood/head start classrooms. Paper presented at the Frog Street Press $18^{\text {th }}$ Educational Conference. Grapevine, TX.

Day, C., Myers, G., Payne, J., \& Haynes, L. (2009, May). Frog street press sing \& read materials for school readiness: Use and effects in JCPS early childhood/head start classrooms. Poster session presented at the Kentucky Conference on the Scholarship of Teaching and Learning. Lexington, KY.

Day, C., Scott, J., Byrne, B., \& Haynes, L. (2009, May). Use and effects of family-school connections and frog street press sing \& read materials for school readiness in JCPS early childhood/head start classrooms. Poster session presented at the Kentucky Conference on the Scholarship of Teaching and Learning. Lexington, KY.

Day, C., \& Burns, B. M. (2009, April). Children's expressions of shame and pride as related to their motivation orientation. Poster session presented at the biennial meeting of the Society for Research in Child Development. Denver, CO.

Day, C., \& Burns, B. M. (2009, April). Examining the relation of children's motivation orientation and verbalizations during a challenging task. Poster session presented at the biennial meeting of the Society for Research in Child Development. Denver, $\mathrm{CO}$.

Fister, E. M., Flores, P., Day, C., \& Burns, B. M. (2009, April). Development and implementation of a theoretically-based intervention to promote healthy caregiver-child attachment. Poster session presented at the Kentucky Innovation and Entrepreneurship Conference, Louisville, KY.

Day, C., \& Burns, B. M. (2009, March). Children's expressions of shame and pride as related to their motivation orientation. Poster session presented at the Kentucky Psychological Association Academic Conference. Lexington, KY.

Fister, E., Flores, P., Day. C., \& Burns, B. M. (2009, March). Development and implementation of a theoretically-based intervention to promote healthy caregiver-child attachment. Poster session presented at the Kentucky Psychological Association Academic Conference. Lexington, KY.

Day, C., Carter, K. Harris, R. C., \& Burns, B. M. (2008, October). Evaluation of a classroom-based intervention on mastery motivation outcomes in children in Head Start. Poster session presented at the Kentucky Association for Psychology in the Schools Annual Conference. Lexington, KY.

Day, C., Ford, A., Harris, R. C., \& Burns, B. M. (2008, October). Examining the relation of the Preschool Learning Behaviors Scale to children's motivation orientation in Head Start. Poster session presented at the Kentucky Association for Psychology in the Schools Annual Conference. Lexington, KY. 
Day, C., Harris, R. C., Carter, K., \& Burns, B. M. (2008, June). Evaluation of a classroom-based intervention on mastery motivation outcomes in children in Head Start. Poster session presented at Head Start's $9^{\text {th }}$ National Research Conference. Washington, D.C.

Day, C., Harris, R. C., Ford, A., \& Burns, B. M. (2008, June). Examining the relation of the Preschool Learning Behaviors Scale to children's motivation orientation in Head Start. Poster session presented at Head Start's $9^{\text {th }}$ National Research Conference. Washington, D.C.

Day, C., Jenkins, L., Harris, R. C., \& Burns, B. M. (2008, April). The relation of selfevaluative emotions to motivation orientation in preschool-aged children. Poster session presented at the $20^{\text {th }}$ Biennial Conference on Human Development. Indianapolis, IN.

*Jenkins, L., Day, C., Harris, R. C., \& Burns, B. M. (2008, April). The relation of selfevaluative emotions to motivation orientation in preschool-aged children. Poster session presented at the University of Louisville Undergraduate Research Symposium. Louisville, KY.

Day, C., Flores, P., Harris, R. C., \& Burns, B. M. (2008, March). Characterizing motivation and helplessness in low and middle income children. Poster session presented at the Kentucky Psychological Association Academic Conference. Louisville, KY.

Flores, P., Gordon, M., Day, C., \& Burns, B. M. (2008, March). The relation of spontaneous verbalizations to motivation orientation. Poster session presented at the Kentucky Psychological Association Academic Conference. Louisville, KY.

Richard, H., Day, C., Jenkins, L, Carter, K., Bhavalkar, A., Unger, S., \& Burns, B. M. (2008, March). Characterizing achievement motivation in young children in Head Start. Poster session presented at the Kentucky Psychological Association Academic Conference. Louisville, KY.

*Jenkins, L., Carter, K., Unger, S., Bhavalkar, A., Day, C., \& Burns, B. M. (2008, January). Characterizing achievement motivation in young children in Head Start. Poster session presented at the annual Posters at the Capitol meeting. Frankfort, KY.

*Bhavalkar, A., Day, C., Harris, R. C., \& Burns, B. M. (2007, August). The relation of children's gaze patterns to motivation orientation. Poster session presented the SROP Undergraduate Conference. Louisville, KY.

Chang, F., Harris, R. C., Flores, P., Day, C., \& Burns, B. M. (2007, March). Characterizing motivation and helplessness in low and middle income children. Poster session presented at the meeting of the Society for Research in Child Development. Boston, MA.

Harris, R. C., Brown, D. D., Day, C. \& Burns, B. M. (2007, March). The relation of spontaneous verbalizations to motivation orientation. Poster session presented at the meeting of the Society for Research in Child Development. Boston, MA.

Day, C. (2006, May). Exposure to interadult conflict and processing of conflict-related information. Poster session presented at the annual meeting of the Midwestern Psychological Association, Chicago, IL.

Allen, C. L., \& Day, C. (2005, May). False memory effect in children. Poster presented at The annual meeting of the Midwestern Psychological Association, Chicago, IL. 
Day, C., \& Allen, C. L. (2005, May). Marital conflict and memory for violent and conflict words. Poster session presented at the annual meeting of the Midwestern Psychological Association, Chicago, IL.

Day, C. (2003, November). Working class heroes. Paper presented at the meeting of the National Collegiate Honors Council, Chicago, IL.

*Undergraduate researcher(s)

PROFFESSIONAL ACTIVITIES AND SERVICE

Ad Hoc Reviewer (November 2007-present). NHSA Dialog: A Research-to-Practice Journal for the Early Intervention Field.

Research Connections Workshop, Examining Child Outcomes and Well-Being in Early Care and Education Settings (July 2008), Ann Arbor, MI.

Experimental Psychology Graduate Student Representative (2007-2009).

Promoting First Relationships Training Program (April 2007), Seattle, WA.

Postpartum Depression and Infant Development Seminar (May 2007), Louisville, KY.

Success by Six Early Childhood Forum (May 2007), Louisville, KY.

\section{Community Experience}

May 2009 - Present. Park DuValle Community Heather Center WIC Program.

3015 Wilson Avenue, Louisville, KY 40211

Supervisor: Dr. Barbara Burns (in collaboration with program director)

I am part of a research team that works with the community Women, Infants, and Children food and nutrition service program to educate and train parents on a variety of parenting skills (e.g., sensitivity) and child development.

July 2008 - July 2009. Seven Counties Services, Inc.

BHSS South Division, 1512 Crums Lane, Louisville, KY 40216

Supervisor: Dr. Barbara Burns (in collaboration with agency director)

I was a member of a research team that worked with the Seven Counties social service agency to design, implement, and evaluate a caregiver-child intervention program aimed at supporting caregiver sensitivity and healthy child outcomes.

Our team also participated in training therapists in the intervention methodology.

April 2007 - May 2010. Jefferson County Public Schools Early Childhood Program 2501 Rockford Lane, Louisville, KY 40216

Supervisors: Dr. Barbara Burns (in collaboration with program administrators) I was a member of a research team that worked with the JCPS Early Childhood Program to conduct research and design, implement, and evaluate classroom and parent-child interventions, and lead teacher training workshops. Our work and trainings focused on the following topics: sensitivity intervention program to support parents of children attending Early Head Start, supporting mastery motivation and positive self-talk in children attending Head Start, supporting home-school connections in Early Head Start and Head Start via the use of classroom curricula, and providing teacher and administrator training and information workshops on these topics. 


\section{Workshops for Teachers and Schools}

Harris, R. C., Day, C., Burns, B. M., Carter, K., Jenkins, L., \& Bhavalkar, A. (2007, April). Musical Motivation Intervention. Presented to JCPS Head Start Teachers, Louisville, KY.

Flores, P., Day, C., Richard, H., Horace, A., \& Burns, B. M. (2007, April). Promoting First Relationships: Project Proposal. Presented to JCPS Early Head Start Administrative Staff, Louisville, KY.

Day, C., Bhavalkar, A., Carter, K., \& Jenkins, L. (2007, August). Musical motivation: A mastery motivation intervention pilot study. Presented to Children, Inc., Louisville, KY.

Flores, P., Day, C., Richard, H., Gordon, M., \& Burns, B. M. (2007, August). Promoting First Relationships. Presented to JCPS Early Head Start Teachers. Louisville, KY.

Burns, B. M., Haynes, L., \& Day, C. (2008, June 18). Social and emotional development in young children: Research to practice. Presented at JCPS Early Head Start Conference, Louisville, KY.

Burns, B. M., \& Day, C. (2008, June 10, 11, 12) Understanding mastery motivation and its role in school readiness: Musical motivation in the classroom. Presented at JCPS Early Childhood First Learning Conference, Louisville, KY.

Burns, B. M., Day. C., \& Haynes, L. (2008, August 18). Teachers, families, and children's school success. Presented at JCPS Early Childhood Professional Development Conference, Louisville, KY.

Day, C., Burns, B. M., \& Haynes, L. (2008, August 18). Creating home-school connections with Frog Street Press materials. Presented at JCPS Early Childhood Professional Development Conference, Louisville, KY.

Day, C., Burns, B. M., \& Haynes, L. (2008, September 12). Supporting family-school connections with Frog Street Press. Presented at JCPS Resource Teacher Professional Development meeting, Louisville, KY.

\section{COMPUTER SKILLS}

Statistical/Data Collection Packages - SPSS, AMOS

Behavioral LData Coding Software - The Observer XT (Noldus)

General Word Processing and Presentation Software

\section{COURSE CURRICULUM RELATED TO PSYCHOLOGY}

Assessment

PSYC 622 Developmental Assessment

\section{Cognitive and Developmental Sciences}

PSYC 604 Attention, Affect, and Motivation

PSYC 604 Motivation Development

PSYC 604 SES Impact on Motivation

PSYC 604 Preliminary Topic Development

PSYC 604 Preliminary Topic Writing

PSYC 605 Development of Motivation in Children

PSYC 605 Motivation and Self-Evaluative Emotions 


$\begin{array}{ll}\text { PSYC 605 } & \text { Motivation Intervention } \\ \text { PSYC 605 } & \text { Motivation \& Emotions I } \\ \text { PSYC 605 } & \text { Motivation \& Emotions II } \\ \text { PSYC 605 } & \text { Attachment and Sensitivity } \\ \text { PSYC 605 } & \text { Sensitivity Intervention I } \\ \text { PSYC 605 } & \text { Sensitivity Intervention II } \\ \text { PSYC 605 } & \text { Sensitivity Intervention III } \\ \text { PSYC 605 } & \text { Sensitivity Parent Groups I } \\ \text { PSYC 605 } & \text { Sensitivity Parent Groups II } \\ \text { PSYC 605 } & \text { Sensitivity Parent Groups III } \\ \text { PSYC 605 } & \text { Family Early Childhood Involvement } \\ \text { PSYC 605 } & \text { Dissertation Proposal } \\ \text { PSYC 605 } & \text { Attention \& Achievement } \\ \text { PSYC 609 } & \text { Developmental Psycholinguistics } \\ \text { PSYC 609 } & \text { Developmental Science } \\ \text { PSYC 609 } & \text { Social Cognition } \\ \text { PSYC 621 } & \text { Cognitive Processes } \\ \text { PSYC 643 } & \text { Principles of Neuroscience } \\ \text { PSYC 661 } & \text { Advanced Developmental Psychology } \\ \text { PSYC 701 } & \text { Dissertation Research }\end{array}$

Statistics

PSYC 610

PSYC 611

PSYC 612

Advanced Statistics I

Advanced Statistics II

Advanced Statistics III 